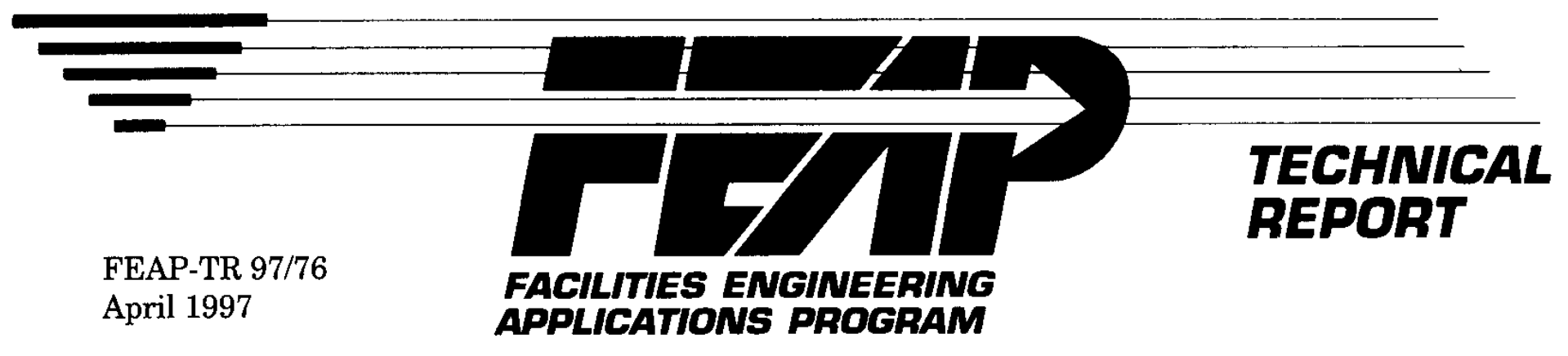

\title{
Demonstration of Remote Monitoring Technology for Cathodic Protection Systems
}

by

Vicki L. Van Blaricum, William R. Norris, Michael J. Szeliga, and James B. Bushman U.S. Army Construction Engineering Research Laboratories Champaign, IL 61826-9005

Approved for Public Release; Distribution Is Unlimited.

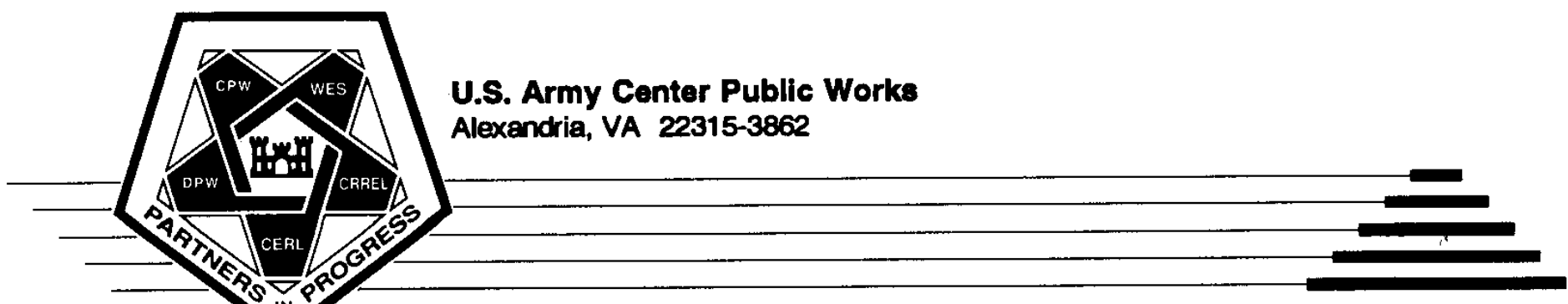


The contents of this report are not to be used for advertising, publication, or promotional purposes. Citation of trade names does not constitute an official indorsement or approval of the use of such commercial products. The findings of this report are not to be construed as an official Department of the Army position, unless so designated by other authorized documents. 


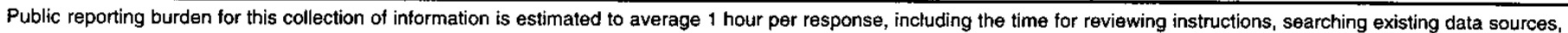

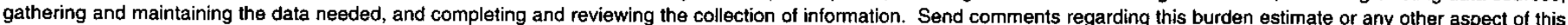

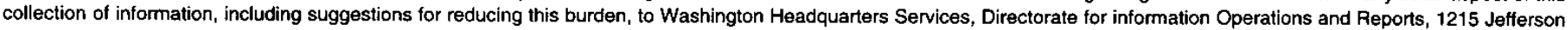
Davis Highway, Suite 1204, Arlington, VA 22202-4302, and to the Office of Management and Budget, Paperwork Reduction Project (0704-0188), Washington, DC 20503.

\begin{tabular}{|l|c|c|}
\hline 1. AGENCY USE ONLY (Leave Blank) & 2. REPORT DATE \\
April 1997 & 3. REPORT. TYPE AND DATES COVERED \\
\hline
\end{tabular}

4. TITLE AND SUBTITLE
Demonstration of Remote Monitoring Technology for Cathodic Protection System

5. FUNDING NUMBERS

FEAP

FL-F16

6. AUTHOR(S)

Vicki L. Van Blaricum, William R. Norris, Michael J. Szeliga, and James B. Bushman

7. PERFORMING ORGANIZATION NAME(S) AND ADDRESS(ES)

U.S. Army Construction Engineering Research Laboratories (USACERL)

P.O. Box 9005

Champaign, IL 61826-9005

PERFORMING ORGANIZATION

REPORT NUMBER

TR 97/76

9. SPONSORING / MONITORING AGENCY NAME(S) AND ADDRESS(ES)

U.S. Army Center for Public Works

ATTN: CECPW-ES

7701 Telegraph Rd.

Alexandria, VA 22310-3862

11. SUPPLEMENTARY NOTES

Copies are available from the National Technical Information Service, 5285 Port Royal Road, Springfield, VA 22161.

12a. DISTRIBUTION/AVAILABILITY STATEMENT

12b. DISTRIBUTION CODE

Approved for public release; distribution is unlimited.

13. ABSTRACT (Maximum 200 words)

The Army owns and maintains more than 3000 miles of buried natural gas pipeline, 20,000 underground storage tanks (USTs), and more than 300 elevated water storage tanks. Cathodic protection (CP) is required by regulation on many of these structures to prevent corrosion. Periodic testing is required to ensure proper CP system operation, but many Directorates of Public Works (DPWs) do not have sufficient resources to conduct such tests regularly. Many malfunctions remain undetected until the structure corrodes and leaks.

Several companies have begun manufacturing remote monitoring units (RMUs) for CP systems. This technology allows personnel to monitor multiple CP systems from a central location so problems can be detected and repaired immediately. An 8 month field evaluation of CP RMUs was performed to determine the effectiveness of systems from three manufacturers. Demonstration systems were selected on the basis of cost, features, availability, etc. RMU readings were compared with manual method readings throughout a variety of conditions.

Units from only one manufacturer performed successfully. New systems have entered the market since this demonstration began.

\begin{tabular}{|c|c|c|c|}
\hline \multirow{2}{*}{\multicolumn{3}{|c|}{$\begin{array}{l}\text { 14. SUBJECT TERMS } \\
\text { cathodic protection } \\
\text { remote monitoring units (RMUs) } \\
\text { corrosion }\end{array}$}} & \multirow{2}{*}{$\begin{array}{l}\text { 15. NUMBER OF PAGES } \\
116 \\
\text { 16. PRICE CODE }\end{array}$} \\
\hline & & & \\
\hline $\begin{array}{l}\text { 17. SECURITY CLASSIFICATION } \\
\text { OF REPORT } \\
\text { Unclassified }\end{array}$ & $\begin{array}{l}\text { 18. SECURITY CLASSIFICATION } \\
\text { OF THIS PAGE } \\
\text { Unclassified }\end{array}$ & $\begin{array}{l}\text { 19. SECURITY CLASSIFICATION } \\
\text { OF ABSTRACT } \\
\text { Unclassified }\end{array}$ & $\begin{array}{l}\text { 20. LIMITATION OF } \\
\text { ABSTRACT } \\
\text { SAR }\end{array}$ \\
\hline
\end{tabular}




\section{Foreword}

This study was conducted for U.S. Army Center for Public Works under the Facilities Engineering Application Program (FEAP); Work Unit FL-F16, "Demonstration of Remote Monitoring for Cathodic Protection Systems." The technical monitor was Malcolm McLeod, CECPW-ES.

The work was performed by the Materials Science and Technology Division (FL-M) of the Facilities Technology Laboratory (FL), U.S. Army Construction Engineering Research Laboratories (USACERL). The Principal Investigator was Vicki L. Van Blaricum. Michael J. Szeliga, P.E., is Chief Engineer with Russell Corrosion Consultants, Simpsonville, MD. James B. Bushman, P.E., is President of Bushman \& Associates, Medina, OH. Dr. Ilker R. Adiguzel is Acting Chief, CECER-FL-M, and Donald F. Fournier is Acting Operations Chief, CECER-FL. The USACERL technical editor was Gordon L. Cohen, Technical Information Team.

Special appreciation is expressed to Mr. Joseph Ogiba and Mr. Thomas Ferguson, Directorate of Public Works, Fort Drum, NY, for their invaluable and enthusiastic support of this demonstration.

Dr. Michael J. O'Connor is the Director of USACERL. 


\section{Contents}

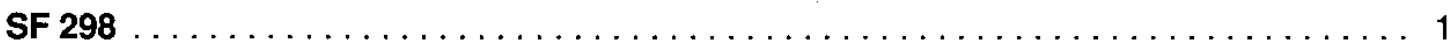

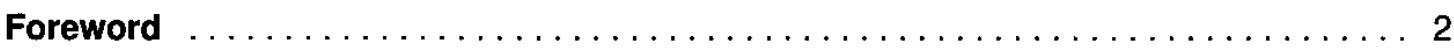

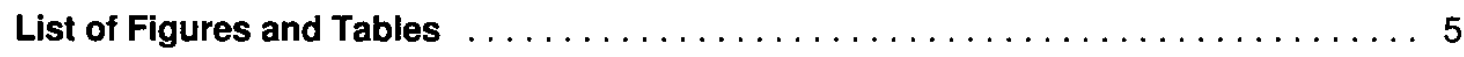

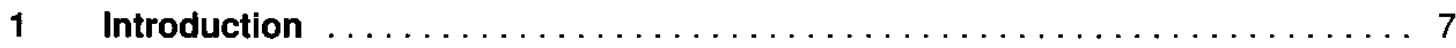

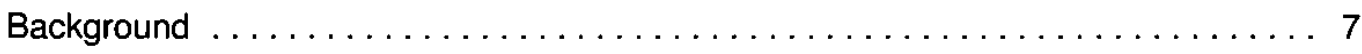

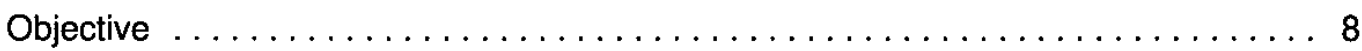

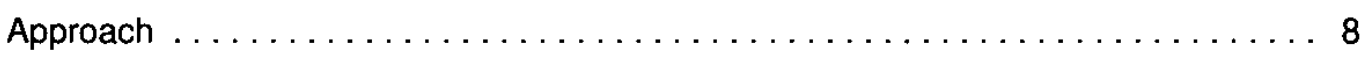

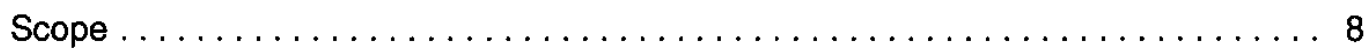

Mode of Technology Transfer $\ldots \ldots \ldots \ldots \ldots \ldots \ldots \ldots \ldots \ldots \ldots \ldots \ldots \ldots \ldots \ldots \ldots \ldots$

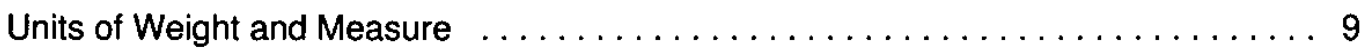

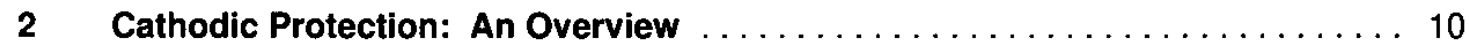

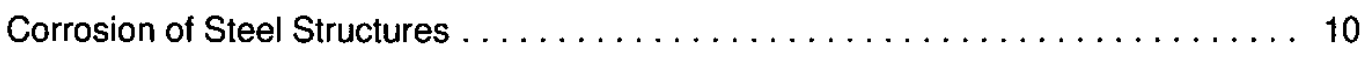

Cathodic Protection Systems . . . . . . . . . . . . . . . . . . 10

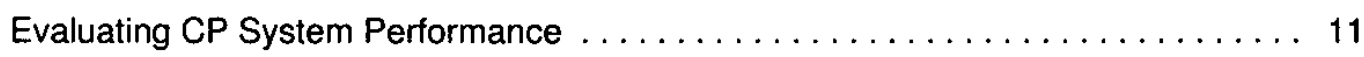

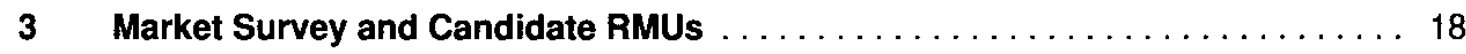

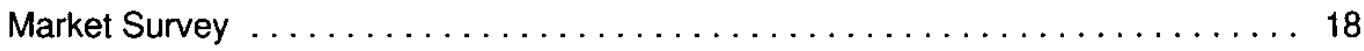

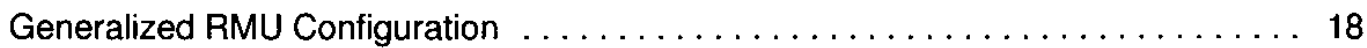

RMU Specifications and Common Features ................... 19

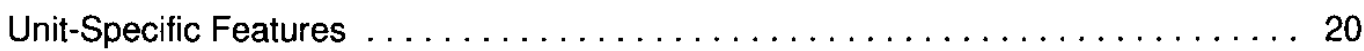

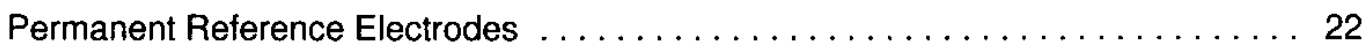

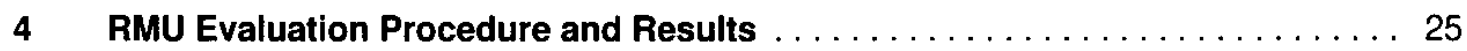

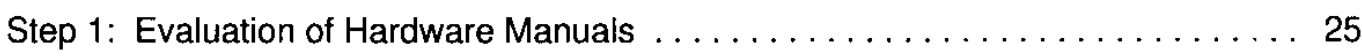

Step 2: Evaluation of Hardware Installation Procedures $\ldots \ldots \ldots \ldots \ldots \ldots \ldots 26$

Step 3: Evaluation of Software Manuals . . . . . . . . . . . . . . 28

Step 4: Evaluation of Software Installation, Configuration, and Technical Support .. 29

Step 5: Evaluation of Software Use $\ldots \ldots \ldots \ldots \ldots \ldots \ldots \ldots \ldots \ldots \ldots \ldots \ldots$

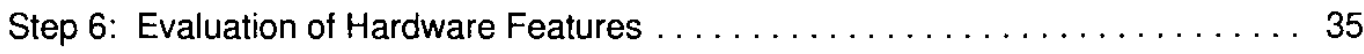

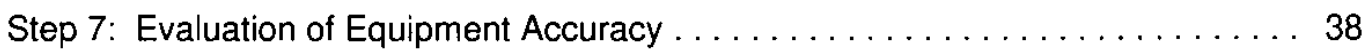

Step 8: Analysis of Results and Ranking of RMUs $\ldots \ldots \ldots \ldots \ldots \ldots \ldots \ldots$ 
5 Conclusions and Recommendations $\ldots \ldots \ldots \ldots \ldots \ldots \ldots \ldots \ldots \ldots$

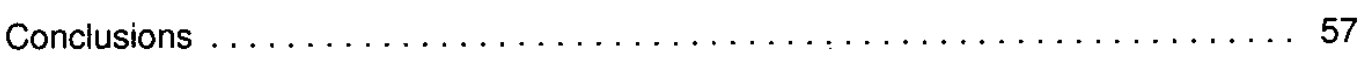

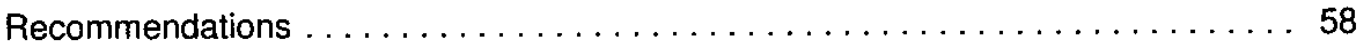

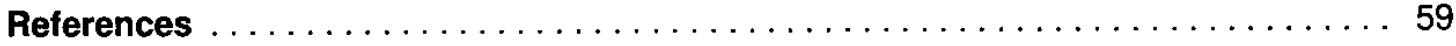

Appendix A:Manufacturer's Brochure for DAX RMU $\ldots \ldots \ldots \ldots \ldots \ldots \ldots \ldots \ldots \ldots \ldots \ldots \ldots$

Appendix B:Supplemental RMU Installation Instructions (Prepared Onsite) . . . . . 65

Appendix C:Suggested Remote Monitoring Unit Relay $\ldots \ldots \ldots \ldots \ldots \ldots \ldots \ldots$

Appendix D:Daily Rectifier Output Voltage Readings at USACERL Test Site . . . . . . 69

Appendix E:Daily Rectifier Output Current Readings at USACERL Test Site $\ldots \ldots \ldots \ldots 77$

Appendix F:Daily Pipe to Soil "On" Potential Readings at USACERL Test Site $\ldots \ldots \ldots 85$

Appendix G:Daily Pipe to Soil Instant Off Potential (IOP) Readings at USACERL Test Site 95 Appendix H:Readings From Fort Drum Test Site $\ldots \ldots \ldots \ldots \ldots \ldots \ldots \ldots \ldots$

\section{Distribution}




\section{List of Figures and Tables}

Figures
The basic corrosion cell $\ldots \ldots \ldots \ldots \ldots \ldots \ldots \ldots \ldots \ldots \ldots \ldots$

Schematic of impressed current CP system $\ldots \ldots \ldots \ldots \ldots \ldots \ldots 14$

Potential changes upon the application of CP $\ldots \ldots \ldots \ldots \ldots \ldots$

Schematic of structure-to-electrolyte potential survey $\ldots \ldots \ldots \ldots \ldots 15$

Rectifier output current measurement using ammeter in series . . . . . 16

Rectifier current measurement using shunt $\ldots \ldots \ldots \ldots \ldots \ldots \ldots 17$

Generalized RMU connection schematic $\ldots \ldots \ldots \ldots \ldots \ldots \ldots \ldots 23$

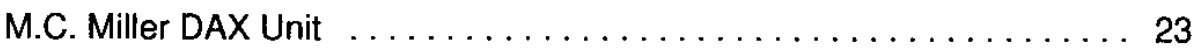

Tomar System SMART unit $\ldots \ldots \ldots \ldots \ldots \ldots \ldots \ldots \ldots \ldots . \ldots \ldots$

Good-All Electric, RAMS monitor . . . . . . . . . . . . . . . . . 24

USACERL test site $\ldots \ldots \ldots \ldots \ldots \ldots \ldots \ldots \ldots \ldots \ldots \ldots \ldots \ldots \ldots$

Locations of RMUs at Fort Drum $\ldots \ldots \ldots \ldots \ldots \ldots \ldots \ldots \ldots$

Sample of DAX data imported into Microsoft Excel ............46

Sample of graphs provided by DAX software $\ldots \ldots \ldots \ldots \ldots 4$

Sample of SMART data imported into Microsoft Excel $\ldots \ldots \ldots \ldots . .48$

Schematic of SMART unit provided by Tomar Systems $\ldots \ldots \ldots \ldots 49$

Weekly average rectifier output voltage at USACERL test site $\ldots \ldots \ldots 50$

Weekly average rectifier output current at USACERL test site $\ldots \ldots \ldots 50$ 


\section{Tables}

Cathodic protection monitoring requirements $\ldots \ldots \ldots \ldots \ldots \ldots \ldots 14$

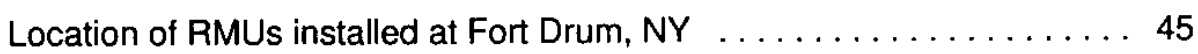

Rectifier tap settings at USACERL test site

49

Readings from DAX unit at Building \#11050, 14 December $1995 \ldots . \ldots 52$

Readings from SMART unit at Building \#4405, 14 December $1995 \ldots 52$

Readings from DAX unit at Building \#11050 (Guthrie, Clinic), 18 June

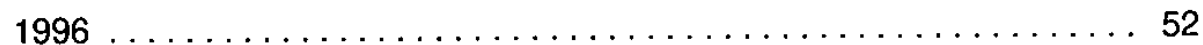

Readings from DAX unit at Building \#10030 (Unit Chapel), 18 June 1996 53

Readings from SMART unit at Building \#4405, 7 August $1996 \ldots \ldots$. . . 53

Readings from SMART unit at Building \#10612, 7 August $1996 \ldots \ldots 53$

RMU software feature comparison $\ldots \ldots \ldots \ldots \ldots \ldots \ldots \ldots \ldots$ 


\section{Introduction}

\section{Background}

Metallic structures buried in soil or submerged in water tend to corrode. Corrosion of storage tanks and piping systems can result in premature failures, costly losses of the substance being conveyed or stored, leakage of hazardous materials into the environment, diminished system reliability, and high life-cycle costs. Cathodic protection (CP) is required by regulation and Army policy on many of these structures to prevent corrosion. CP systems must be periodically evaluated to ensure that they are providing adequate, continuous corrosion protection. The evaluation is typically done by field engineers or technicians who travel to each rectifier and test station and conduct a series of measurements with handheld meters. Lack of resources has made it difficult for Army Directorates of Public Works (DPWs) to perform CP testing on a regular basis. Consequently, many CP system malfunctions may remain undetected until the structure that was supposed to be protected corrodes and leaks.

Several companies have begun manufacturing remote monitoring units (RMUs) that are tailored specifically for evaluating impressed current CP systems. These units allow an engineer or technician to conduct the required measurements on multiple CP systems from a single master computer. This master computer can be located anywhere on or off an installation-even thousands of miles away from the rectifiers and test sites. RMUs minimize the amount of time required for CP system evaluation because personnel do not need to visit the site unless a problem is detected. RMUs therefore make it easier for Army installations to establish a regular CP testing program, and they make it possible to detect and repair CP system malfunctions quickly.

As part of its ongoing research and development in the area of corrosion prevention, the U.S. Army Construction Engineering Research Laboratories (USACERL) conducted a demonstration of remote CP monitoring technology under the Army's Facilities Engineering Applications Program (FEAP). 


\section{Objective}

The objective of this study was to evaluate the field performance of commercially available impressed current CP RMUs for use on Army installations.

\section{Approach}

1. A market survey was conducted to identify commercially available CP RMUs. RMU requirements were developed based on Army needs. The three candidate systems that best met Army requirements were selected for testing.

2. One RMU from each of the three selected manufacturers was installed at USACERL on an outdoor CP test facility. CP system performance was measured daily using the RMUs. The same measurements were also taken onsite daily using standard manual CP testing procedures. The results of the two measurement methods were compared to determine the accuracy of the RMU measurements.

3. Two RMUs from each of the three manufacturers were installed on the CP system that protects the underground high temperature hot water distribution system at Fort Drum, NY. Readings were taken remotely on a weekly basis. RMU readings were compared with manual readings at installation time and 6 months into the testing period to determine the accuracy of the RMU measurements.

4. In addition to the field measurements, units were compared in terms of other features such as ease of installation, software capabilities, and quality of system documentation. The results of these evaluations were used along with the field measurement results to provide a comprehensive evaluation of the three units.

\section{Scope}

This study should not be considered all-inclusive. It includes only the CP RMUs that met specific requirements at the time of the manufacturer survey in early 1995. The requirements were:

- Units must currently be ready for production and testing.

- Units must be manufactured in the United States. 
- Units must be able to monitor a typical CP system without extensive rewiring, configuring, or programming by the user.

- Units must be competitively priced.

There were systems available at the time of the survey that did not fully meet these requirements, but might meet them now. Furthermore, other manufacturers may have introduced new systems onto the market since the time of the survey.

The hardware that was tested was procured between July and October of 1995 and can be assumed to be representative of the hardware that was available from the three manufacturers at that point in time. Some of the manufacturers may have updated or improved their hardware since that time, but these updates were not addressed in this study. Software updates that were provided by the manufacturers were implemented throughout the study period.

\section{Mode of Technology Transfer}

The results of this work are being published in a FEAP User Guide and a FEAP Ad Flyer to assist installations in procuring the technology. In addition, specifications for CP RMUs should be incorporated into Corps of Engineers Guide Specification 16642, Cathodic Protection System, Impressed Current.

\section{Units of Weight and Measure}

U.S. standard units of measure are used in this report. A table of standard international (SI) units is provided below.

$\begin{aligned} 1 \mathrm{in.} & =25.4 \mathrm{~mm} \\ 1 \mathrm{ft} & =0.305 \mathrm{~m} \\ 1 \mathrm{sq} \mathrm{ft} & =0.093 \mathrm{~m}^{2} \\ 1 \mathrm{sq} \mathrm{ft} / \mathrm{min} & =0.093 \mathrm{~m}^{2} / \mathrm{min} \\ 1 \mathrm{cu} \mathrm{ft} & =0.028 \mathrm{~m}^{3} \\ 1 \mathrm{mi} & =1.61 \mathrm{~km} \\ 1 \mathrm{lb} & =0.453 \mathrm{~kg} \\ 1 \mathrm{gal} & =3.78 \mathrm{~L} \\ 1 \mathrm{psi} & =6.89 \mathrm{kPa} \\ 1 \mu \mathrm{m} & =1 \times 10^{-6} \mathrm{~m} \\ { }^{\circ} \mathrm{F} & =\left({ }^{\circ} \mathrm{C} \times 1.8\right)+32\end{aligned}$




\section{Cathodic Protection: An Overview}

\section{Corrosion of Steel Structures}

Corrosion is an electrochemical process. Four elements must be present for corrosion to occur: an anode, a cathode, an electrolyte (such as soil or water), and a metallic connection between the anode and cathode. Electron flow, or current, leaves the structure at the anode, passes through the electrolyte, reenters the structure at the cathode site, and returns to the anode through the metallic connection (Figure $1^{*}$ ). Corrosion, or the dissolution of metal, occurs at the anode site. Electrons lost at the anode flow through the metallic connection and are gained by the cathode. The overall process is an oxidation-reduction reaction. Insoluble corrosion products form at the cathode by a nonelectrochemical reaction (Myers 1974).

\section{Cathodic Protection Systems}

Cathodic protection (CP) is an electrical method of mitigating corrosion on structures that are exposed to electrolytes. Corrosion control is achieved by forcing a proper amount of direct current to flow from auxiliary anodes, through the electrolyte, and onto the structure to be protected. The entire protected structure becomes cathodic relative to the auxiliary anodes. There are two types of $\mathrm{CP}$ systems: sacrificial and impressed current. This report addresses only the monitoring of impressed current CP systems (Figure 2), which use an external power source to apply protective current through auxiliary anodes (Myers 1974).

The U.S. Environmental Protection Agency (EPA) mandates the use of CP to prevent corrosion of metallic underground fuel storage tanks (USTs) and associated piping (40 CFR 280-281). The U.S. Department of Transportation (DOT) requires CP on natural gas transmission and distribution systems (49 CFR 192). Army guidance (Engineering Technical Letter [ETL] 1110-3-440) requires CP on a number of structures, including all ferrous metallic natural gas piping, all steel water storage tank interiors, and underground heat distribution and chilled water piping in ferrous metallic conduit where soils have a resistivity of $30,000 \mathrm{ohm}-\mathrm{cm}$ or less.

\footnotetext{
Figures and tables are located at the end of their associated chapters.
} 


\section{Evaluating CP System Performance}

CP systems must be monitored periodically to ensure that they are providing proper corrosion protection to the structure. A typical impressed current CP evaluation includes the analysis of structure-to-electrolyte potential measurements and rectifier input and output measurements. To be useful for Army needs CP RMU must be able to conduct these tests. Other tests, such as dielectric joint testing, interference testing, and electrical continuity testing, may be conducted as necessary.

Regulatory requirements and military guidance for monitoring impressed current CP systems are shown in Table 1.

\section{Structure-to-Electrolyte Potentials and Criteria for Protection}

When $\mathrm{CP}$ is applied to a structure, the structure's potential changes in the negative direction (Figure 3). The amount of change produced is a measure of the effectiveness of the $\mathrm{CP}$ at that location (Husock 1979). The potential of an underground structure is generally measured relative to a stable copper-copper sulfate $(\mathrm{Cu} /$ $\mathrm{CuSO}_{4}$ ) reference electrode as shown in Figure 4. This potential is called the structure-to-electrolyte potential, structure-to-soil potential, or pipe-to-soil potential. The reference electrode may either be a portable electrode placed on the surface of the soil as close as possible to the structure (see Figure 4), or a permanent electrode buried 12 to $24 \mathrm{in.}$ away from the structure.

A structure-to-soil potential that is measured before CP is applied is called the "natural potential" or "native potential." A structure-to-soil potential that is measured with the CP current applied is called an on-potential. On-potentials contain the error (called "IR drop") that is produced by the voltage drops in the electrolyte (soil or water) and in the structure itself. A structure-to-soil potential that is measured instantaneously after the protective current is interrupted is called an "instant-off potential," or IOP. IR drop error is removed because no current flows during the measurement, so the IOP allows the true polarized potential of a cathodically protected structure to be determined in the field. The current is usually interrupted in these measurements with an interrupting device placed in series with the power source, or by manually switching the rectifier off.

To determine whether the structure of interest is cathodically protected, the structure-to-electrolyte potential measurements are evaluated against National Association of Corrosion Engineers (NACE) criteria for CP. The following criteria 
for steel and cast iron piping are extracted from Recommended Practice RP0169-96 (NACE International $1996^{*}$ ):

6.2.2.1 External Corrosion control can be achieved at various levels of cathodic polarization depending on the environmental conditions. However, in the absence of specific data that demonstrate that adequate cathodic protection has been achieved, one or more of the following shall apply:

6.2.2.1.1 A negative (cathodic) potential of at least $850 \mathrm{mV}$ with the cathodic protection applied. This potential is measured with respect to a saturated copper/copper sulfate reference electrode contacting the electrolyte. Voltage drops other than those across the structure-to-electrolyte boundary must be considered for valid interpretation of this voltage measurement.

NOTE: Consideration is understood to mean the application of sound engineering practice in determining the significance of voltage drops by methods such as:

6.2.2.1.1.1 Measuring or calculating the voltage drop(s);

6.2.2.1.1.2 Reviewing the historical performance of the cathodic protection system;

6.2.2.1.1.3 Evaluating the physical and electrical characteristics of the pipe and its environment; and

6.2.2.1.1.4 Determining whether or not there is physical evidence of corrosion.

6.2.2.1.2 A negative polarized potential . . of at least $850 \mathrm{mV}$ relative to a saturated copper/copper sulfate reference electrode.

6.2.2.1.3 A minimum of $100 \mathrm{mV}$ of cathodic polarization between the structure surface and a stable reference electrode contacting the electrolyte. The formation or decay of polarization can be measured to satisfy this criterion.

\footnotetext{
C 1996, NACE International. Reprinted with permission. To obtain complete copies of RP0169-96, please contact:

NACE International P.O. Box 218340 Houston, TX 77812-8340 Phone: (218) 492-0535 FAX: (218) 492-8254 Internet: www.nace.org
} 


\section{Rectifier Testing}

In impressed current systems, the rectifier output direct current (DC) voltage and current must be monitored. Measuring the rectifier output voltage involves using a DC voltmeter to measure the potential difference between the positive and negative output terminals of the rectifier. Measuring the rectifier output current involves either (1) connecting an ammeter in series with the rectifier on its output side (Figure 5) or (2) measuring the voltage across the rectifier shunt of known resistance and using Ohm's Law (V = IR) to calculate the current (Figure 6).

It is also a good idea to monitor the alternating current (AC) power supply to the rectifier so power outages can be detected.

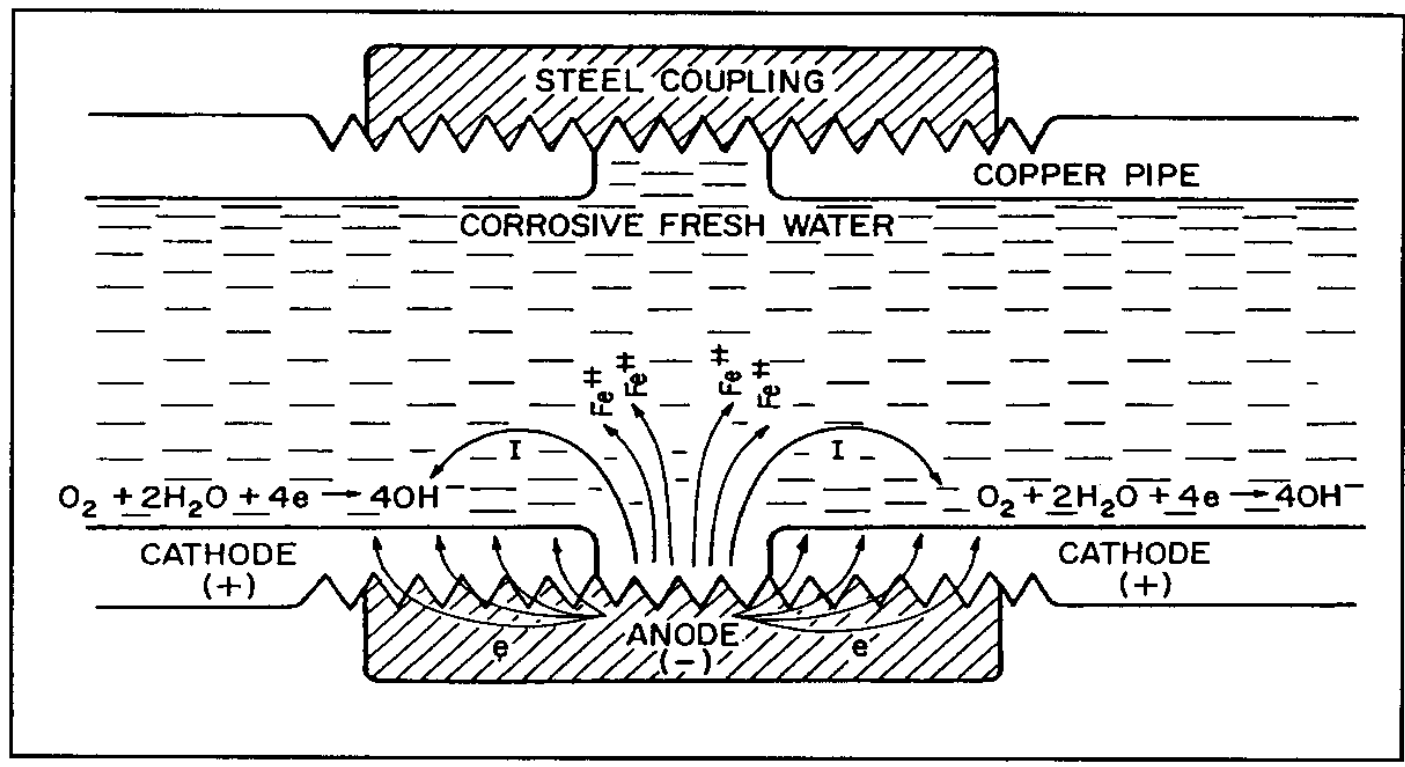

Figure 1. The basic corrosion cell. 


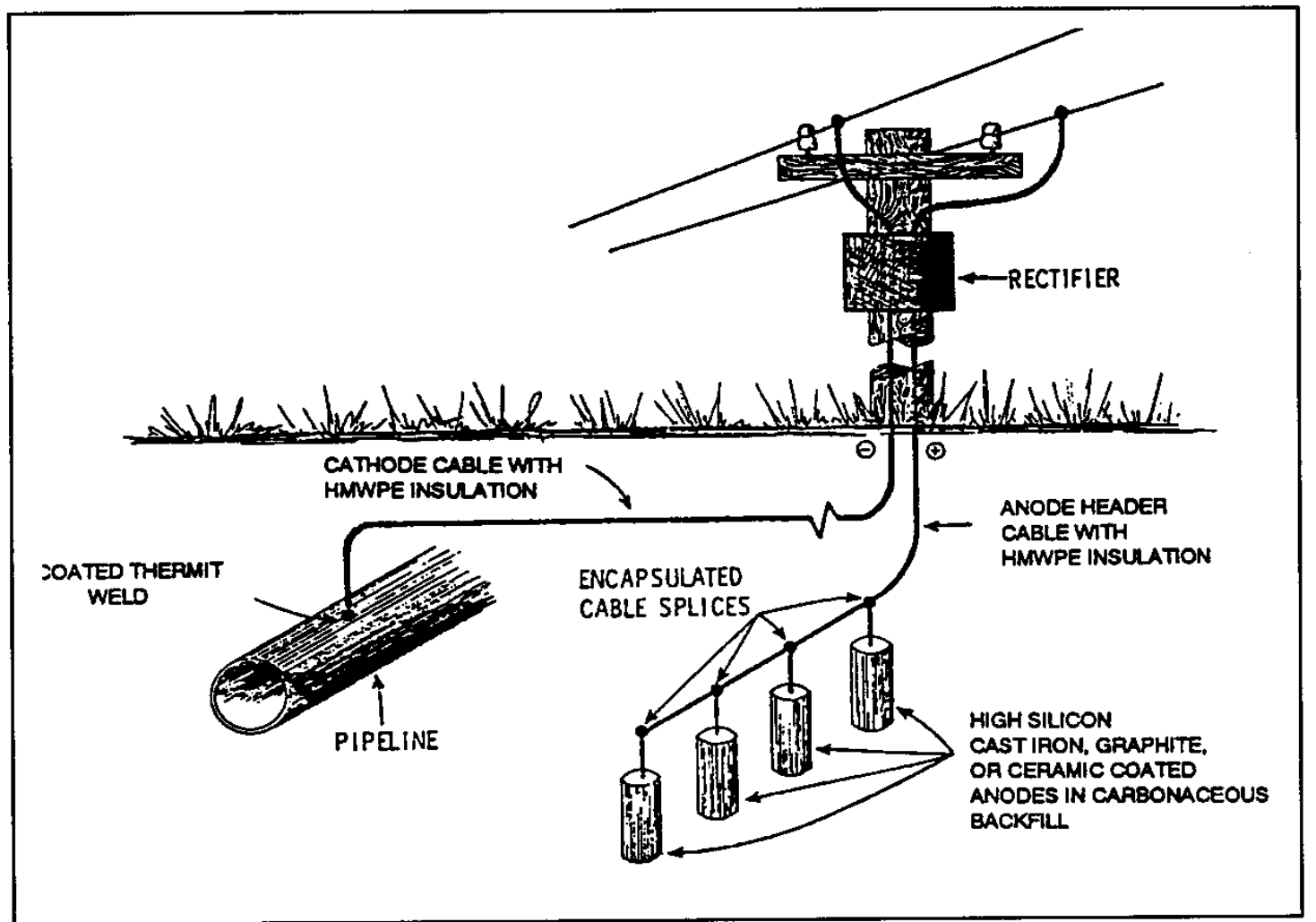

Figure 2. Schematic of impressed current CP system.

Table 1. Cathodic protection monitoring requirements.

\begin{tabular}{|c|c|c|c|}
\hline $\begin{array}{l}\text { Regulation or } \\
\text { Guidance }\end{array}$ & Structure & Type of Test & Required Frequency \\
\hline \multirow[t]{2}{*}{$40 \mathrm{CFR}$} & $\begin{array}{l}\text { Underground storage } \\
\text { tanks and piping } \\
\text { containing regulated } \\
\text { substances }\end{array}$ & $\begin{array}{l}\text { Structure-to-electrolyte potential } \\
\text { survey }\end{array}$ & Every 3 years \\
\hline & & Rectifier test & Every 60 days \\
\hline \multirow[t]{2}{*}{49 CFR } & $\begin{array}{l}\text { Natural gas distribution } \\
\text { and transmission }\end{array}$ & $\begin{array}{l}\text { Structure-to-electrolyte potential } \\
\text { survey }\end{array}$ & $\begin{array}{l}\text { Once per calendar year, } \\
\text { not to exceed } 15 \text { months } \\
\text { between tests }\end{array}$ \\
\hline & & Rectifier test & $\begin{array}{l}\text { Six times per calendar } \\
\text { year, not to exceed } 21 / 2 \\
\text { months between tests }\end{array}$ \\
\hline \multirow[t]{3}{*}{ MIL. HDBK-1004/10 } & $\begin{array}{l}\text { All cathodically protected } \\
\text { structures }\end{array}$ & $\begin{array}{l}\text { Structure-to-electrolyte potentials } \\
\text { at } 3 \text { points of least negative } \\
\text { potential and } 1 \text { point of highest } \\
\text { negative potential per CP system }\end{array}$ & Every 3 months (quarterly) \\
\hline & & $\begin{array}{l}\text { Structure-to-electrolyte potential } \\
\text { survey at all test points; inspect } \\
\text { for damage and anode } \\
\text { consumption }\end{array}$ & Annually \\
\hline & & $\begin{array}{l}\text { Rectifier test (impressed current } \\
\text { only) }\end{array}$ & Monthly \\
\hline
\end{tabular}




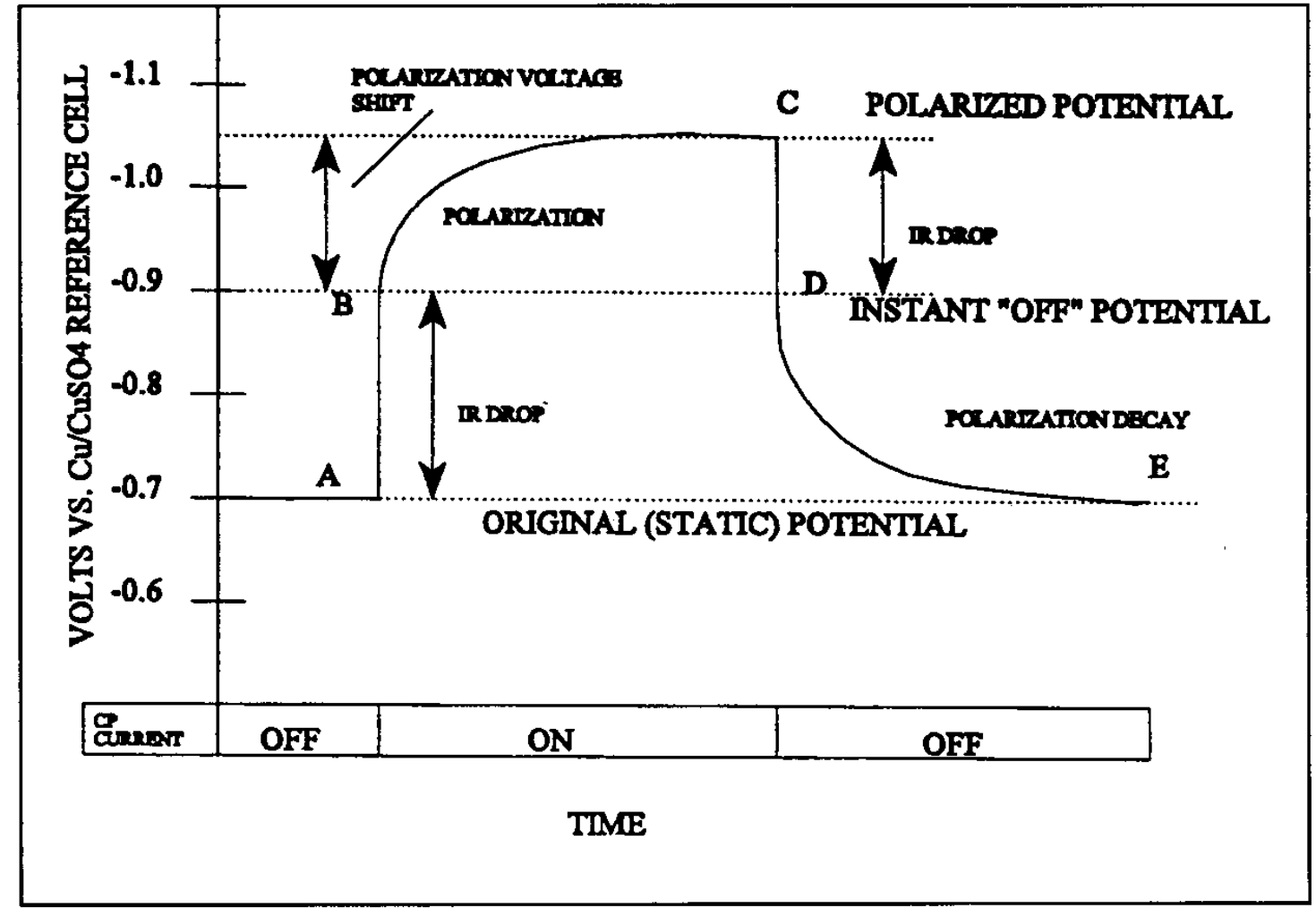

Figure 3. Potential changes upon the application of CP.

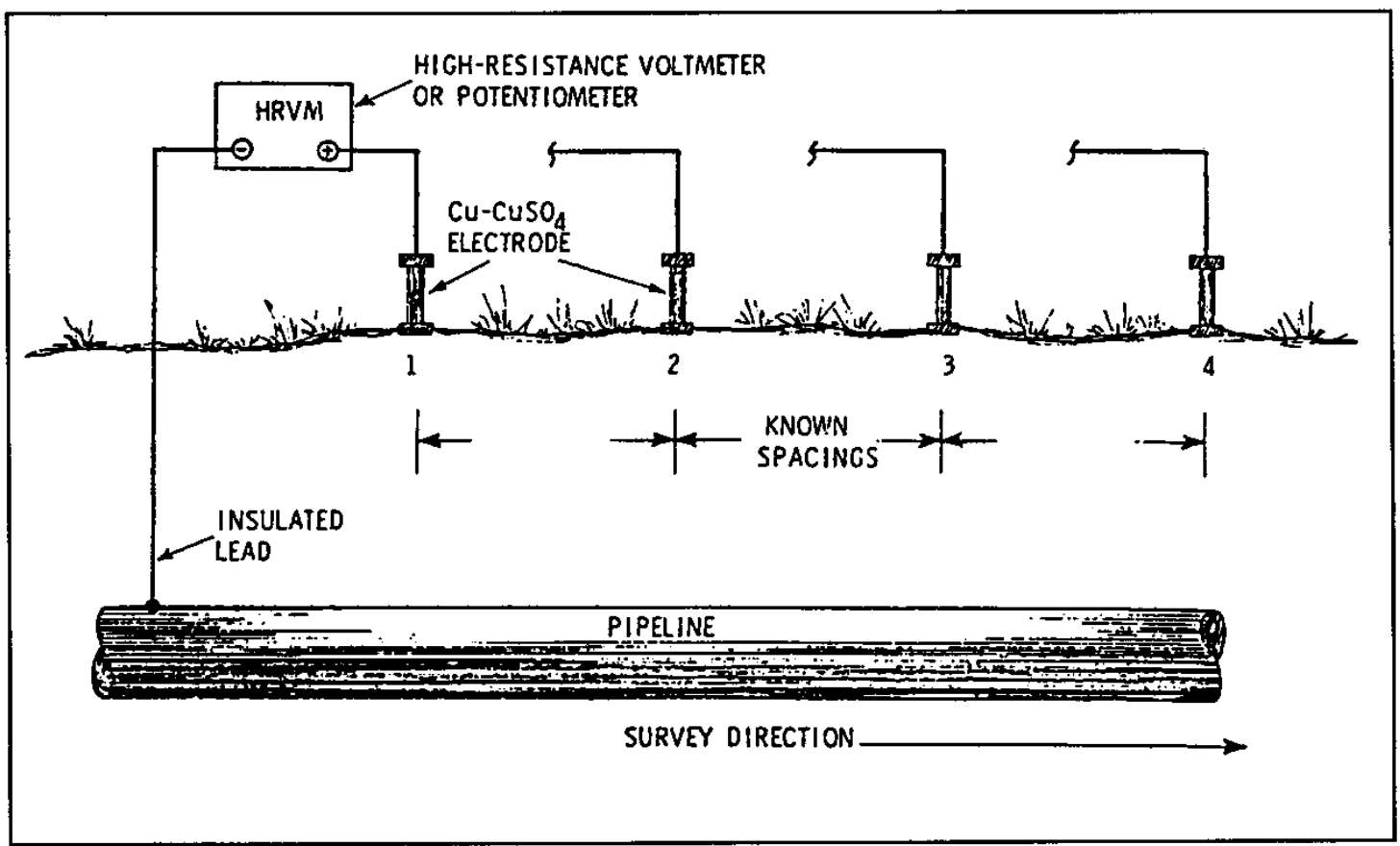

Figure 4. Schematic of structure-to-electrolyte potential survey. 


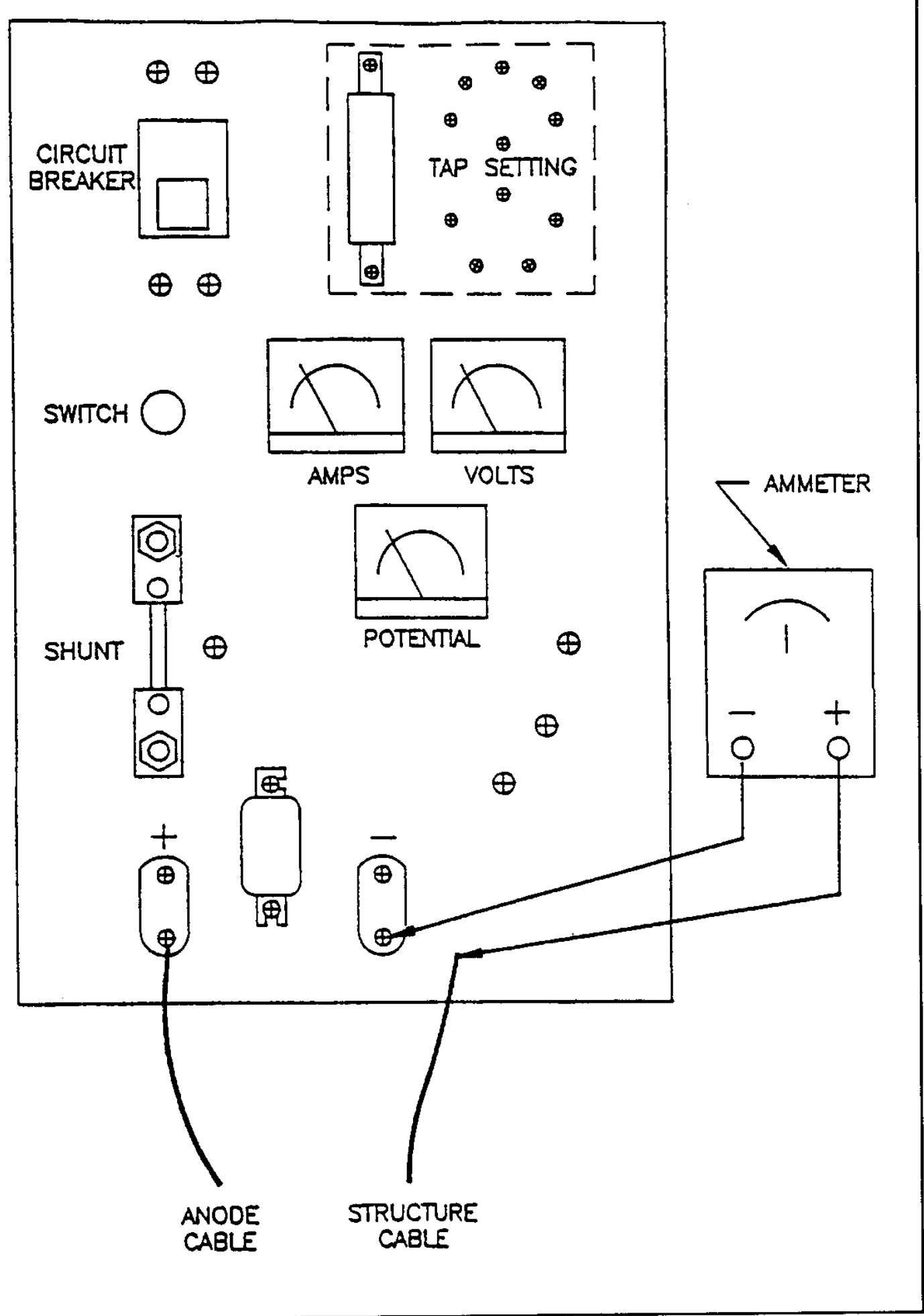

Figure 5. Rectifier output current measurement using ammeter in series. 


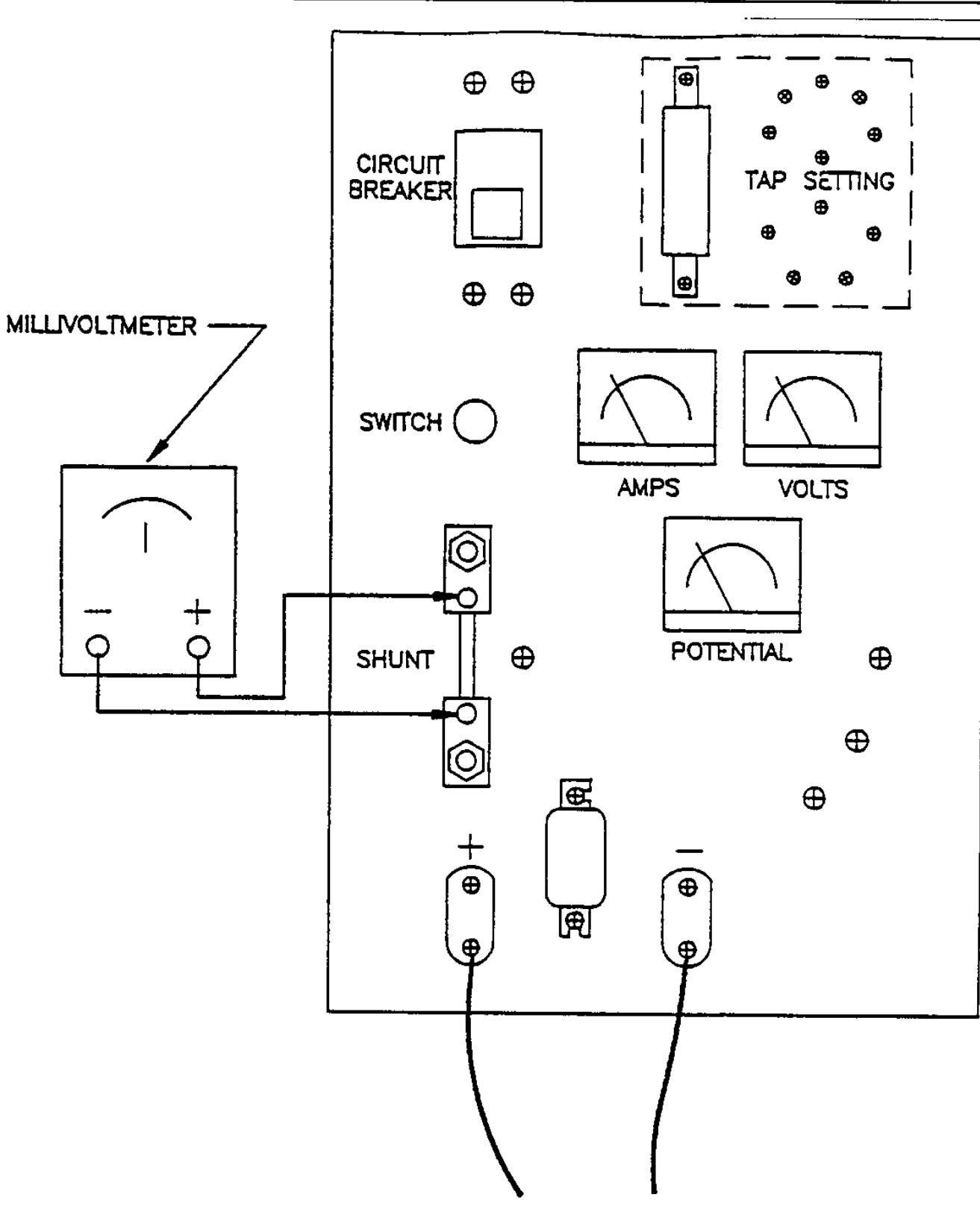

$I_{R}=E_{S}(m v) \times A / m v$ OF SHUNT

Figure 6. Rectifier current measurement using shunt. 


\section{Market Survey and Candidate RMUs}

\section{Market Survey}

The market survey of commercially available CP RMUs was conducted at the beginning of the project, in early 1995 . Nine systems were investigated. The systems were evaluated against the following criteria:

1. Units must currently be ready for production and testing.

2. Units must be manufactured in the United States.

3. Units must be able to monitor a typical $\mathrm{CP}$ system without extensive rewiring, configuring, or programming by the user.

4. Units must be competitively priced.

Units that did not meet these criteria were eliminated from consideration. The three that met the screening criteria were:

1. The DAX Remote Monitoring System (M.C. Miller Co., Inc.)

2. SMART Remote Monitoring System (Tomar Systems, Inc.)

3. RAMS Remote Monitoring System (Good-All Electric).

\section{Generalized RMU Configuration}

A generalized CP remote monitoring system is shown in the schematic in Figure 7. Connection details are specific to each manufacturer. Each RMU is installed near a CP rectifier. A permanent copper-copper sulfate reference electrode is buried near the pipe at each monitoring location and its lead wire is routed to the RMU. The terminals of the RMU are connected to the CP equipment so the rectifier output voltage, rectifier output current, rectifier input voltage, and pipe-to-soil potential (versus the permanent reference electrode) can be measured. A telephone line is connected to each RMU to enable communication to the central computer. 


\section{RMU Specifications and Common Features}

The ordering specifications for the RMUs included in the study were determined on the basis of what an Army installation would require. Some of the requirements were specific to the Fort Drum and USACERL test sites, as noted below. The initial requirements list was as follows:

1. RMUs shall be able to read both on-potentials and IOPs from 0-4 VDC with a resolution of $10 \mathrm{mV}$ using an existing reference electrode permanently installed at each test site.

2. The manufacturer shall supply external relay control or other means necessary for RMUs to measure IOPs by interrupting the rectifier current. If possible, systems shall be equipped to interrupt all units of the same make on site simultaneously.

3. RMUs shall be able to read rectifier voltages of $0-60 \mathrm{VDC}$ (site-specific requirement) with a resolution of $100 \mathrm{mV}$.

4. RMUs shall be able to read rectifier DC amperage from 0-12 amp (site specific requirement) with a resolution of $100 \mathrm{~mA}$.

5. RMUs shall be able to read rectifier AC voltage with a resolution of $1 \mathrm{VAC}$ at a test point located after the rectifier circuit breaker. Units shall be supplied to operate from the specified AC voltage. (AC voltages of 120,240 , and 480 were tested.)

6. RMUs shall have a battery backup that will be used in the event of power failure.

7. RMUs shall notify the master computer when an "out of limits" condition is measured and shall identify the location and nature of the problem ("alarm feature").

8. The manufacturer shall supply all software required to operate and monitor the RMU.

In addition to the above specifications, the RMUs had several other common features. All units are system-independent, which means they can be used with any manufacturer's rectifier. All units have 100 percent solid state circuitry, which means that there are no mechanical connectors or other mechanical components used (except for the solenoid used to interrupt the CP current). (In general, equipment reliability improves when there are fewer mechanical components.) All units were manufactured from industrial-grade components, which means they can operate at temperatures from -40 to $85^{\circ} \mathrm{C}$. All of the units tested have a humidity rating greater than 90 percent. The humidity rating measures a unit's ability to withstand moisture. The DAX unit was rated to 100 percent hosedown. All units 
are equipped with a standard Hayes-compatible 2400 baud modem; faster modems were optional on some units.

All of the units were call-up addressable, meaning that they can be interrogated at any time from the master computer. Each RMU uses Windows ${ }^{*}$-based software and can export data into a spreadsheet.

\section{Unit-Specific Features}

While all of the selected RMUs met the minimum specified requirements, there were many hardware and software variations among them. This demonstration ultimately revealed that such unit-specific features account for significant differences in unit reliability, accuracy, and ease of use.

\section{M.C. Miller Co., Inc., DAX Monitor}

The Miller DAX Monitor (Figure 8) had several unique features. A product brochure is shown in Appendix A.

The DAX was the only RMU in the evaluation that was listed by Underwriters Laboratories (UL). This is an important safety consideration because high voltages and currents can be present in CP systems. Also, the DAX was the only RMU that had surge protection on all of its inputs and outputs, including the data channels, power supply, and telephone line. This feature was found to be a very important factor in RMU reliability.

Another unique DAX feature was the use of differential input to all data channels. Each channel has its own dedicated negative terminal rather than the shared negative bus ("common ground") used by the other units demonstrated. By supplying dedicated positive and negative terminals for each data channel, the DAX unit allows the monitoring of multiple CP systems while maintaining electrical isolation among them. Differential input is a necessity in cases where one RMU is used to monitor two or more electrically isolated CP systems; when electrical isolation is compromised (1) anode service life may be shortened and (2) the affected CP systems may become incapable of providing adequate corrosion protection. The other units evaluated in this demonstration used a common negative bus for all data channels, so those units would not be usable to monitor multiple CP systems

* Windows is a registered trademark of Microsoft Corp., Redmond, WA. 
Connections to the DAX data channels are made through a unique "waterproof quick disconnect interface." Stripped wire ends are affixed into a waterproof terminal port with a set screw, which helps protect the data channel connections and the RMU's internal components from moisture and humidity damage.

The DAX unit is the only one of the three products available with a user-specified number of data channels, up to a maximum of 8 . The unit cost varies with the number of channels.

The DAX offered a great deal of flexibility in the range of voltages that could be monitored without reconfiguration of hardware or factory reprogramming. The DAX software allowed the user to directly specify the expected range of voltages to be measured. The selections include direct current voltage ranges of $0-300 \mathrm{VDC}, 0-40$ VDC, 0-4 VDC, or 0-400 $\mathrm{mVDC}$, and alternating current voltage ranges of $0-240$ VAC, 0-40 VAC, or 0-4 VAC. The DAX's autoranging capability enables the user to contact any remote unit, take readings on all channels, and determine the proper voltage range setting for each channel. These features allow any input to be interfaced with any channel.

Onboard memory in the DAX consists of $8 \mathrm{~Kb}$ nonvolatile FRAM (ferroelectric random access memory) with the option of adding up to $1 \mathrm{Mb}$ of memory capable of storing 2000 to 4000 readings onsite. FRAM allows the unit to be easily reprogrammed from a remote computer to customize it or install software upgrades. It also allows the user or the manufacturer to perform remote troubleshooting.

\section{Tomar Systems, SMART Monitor}

The Tomar SMART unit (Figure 9) has several unique features. It has the ability to synchronize and interrupt multiple rectifiers. In addition to conducting onpotential and IOP measurements, it is capable of conducting $100 \mathrm{mV}$ depolarization tests. The SMART unit supports several communication platforms in addition to its internal modem, including: (1) RS232, (2) RS485 for networking up to 30 monitors together, and (3) external modems. Thermistors and humidity indicators can be added to assist in monitoring weather data. Standard memory is $16 \mathrm{~Kb}$, which can store 365 days of data based on one set of measurements per day.

The SMART unit is not UL-listed, nor does it have surge protection on its inputs and outputs.

The SMART unit has a "common ground" channel type and is available only with 8 channels. Connections are standard screw-type connections. The SMART unit does 
not allow the operator to select operating voltage ranges: the ranges were preconfigured at the factory according to the contract specifications.

\section{Good-All Electric, RAMS Monitor}

Some of the unique RAMS features (see figure 10) include the option of four power supplies including: (1) 120/240 VAC, $50 / 60 \mathrm{~Hz}$, (2) 6-24 VDC, (3) off-board battery, and (4) solar. The RAMS unit includes an RS232 direct connect to serial port for direct laptop communication, and has $128 \mathrm{~Kb}$ onboard memory accommodating up to 10,000 records.

The RAMS is not UL-listed and has surge protection on the data channels only-not on the power supply or the telephone input. The RAMS unit uses a "common ground" channel type, and is available only with 8 channels. The unit uses standard screw-type connections. The RAMS unit does not allow the operator to select operating voltage ranges.

\section{Permanent Reference Electrodes}

A permanent copper-copper sulfate reference electrode is installed with each remote monitoring system. The electrodes used in this study were model number UR-CUGSW manufactured by Electrochemical Devices, Inc., of Belmont, MA. They consist of a saturated gelled copper-copper sulfate element surrounded in a prepackaged backfill mix designed to minimize migration of contaminants from the surrounding soil. The manufacturer specifies an electrode design life of 15 years and a stability of $\pm 5 \mathrm{mV}$. Each electrode is approximately $8 \mathrm{in}$. in diameter, $16 \mathrm{in}$. long, and weighs approximately $25 \mathrm{lb}$. The electrode comes with a factory-installed \#14 $\mathrm{AWG}^{*}$ lead wire with $\mathrm{HMWPE}^{* *}$ insulation for connection to the measurement circuit.

The electrode is installed at pipeline depth, and 12 to 24 in. from the pipe's surface. 


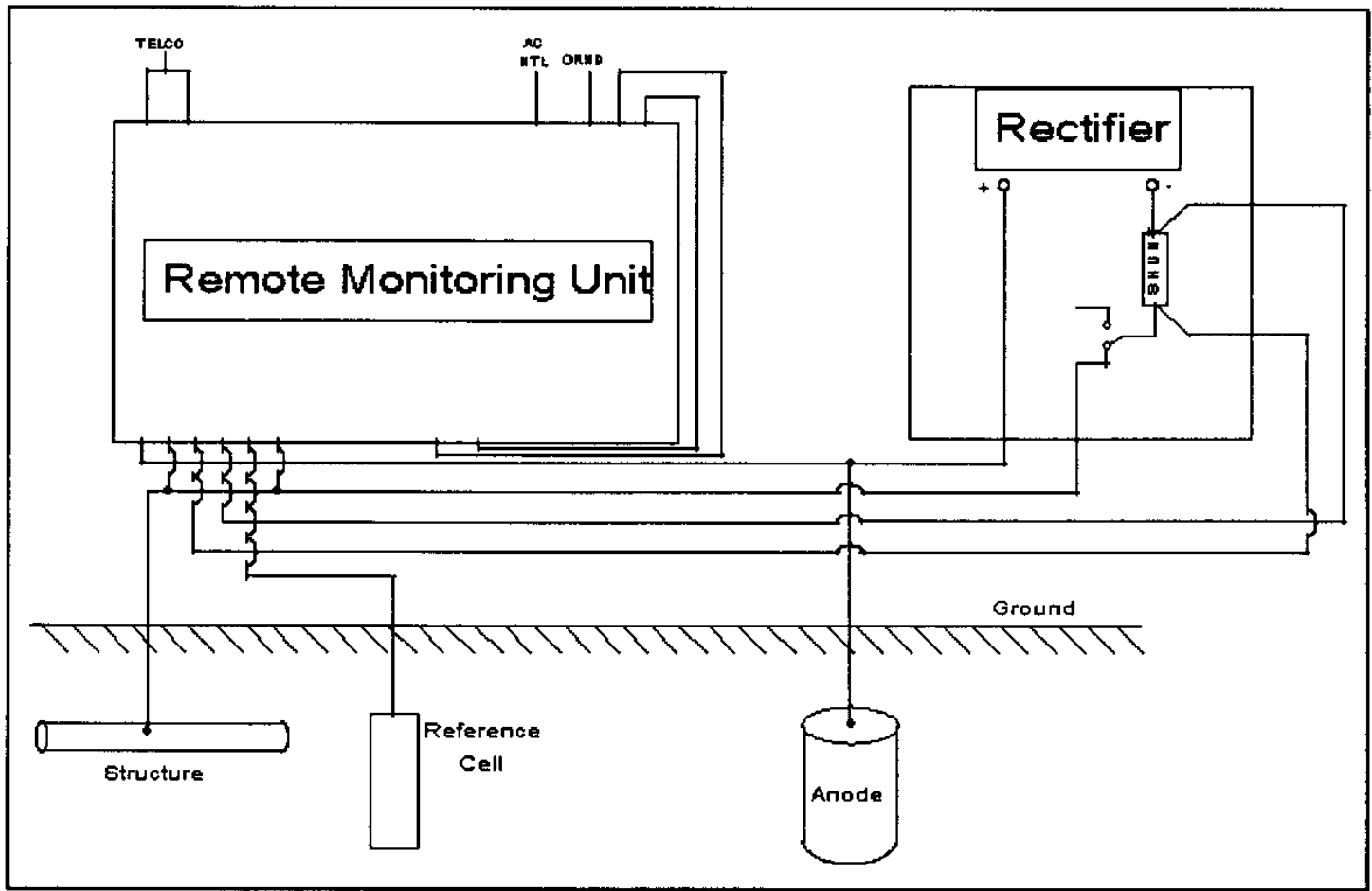

Figure 7. Generalized RMU connection schematic.

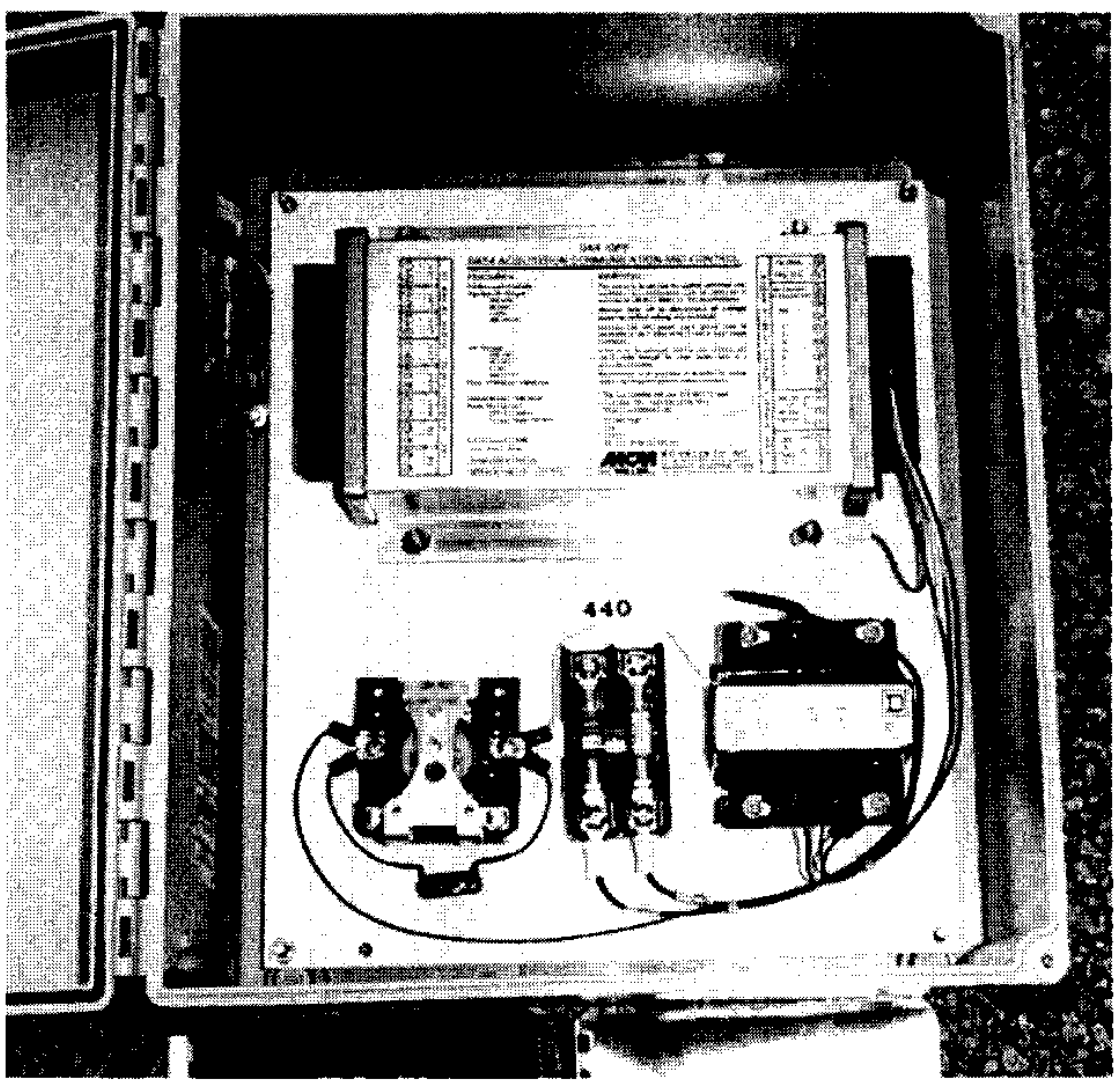

Figure 8. M.C. Miller DAX Unit. 


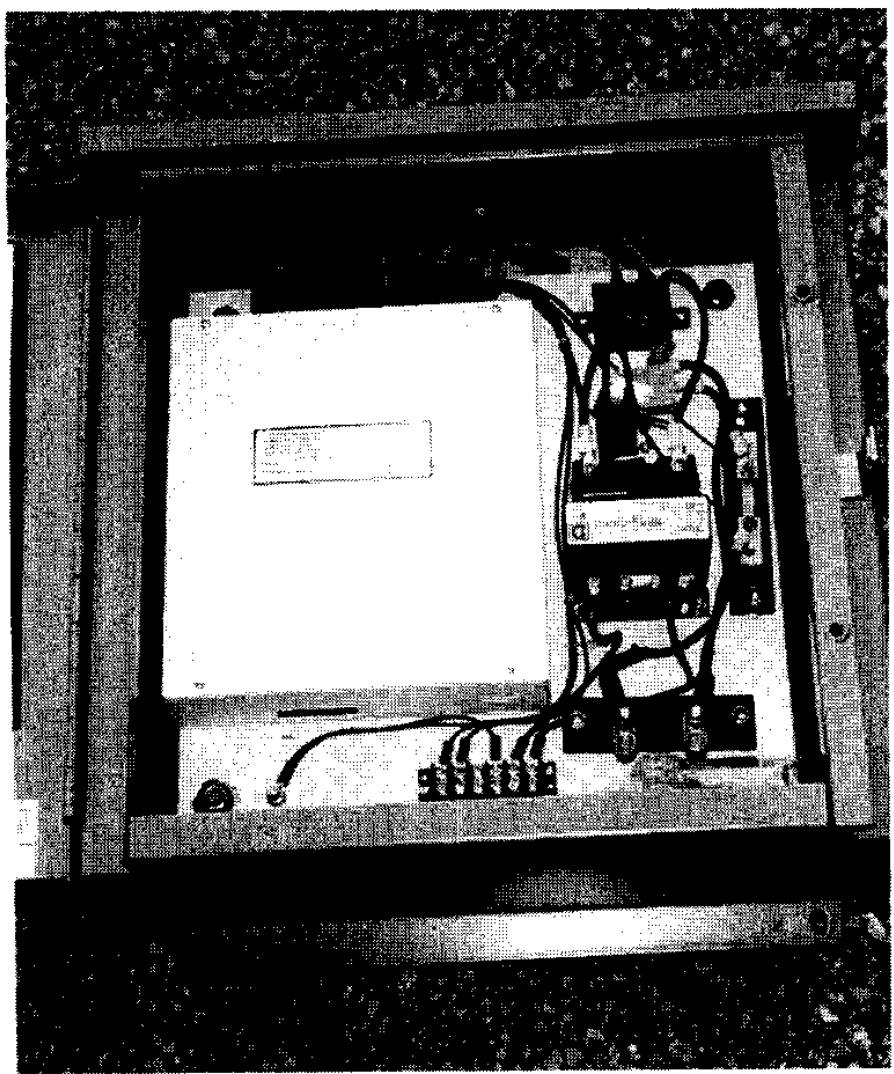

Figure 9. Tomar System SMART unit.

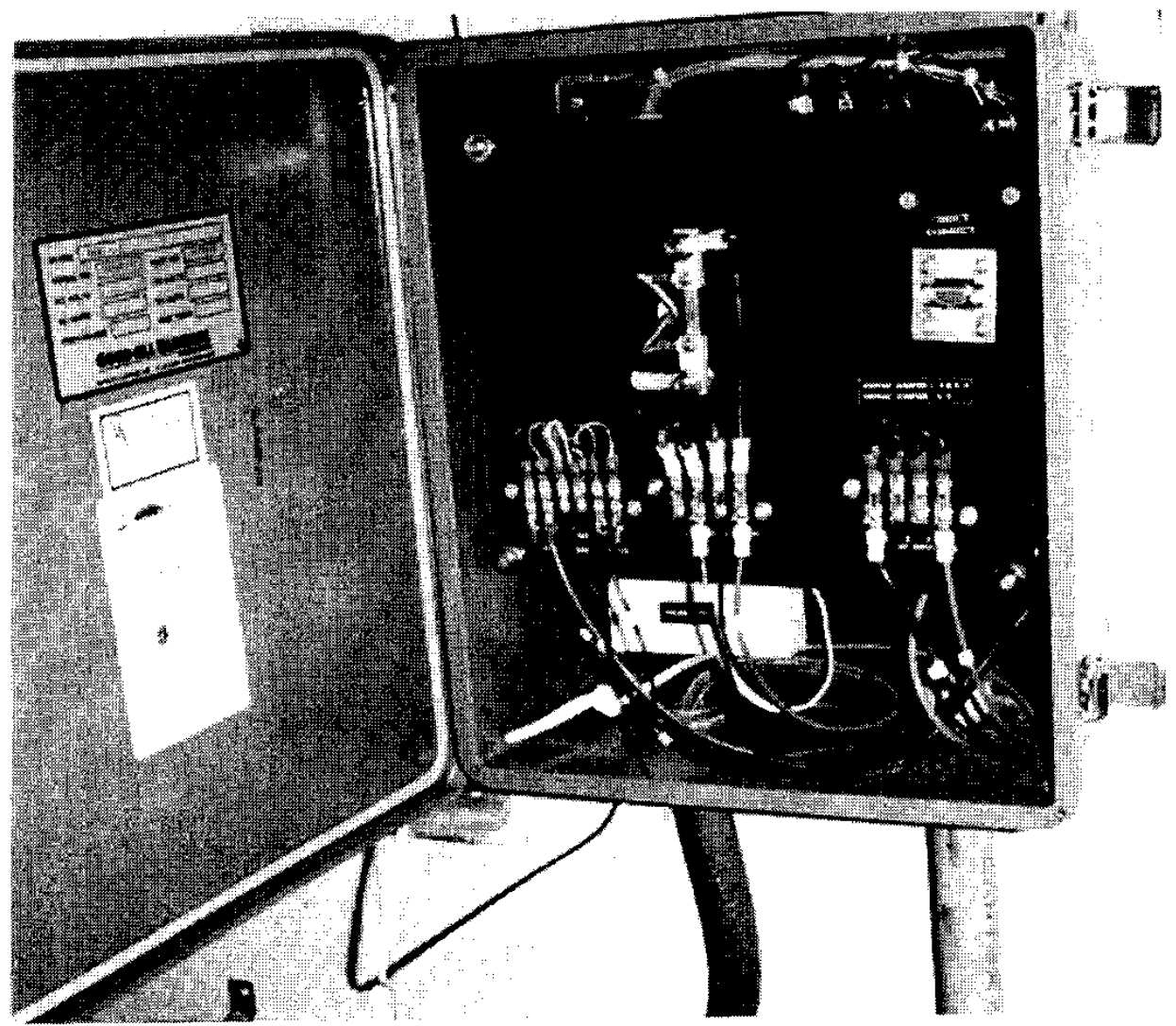

Figure 10. Good-All Electric, RAMS monitor. 


\section{RMU Evaluation Procedure and Results}

An eight-step test procedure was developed for evaluation of the RMU systems. The evaluation focused on factors such as field installation, hardware performance and reliability, software performance, and quality of hardware and software manuals. The steps are described in order, and the results are documented for each RMU.

\section{Step 1: Evaluation of Hardware Manuals}

The hardware manuals were reviewed and evaluated in terms of their clarity, completeness, and conciseness in documenting the preparation and procedures necessary for installing the RMU hardware. A good manual should be well organized and easy to follow. System components and their purposes should be clearly explained, and tools and equipment required to install the systems should be identified. Installation sequencing should be ordered, complete, and understandable, and any required post-installation field testing should be explained.

\section{Results: M.C. Miller DAX}

The hardware manual provided with the DAX unit (M.C. Miller Co. 1995) was complete and easy to follow. Supplemental installation instructions were prepared at Fort Drum to ensure that the proper test leads were connected to the correct DAX terminals. The supplemental instructions are reprinted in Appendix B.

\section{Results: Tomar SMART}

The hardware manual provided with the SMART unit (Tomar Systems 1995) was complete and easy to follow. Supplemental installation instructions were prepared at Fort Drum to ensure that the proper test leads were connected to the correct SMART terminals. The supplemental instructions are in Appendix B. One minor problem with the manual was that it did not give procedures for hooking up the RMU's backup battery. 


\section{Results: Good-AII RAMS}

No hardware manuals were provided with the RAMS unit. A RAMS hardware manual was not available from the manufacturer at the time of this demonstration. Without manuals, installation of the system was considered difficult for anyone except the most experienced RMU users. The RAMS unit had to be opened and the internal circuits traced to determine the proper method for connection of the unit to the CP rectifier at Fort Drum.

\section{Step 2: Evaluation of Hardware Installation Procedures}

One RMU from each manufacturer was installed at the existing. USACERL CP test site (Figure 11). The outdoor facility provided the opportunity for studying the system under a variety of weather conditions and user-varied rectifier outputs. All tests were performed on the bare steel pipe labeled P3. Two permanent copper/ copper sulfate reference cells were installed between the magnesium anodes and at the intersection of the 3 in. diameter coated steel pipe and the 3 in. diameter bare steel pipe as shown in the diagram. They were placed approximately $24 \mathrm{in}$. from the pipes at pipeline depth. Two telephone lines were routed to the RMUs from a nearby building.

At Fort Drum, the RMUs were demonstrated on the impressed current CP system that protects the underground high-temperature hot water (HTHW) distribution system. The HTHW system, which is 20 miles long and was installed in FY86-87 at a cost of $\$ 55$ million, has experienced numerous leaks in the past few years. The Fort Drum DPW has budgeted over $\$ 1$ million per year for FY96-98 to repair and replace sections of the system.

Two RMUs from each manufacturer were installed at Fort Drum in December 1995. Locations of the units are shown in Figure 12 and are listed in Table 2. A permanent reference cell was buried 12 to $24 \mathrm{in}$. from the pipe at each location. One of the Miller DAX units was configured to monitor a dual-circuit rectifier (Bldg. 10030) that powered two separate CP systems on electrically isolated pipelines. One permanent reference cell was used. The purpose of this setup was to evaluate the DAX full differential channel design.

RMUs were evaluated for ease of installation at both sites. Installation and initial testing problems were documented. The manufacturer support required during this process was noted and appraised as to speed, clarity, and effectiveness of response. 


\section{Results: M.C. Miller DAX}

The DAX RMU was relatively easy to install and service. A high level of technical support was readily available from the manufacturer for any questions or problems that occurred during installation. The main concern with the hardware installation was that the high-voltage connections to the unit were exposed within the electrical box where the unit and relay were installed. The high-voltage connections should have insulating shields to protect personnel working with the unit. Also, highvoltage warning labels should be provided on the exterior of the box where the unit and relay were enclosed.

The unique waterproof quick disconnect terminals made installation of the DAX easy and efficient.

At both sites, it was observed that the configuration of the case enclosing the DAX and the additional components did not provide adequate space for attaching the backup battery and the required wiring. The unit had to be removed from the case, with some difficulty, to accomplish those required tasks.

\section{Results: Tomar SMART}

The SMART RMU was relatively easy to install and service. Technical support was available from the manufacturer for questions and problems that occurred during installation. The main concern with the hardware installation was that the highvoltage connections to the unit were exposed within the electrical box where the unit and relay were installed. The high-voltage connections should have insulating shields to protect personnel working with the unit. Also, high-voltage warning labels should be provided on the exterior of the box where the unit and relay were contained.

A minor problem encountered during installation was that a component on the circuit board of one unit was partially out of its socket. The unit did not function properly until the circuit board cover was removed and the component was reseated into the correct position.

\section{Results: Good-All RAMS}

Installation of the RAMS unit was difficult due to the lack of an installation manual. The unit had to be opened and the various circuits had to be traced to determine how the unit was to be installed. This problem would make installation 
extremely difficult for personnel without an extensive background with RMUs. The units did not appear to be easy to service in the field.

\section{Step 3: Evaluation of Software Manuals}

The software manuals were reviewed in terms of their adequacy for novice RMU users and for experienced RMU users. The instructions were evaluated for clarity, completeness, and conciseness. A good manual should clearly present the procedures necessary to install the program on the master computer. System requirements should be clearly identified. Procedures for using the software, setting the necessary operating parameters, obtaining data, exporting data to a spreadsheet, and enabling automated monitoring features should be explained clearly and in detail.

\section{Results: M.C. Miller DAX}

The software manual for the DAX system (M.C. Miller Co. 1996) was considered adequate for novice RMU users. The instructions were relatively clear and concise as to the proper methods and commands for setting up the software for use with the RMU. The manual contained several limited examples that illustrated the use of various commands. Additional examples would make the manual clearer for the novice user. The lack of page numbers made the manual somewhat cumbersome to use.

The software manual would be adequate for experienced RMU users who typically require very little assistance in configuring the software.

\section{Results: Tomar SMART}

The software manual for the SMART system (Tomar Systems 1995) was considered excellent and easy for novice RMU users to follow. The instructions were clear and concise as to the proper methods and commands for setting up the software for use with the RMU. The manual included specific examples illustrating use of the commands. The lack of page numbers made the manual somewhat cumbersome to use.

One problem with the manual was that it did not specify that the modem setup required the user to enter a modem initialization string. The manual left it to the user to discover the initialization string, which is found under Settings in the Windows telecommunication program. Another problem was that the manual did not specify the password that was required to operate the software. 
The software manual would be adequate for experienced RMU users who typically require very little assistance in configuring the software.

\section{Results: Good-AII RAMS}

The software manual for the RAMS system (Good-All Electric 1995) was considered difficult for novice RMU users to follow. The instructions were not clear or concise as to the proper methods and commands for setting up the software for use with the RMU. The manual did not include specific examples illustrating use of the commands. Examples would make the manual clearer for the novice RMU user. The version of the manual evaluated in this study would not be considered adequate for the novice user.

The software manual would be adequate for experienced RMU users who typically require very little assistance in configuring the software.

\section{Step 4: Evaluation of Software Installation, Configuration, and Technical Support}

The software was installed and configured immediately following review of the software manuals to ensure maximum familiarity with the procedures. Installation and configuration procedures were evaluated according to software loading time required, ease of configuring the software to perform the desired measurements, and the amount of technical support required. Configuration or compatibility problems and issues were recorded, along with the appropriate solution.

\section{Results: M.C. Miller DAX}

Software loading. The DAX software took approximately 1 minute to fully load. This was considered excellent.

Software configuration. The software was relatively easy to configure with the assistance of M.C. Miller personnel through their toll-free technical assistance telephone line. The manufacturer has a control unit installed at its offices for verification of the operating parameters of their software. The technical assistance greatly simplified software configuration. Multiple RMUs intended to have the same configuration can be batch-configured by copying the configuration from one RMU to others. 
Technical support. The software manual provided a toll-free telephone number for obtaining technical assistance in the configuration and operation of the software. The level of technical support available for the software was excellent. The DAX support staff was knowledgeable and capable of correcting difficulties, not only with the DAX software configuration but also with the operating system of the computer upon which the software was being installed. Follow-up support for the units was outstanding.

\section{Results: Tomar SMART}

Software loading. The SMART software took approximately 1 minute to fully load. This was considered excellent.

Software configuration. The software was extremely easy to configure with no assistance from Tomar's technical assistance phone line. The software was so simple to configure that readings from the RMUs at Fort Drum and USACERL were made within minutes of loading the software.

Technical support. The software manual provided a toll-free telephone number for obtaining technical assistance in the configuration and operation of the software. The Tomar manual notes that installation, operations and training are available on a "prorated fee basis." Tomar personnel were not contacted for assistance in configuring the software for this study since no assistance was needed.

\section{Results: Good-All Electric RAMS}

Software loading. The RAMS software took approximately 5 minutes to fully load, which was somewhat slower than the other RMU software. RAMS installed configuration files directly into the Windows system files. When a previous version of the software had been installed and later deleted from the computer, various .ini files were left in the Windows System subdirectory. These leftover files prevented successful installation of updated RAMS software until the user could determine the cause of the problem and identify which ini files had to be removed. Also, the installation process also made changes to the main system.ini file; while these changes did not cause any known problems, it cannot be stated with certainty that the changes would have no effect on later upgrade installations. (The software manual did not document this aspect of installation and upgrade.)

Software configuration. The software could not be fully configured because the RMUs installed at Fort Drum and USACERL never became operational. 
Technical support. The software manual provides a phone number for obtaining technical assistance in the configuration and operation of the software. The phone number was not a toll-free (800) number. This could result in substantial longdistance charges to the novice RMU user who would require a substantial amount of assistance in configuring and operating the software. The level of technical support available during the evaluation of this software was considered inconsistent and inadequate for novice RMU users. Follow-up support for these units was a problem, and may be a potential long-term problem for this equipment.

\section{Step 5: Evaluation of Software Use}

The evaluation of software use occurred throughout the RMU demonstration period and addressed the following issues:

- Ease of operation (user-friendliness).

- Software versatility. A good software package should be easily adaptable to a variety of situations and configurations. Evaluation of this capability involves questions such as: Can the software interrogate both single units and multiple units? Does the software allow remote configuration of the RMU?

- Software interface appearance.

- Help function. Online help was evaluated for its usefulness and completeness.

- Data report format. This refers to the clarity, flexibility, and appearance of the standard data reports produced by the RMU software.

- Exportability. This refers to the ability of the software to organize and format data for use by other programs such as spreadsheets. Where the program was unable to do this, the number of steps and time required to organize the data into a clear and presentable format within Microsoft Excel ${ }^{*}$ was noted.

- Alarm capability. This refers to an automatic alarm to notify the operator if a problem has occurred with the CP system.

- Synchronized interruption. This refers to the ability of the software to perform interruption of several rectifiers simultaneously.

- Availability of an un-install feature.

Results: M.C. Miller DAX

Software versatility. The present software allows easy monitoring of either single or multiple units. The software has an alarm reporting capability. The next version

*xcel is a registered trademark of Microsoft Corp., Redmond, WA. 
of the software will allow for simultaneous interruption of multiple units. With the coming upgrades, the software should fully meet the needs of any RMU user.

Help function. The help function built into the software provided detailed information that was much more complete than that published in the software manual. The help function would be of great assistance both to the more experienced computer user and to novice users.

Ease of operation. The DAX software was relatively user-friendly. The interface is attractive and organized in a manner that both novice and experienced users should find easy to operate.

Data format. The standard data reports provided by the DAX software were very clear and easy to read. In early versions of the software, the data channels were not labeled on the printout, but the latest version allows the user to specify a name for each channel. The DAX output file was found to be very flexible. It was in a comma-delimited text format that could be imported directly into Microsoft Excel without any changes to the data file (Figure 13). Data from each individual DAX unit was stored on the master computer in a separate file. The software allowed the user to create a file containing a subset of data that was measured during a userspecified range of dates. The latest version of the software includes an automated graphing function that allows data to be analyzed immediately without importing it into a spreadsheet program. Sample graphs are shown in Figure 14.

Alarm capability. The DAX RMU was provided with automatic alarms that would notify the operator if a problem had occurred with the CP system. The software version that included this feature became available too late in the demonstration to allow evaluation of the alarm mode. Any future version of the DAX RMU to be field-tested should include an operable alarm capability.

Synchronized interruption. The next version of the DAX software is scheduled to include the ability to perform synchronized interruption of multiple rectifier units. This powerful feature would allow accurate measurement of IOPs on piping systems that contain multiple rectifiers. Any future version of the DAX RMU to be fieldtested should have an operable synchronized interruption capability.

Un-install feature. The built-in un-install feature in the software package was powerful and useful, both for the novice and the experienced computer operator. The function quickly and automatically removes the DAX program, its subdirectories, and all associated system files and settings. The software could easily be reinstalled and upgraded with no problem. 


\section{Results: Tomar SMART}

Software versatility. The software was considered adequate for monitoring one RMU at a time, but was incapable of automatically interrogating multiple units. This lack of flexibility in handling multiple units simultaneously would be awkward for monitoring CP systems with multiple rectifiers on a single piping network. In addition, the software could configure an RMU only while directly connected to the RMU via the host computer's serial port; it could not fix RMU configuration problems remotely via modem.

Help function. The help function built into the software provided very detailed information that appeared more complete than that printed in the software manual. The help function would be of great assistance to most users.

Ease of operation. The SMART software was very user friendly. The software interface is organized in a manner that any novice or experienced user should find easy to operate.

Data format. The standard data reports provided by the SMART software were relatively simple. The data are automatically maintained by the software in a format that may not be clear and easy to understand if multiple units are being interrogated. The data are stored sequentially by date of interrogation, in a common file. The file size for the USACERL test site grew quickly and contained approximately 1 megabyte of data after a month of daily interrogations. Sorting or extracting subsets of data was not possible except by exporting the data to another program. Two methods of exporting the data were devised by the evaluation team. The first involved exporting the data to a word processor where it could be exported as an ASCII file into Microsoft Excel. This two-step process was not simple or direct. The other, more successful method used at the USACERL facility involved the development of a macro in Microsoft Excel that accounted for the various delimiters (tab, space) while importing the data file. Once the file was entered into Excel, the contents of the data file provided by the RMU were erased to prevent the file from becoming too large. This approach proved to be inconvenient because only one RMU's data could only be imported at a time. Another problem with the TOMAR output file was that some of the data labels in the template were in improper locations. A sample of the output data file from the SMART unit, formatted in Microsoft Excel, is shown in Figure 15.

ASCII: American Standard Code for Information Interchange. 
Alarm capability. The SMART RMU was provided with automatic alarms that would notify the operator if a problem had occurred with the CP system. The alarm mode was tested and it did not function properly. The RMU did not recognize and report failures that were initiated at the Fort Drum or USACERL test sites. The alarm failure is a critical problem that would have to be corrected before the SMART units could be considered for possible Army use. This feature should be carefully evaluated in any future demonstrations conducted with the SMART RMU.

Synchronized interruption. The SMART unit can not perform synchronized interruption of multiple rectifiers. This shortcoming would be a disadvantage users who have multiple rectifiers protecting a single piping network because synchronized interruption of the rectifiers is required in most of these cases for accurate CP evaluation.

Un-install feature. There is no built-in un-install feature in this software package. This could be an inconvenience to novice computer operators, but should not be detrimental to experienced computer users, especially if the master computer is equipped with a third-party "un-installer" program.

\section{Results: Good-All RAMS}

Software versatility. Software versatility could not be fully evaluated because none of the RMUs were operational. A review of the functions that were available in the software provided evidence that the software may be adequate.

Help function. The help function built into the software provided information that was only slightly more complete than the software manual. The help function would have been of more use to experienced computer users than to novice users.

Ease of operation. The RAMS software appeared to be user-friendly. The software interface was attractive and organized in a manner that most novice and experienced users should find easy to operate. The software could not be fully evaluated as none of the RAMS units in the evaluation were ever fully functional.

Data format. The standard data reports provided by the RAMS software could not be evaluated as none of the RAMS units were fully operational.

Alarm capability. The RMU was not provided with automatic alarms that would notify the operator if a problem had occurred with the cathodic protection system. The lack of an alarm mode is considered a serious deficiency in the RAMS unit. 
Synchronized interruption. The RAMS unit could not perform synchronized interruption of multiple rectifier units. This shortcoming would be a significant disadvantage to users who have multiple rectifiers installed on a single piping network.

Un-install feature. There is no built-in un-install feature in this software package. This could be an inconvenience to novice computer operators, but should not be detrimental to experienced computer users, especially if the master computer is equipped with a third-party "un-installer" program.

\section{Step 6: Evaluation of Hardware Features}

RMU hardware abilities and reliability were rated. A log was maintained of all problems encountered throughout the evaluation. The manufacturer support required during this process was noted and appraised as to speed, clarity, and effectiveness of response. Other factors and features considered included safety, surge protection, reliability of the relay that interrupts the CP current, and ability to program the RMU remotely from the master computer. The reader should note that some findings from this portion of the evaluation can explain findings on RMU accuracy documented below in Step 7.

\section{Results: M.C. Miller DAX}

The DAX experienced only one hardware problem during the test period, and it was caused by an oversight during installation. The installer did not connect the internal backup battery. After a power failure to the RMU the DAX reset itself automatically, so its time setting was different from the master computer's time setting. Due to the discrepancy in timing, the DAX was unable to take the readings properly. The problem was corrected by connecting the backup battery and synchronizing master computer and DAX clocks. This incident underlines the importance of connecting the DAX's backup battery. The latest version of the DAX software automatically sets the DAX's time upon contact with a master computer. Throughout the remainder of the evaluation, there were no other hardware problems with the DAX.

As noted in Chapter 3, the DAX was the only RMU with surge protection on all of its inputs and outputs, including the data channels, power supply, and telephone line. The DAX remained fully functional through several power losses and surges during the demonstration period. The only times that the DAX did not provide data were when there were installation-wide telecommunication problems. 
Also noted previously, the DAX was the only RMU with full differential data input channels. The unit at Fort Drum that monitored two electrically isolated structures simultaneously performed successfully and reliably throughout the evaluation.

The FRAM, described in Chapter 3, was found to provide an advantage in that the unit could be reprogrammed from a remote computer, easing both installation of program upgrades and customization of the application remotely. In the case of the clock problem noted above, engineers at M.C. Miller headquarters used this feature to troubleshoot the DAX.

\section{Results: Tomar SMART}

Throughout the evaluation (including the time of installation) the SMART units failed to make accurate readings. (This problem is discussed in Step 7.) It was initially believed by USACERL and Tomar engineers that this inaccuracy was due to a calibration problem, but, recalibration did not solve the problem. Detailed troubleshooting revealed that hardware problems were most likely the cause of the inaccurate readings.

The most serious problem in the SMART unit was the relay switch that interrupts the CP current during an IOP reading. The problem was detected during the June 1996 visit to Fort Drum, and helped to explain some of the inaccuracies in the readings. The SMART system's relay switch was rated to $20 \mathrm{~A}$. Although the currents never exceeded $12 \mathrm{~A}$, the relays on both units at Fort Drum regularly stuck in the open position when an IOP reading was attempted. This opened the CP circuit and left the structure unprotected. The problem did not occur at the USACERL site, where the maximum current was on the order of $1.5 \mathrm{~A}$. It is believed that the relay problem was partially responsible for the extreme variations in the IR-free readings that were observed throughout the evaluation. A possible explanation for the malfunctioning relay and the specifications for the working magnetic relay are shown in Appendix C.

As the demonstration continued and the SMART units were still not providing accurate readings, Tomar engineers provided possible solutions in the form of a hand-drawn schematic, which has been recreated using computer-aided drafting (CAD) software in Figure 16. The units were all configured in this manner and then verified during the field tests at Fort Drum and at USACERL by an electronics engineer. The SMART RMU was extremely difficult to troubleshoot because the wiring was not color-coded. The cause of the problem with receiving acceptable IRfree readings at the USACERL test site was discovered inadvertently while troubleshooting another problem. One of the jumper switches shown on the 
manufacturer's schematic was missing. After installation of the jumper, relatively accurate IR-free remote readings were achieved at the USACERL site. However, the jumper was not missing from the units at Fort Drum, so this did not contribute to their problems with accurate readings.

Another problem with the SMART units was the lack of surge protection on RMU inputs and outputs. It is likely that the lack of surge protection caused two SMART unit malfunctions at the CERL test site. In one case, an electrical surge apparently occurred along CERL phone lines during a lightning storm, causing the ground for the SMART unit modem to burn and curl up on the circuit board. As a result, the modem emitted a continuous signal that interfered with telephone communication to the other units. The problem was fixed by replacing the circuit board. Another problem occurred at the same time as the modem problem. In the process of adjusting rectifier settings at the USACERL test site, the pipe-to-soil potential momentarily surged higher than 4.0 VDC. Consequently, the diodes used in processing the reference cell voltages malfunctioned, resulting in a complete failure in receiving a reliable reference cell voltage and large fluctuations in other readings. Replacement of the circuit board also solved this problem.

One other problem with the SMART units was that when the unit was disconnected from the AC power supply, pipe-to-soil potentials at the CP site would vary by more than 1 VDC. The situation was corrected without consulting Tomar customer service personnel. The problem occurred when the ground from the AC input was attached to the Tomar-designated ground on the terminal strip. When the ground was disconnected, accurate readings were obtained. However, disconnecting the ground is not advisable from the standpoint of electrical safety.

\section{Results: Good-All Electric RAMS}

There were a number of problems in the RAMS hardware provided.

First, the units that were initially supplied by Good-All did not have an external relay control for interrupting the $\mathrm{CP}$ current. This violated the specifications of the purchase order. When Good-All supplied units with relays, these relays were in the normally-open position. As a result, when power to the RAMS unit was interrupted, the relay would open the CP circuit and leave the structure unprotected.

Only one RAMS unit responded to modem calls throughout the evaluation. The readings on this unit were on the order of $600 \mathrm{VDC}$ for an actual rectifier voltage of 24 VDC. (The inaccuracies were carried throughout all of the data readings.) The other units were completely inoperative. The unit that answered modem calls 
had too large of a relay; the clicking caused by activation of the relay could be heard over $200 \mathrm{ft}$ away.

RMU power supplies were all $120 \mathrm{VAC}$, which violated the configuration specified in the purchase order. Also, there was no safety ground provided.

\section{Step 7: Evaluation of Equipment Accuracy}

\section{Instrumentation}

Throughout the course of the project, several different instruments were used to verify the accuracy of the RMUs. A complete explanation of many of these instruments has been previously published (Hock et al. 1994). The instruments used included:

- $\quad$ Fluke Model 87 True RMS* Digital Multimeter (DMM)

- $\quad$ Fluke Model 867 Graphical Multimeter

- M.C. Miller Waveform Analyzer (WFA) Model WFA-1

- Xetron Cathodic Protection Analyzer (CPA) Model 730

- Leader Electronics DMM/Oscilloscope $200 \mathrm{KHz}$ Model 100P.

\section{Procedures Used at USACERL Test Site}

At the USACERL test site, remote and manual onsite measurements were taken daily (Monday through Friday) to evaluate the accuracy of the RMUs. The following readings were tạken each day:

- $\quad$ rectifier DC voltage with each $\mathrm{RMU}$

- rectifier DC voltage with DMM

- $\quad$ rectifier DC current with each RMU (measured with a shunt)

- rectifier DC current with DMM (measured with a shunt and in series)

- rectifier AC voltage with each RMU

- pipe-to-soil on-potential measurement using each RMU and permanent reference electrodes

- pipe-to-soil on-potential measurement using DMM and permanent reference electrodes

- pipe-to-soil on-potential measurement using DMM and portable copper/copper sulfate reference electrode placed on the surface of the soil directly above the pipe 
- $\quad$ pipe-to-soil IOP measurement using each RMU and permanent reference electrodes

- pipe-to-soil IOP measurement using DMM and permanent reference electrodes. (The rectifier current was interrupted by switching the rectifier off. The IOP reading was taken on the second meter update after the current was interrupted. This is common field practice.)

- $\quad$ pipe-to-soil IOP measurement using DMM and portable copper/copper sulfate reference electrode placed on the surface of the soil directly above the pipe. (The rectifier current was interrupted by switching the rectifier off. The IOP reading was taken on the second meter update after the current was interrupted. This is common field practice.)

Four sets of readings were taken from each RMU daily, approximately 15 seconds apart. The four readings for each parameter were averaged and used as the daily reading for that parameter. This technique was used consistently throughout the demonstration. Data were logged daily and copied into a spreadsheet program for analysis and plotting. Rectifier settings (i.e., tap settings) were varied every few weeks throughout the test period to determine the effects on the various RMUs. The settings for each range of dates are listed in Table 3.

During the final month of site testing, on-potential and IOP measurements were taken with the WFA, the CPA, and the portable oscilloscope in addition to the RMUs and the DMM.

For one RMU of each type being demonstrated, a rectifier failure was to be simulated to check the built in alarm features of the individual types of units. (As explained in Step 6, these tests ultimately were not conducted because none of the RMUs' alarm features were operable during the demonstration period.)

\section{Procedures Used at Fort Drum Test Site}

During the December 1995 installation site visit, the accuracy of the remots monitoring equipment was checked by comparing the RMU readings with readings taken onsite with a Fluke Graphical Multimeter. RMU readings and onsite manual readings were taken within 5 minutes of each other so the environmental conditions were effectively the same for both measurements.

Measurements from Fort Drum were collected weekly by interrogating the RMIS remotely from USACERL. Four sets of readings were taken from each RMLI during the interrogation, approximately 15 seconds apart. The four readings for ciach parameter were averaged and used as the weekly reading for that parameter. 'This 
technique was used consistently throughout the demonstration. Data were copied into a spreadsheet program for analysis and plotting. At each rectifier equipped with a remote monitoring system, the following measurements were performed:

- $\quad$ rectifier DC voltage

- rectifier DC current (measured with a shunt)

- rectifier AC voltage

- pipe-to-soil on-potential measurement

- pipe-to-soil IOP measurement

A second site visit was conducted in June 1996. As during the initial visit, the accuracy of the remote monitoring equipment was checked by comparing the RMU readings with readings taken onsite with a Fluke Graphical Multimeter.

\section{Results}

Plots of the daily rectifier output voltage measurements taken at the USACERL test site are shown in Appendix D. On every Friday during the test period, the measurements taken during the week were averaged and plotted on the graph in Figure 17. Plots of the daily rectifier output current measurements taken at the USACERL test site are shown in Appendix E. Weekly averages are plotted on the graph in Figure 18. Plots of the daily on-potential measurements taken at the USACERL site are shown in Appendix F, and weekly averages are shown in Figure 19. Daily IOP plots taken at the USACERL site are shown in Appendix G, and weekly averages are in Figure 20. (Note: The Tomar Smart unit was out of service between 3 May and 28 June due to the hardware problems described earlier.)

Measurements taken during the Fort Drum site visits are shown in Tables 4-9. Weekly RMU measurements gathered remotely from Fort Drum are plotted in Appendix $\mathrm{H}$.

M.C. Miller DAX. The plots show that the DAX accurately tracked rectifier outputs, on-potentials, and IOPs at the USACERL test site. Any fluctuations were linear and were readily correctable with calibration. During the last month of the evaluation, where IOPs were taken with the CPA, portable oscilloscope, and WFA, it was determined that the IOPs gathered with the DMM were slightly inaccurate (Figure 21). The IOPs taken with the DMM were regularly 100 to $200 \mathrm{mV}$ less negative than the IOPs provided by the CPA, WFA, and oscilloscope. The measurement methodology was changed in the DAX by altering the unit sampling rate to 200 milliseconds for the remainder of the evaluation. The DAX readings 
then closely corresponded to those taken by the more accurate WFA and CPA (see Figure 21).

At Fort Drum, the readings that were taken onsite with the graphical multimeter in December 1995 and June 1996 almost exactly matched the readings taken remotely on the same day with the DAX (Tables 4-9). Weekly onsite readings from Fort Drum were not available for comparison with the readings taken remotely from USACERL. However, the DAX units provided readings every time they were contacted, and those readings were within the range of values that would be expected during normal CP system operation.

Tomar SMART. Readings taken by the SMART unit typically fluctuated somewhat from the "control" voltages taken with the DMM. Rectifier voltage output measurements varied up to 2 VDC from the voltages taken with the DMM. In addition, IOPs were occasionally more negative than the on-potential readings. Tomar engineers stated that the problem was due to faulty calibration, but the problem persisted throughout the demonstration despite unit recalibration. Troubleshooting solved some of the problems, as discussed previously in Step 6. However, there was never a time during the demonstration when every channel on a SMART RMU consistently provided accurate readings. A sample of the average SMART data is shown in the weekly average plots (Figures 17-20). Because, the units were out of service for several long periods of time, data are not presented for those intervals.

As stated previously, during the last month of the evaluation it was determined that the IOPs gathered with the DMM were slightly inaccurate. The measurement methodology was changed in the SMART RMU by altering the unit sampling rate to $10 \mathrm{~ms}$ (the TOMAR IR-Free setting) for the remainder of the evaluation. The readings then corresponded to those taken by the more accurate WFA and CPA (See Figure 21).

Good-All RAMS. As stated previously, the Good-All RAMS did not provide any accurate readings during the entire demonstration period, so its accuracy was rated unacceptable.

\section{Step 8: Analysis of Results and Ranking of RMUs}

A matrix approach was developed to rank the RMUs according to the evaluated features. A hardware matrix and a software matrix were developed. Each feature 
was assigned a weighting factor on a scale of 1 to $10^{*}$ based on its importance, with the most important features receiving a factor of 10. Each RMU system was graded for each feature on a scale of 1 to 5 , where 5 was considered excellent, 4 was considered very good, 3 was average, 2 was acceptable, and 1 was unacceptable. To score for each feature, the weighting factor was multiplied by the grade. The scores for each RMU were then subtotaled to obtain a hardware score and a software score. The hardware and software scores were added to obtain an overall RMU system score. The highest and lowest possible system scores for hardware or software were 250 and 50, respectively. The highest and lowest overall system scores were 500 and 100 respectively.

The hardware and software matrices used to rank the RMUs are shown in Tables 10 and 11. The M.C. Miller DAX system received the highest (best) rating with an overall score of 418 . The Good-All RAMS system received the lowest rating with an overall score of 124 .

\footnotetext{
While two hardware factors - data accuracy and reliability-were weighted 10 in importance, the reader may note that no software features were weighted higher than 5 . This does not mean that software is less important than hardware to the proper real-time operation of an RMU, but indicates that hardware features generally should be considered more important than software as RMU selection criteria. Reason: systemic weaknesses in hardware materials or component design are not readily correctable by the user or manufacturer whereas software flaws are routinely identified and corrected as part of the manufacturer's ongoing software maintenance activities.
} 


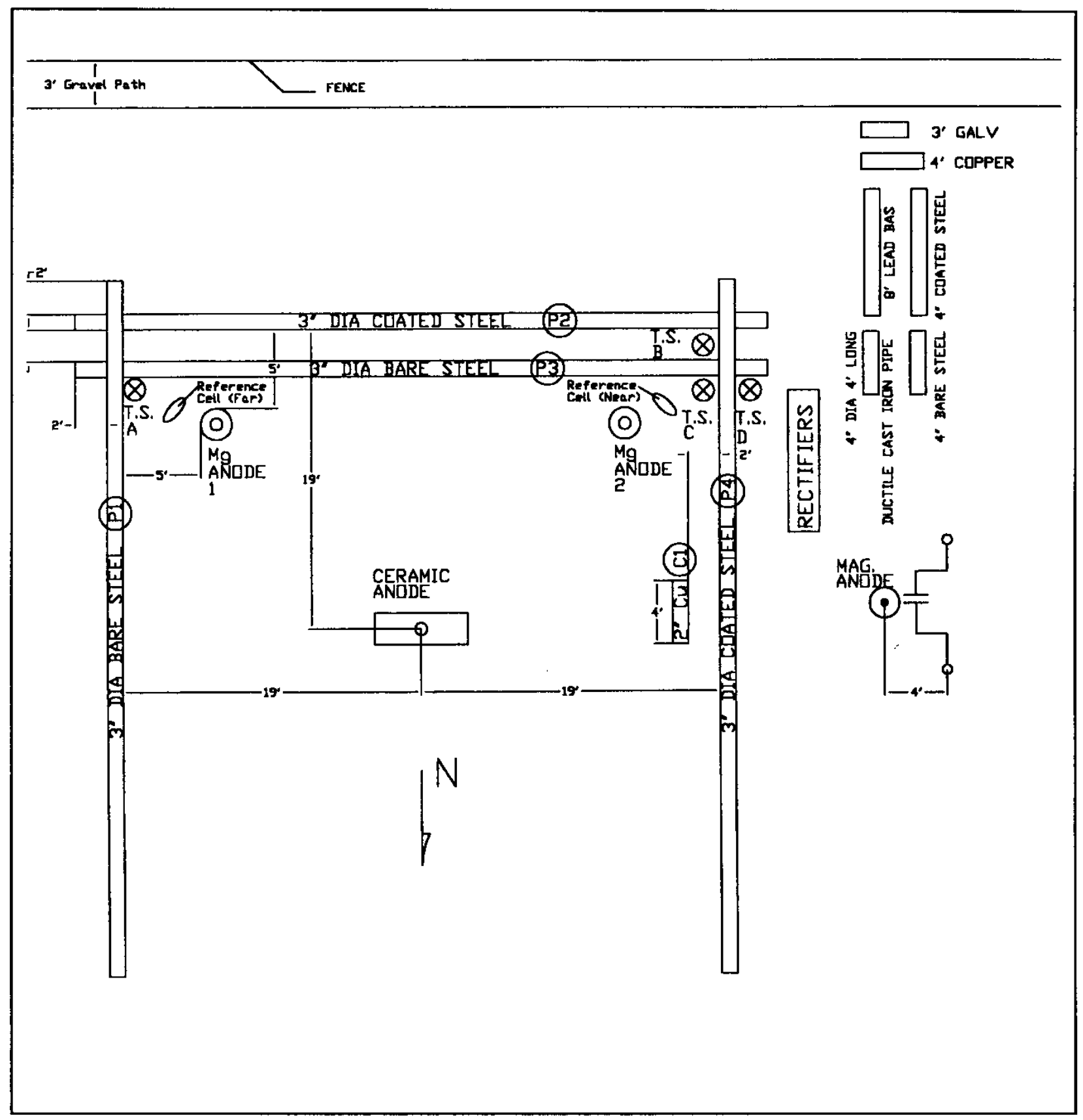

Figure 11. USACERL test site. (Note: RMUs were installed near the rectifiers.) 


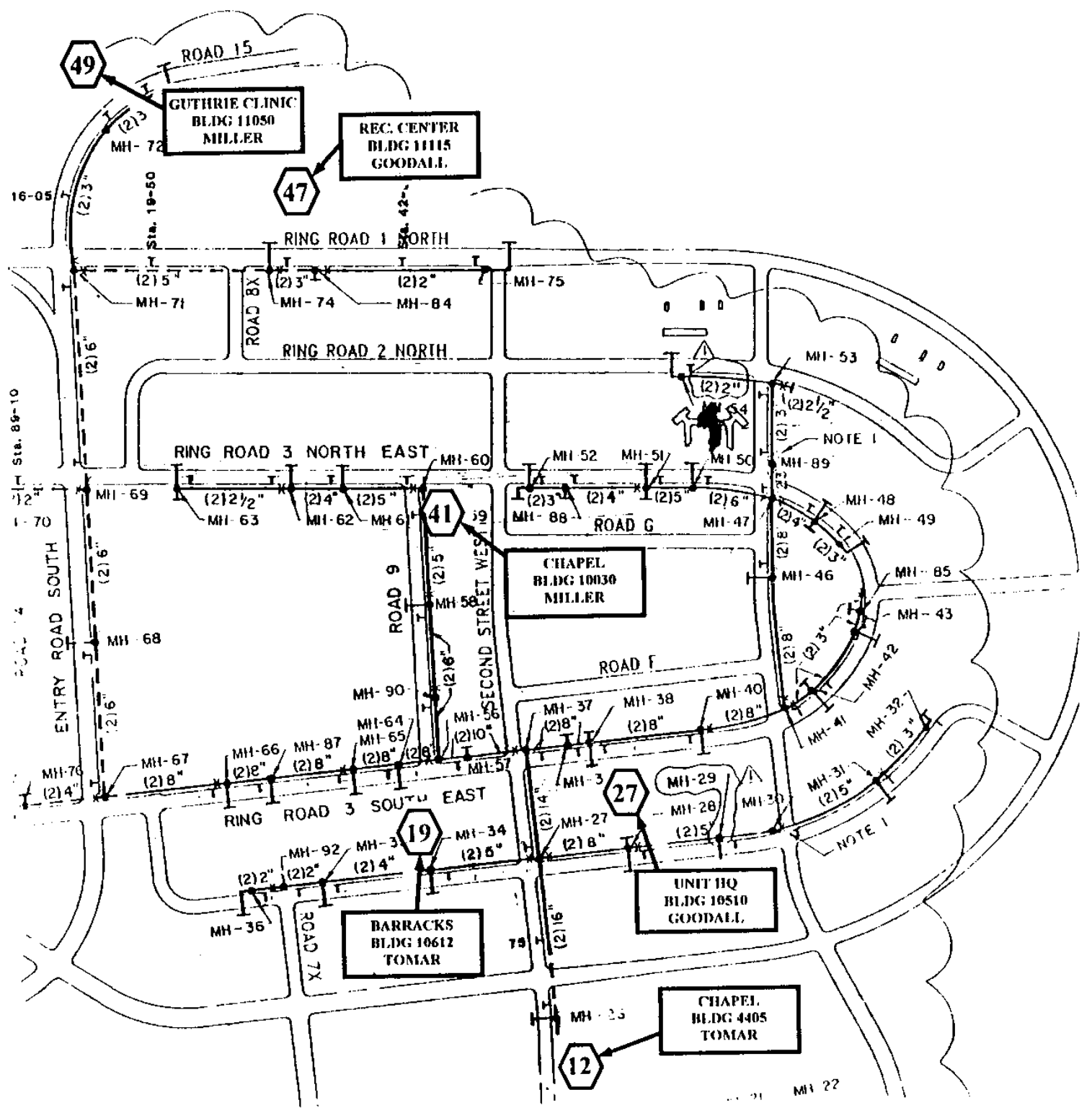

Figure 12. Locations of RMUs at Fort Drum. 
Table 2. Location of RMUs installed at Fort Drum, NY.

\begin{tabular}{|l|l|l|l|}
\hline $\begin{array}{l}\text { Building } \\
\text { Number }\end{array}$ & Building Description & $\begin{array}{l}\text { Rectifier } \\
\text { Number }\end{array}$ & RMU Installed \\
\hline 10030 & Unit Chapel & 41 & M.C. Miller DAX \\
\hline 11050 & Guthrie Clinic & 49 & M.C. Miller DAX \\
\hline 10510 & Unit Headquarters & 27 & Tomar Systems SMART \\
\hline 11115 & Recreation Center & 47 & Tomar Systems SMART \\
\hline 4405 & Unit Chapel & 12 & Good-All Electric RAMS \\
\hline 10612 & Barracks & 19 & Good-All Electric RAMS \\
\hline
\end{tabular}




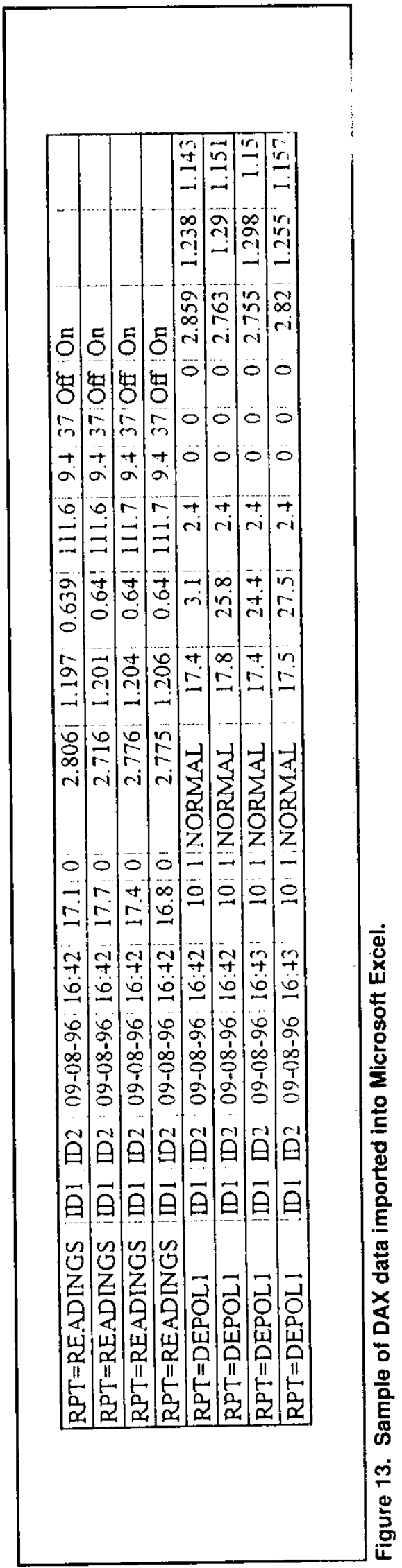




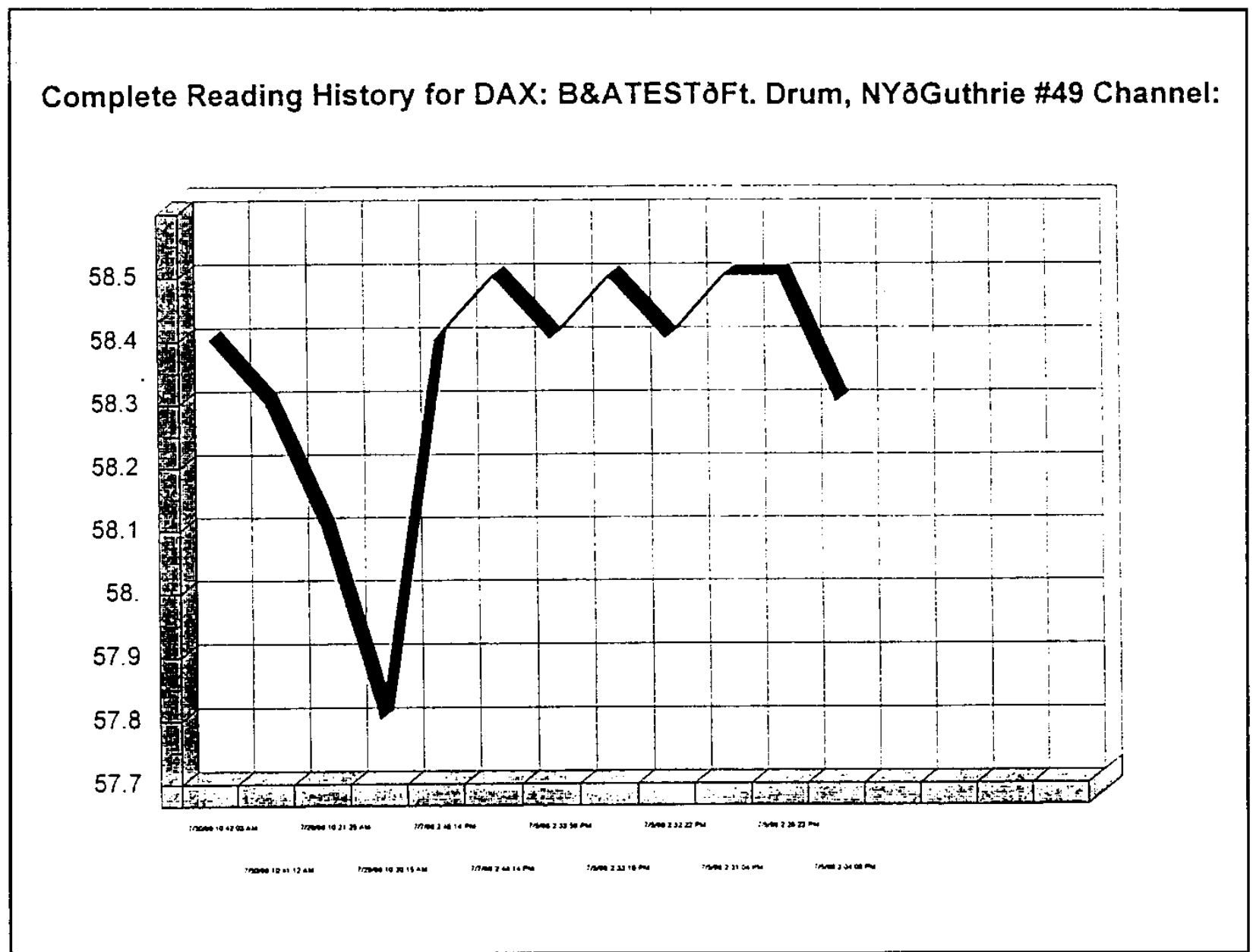

Figure 14. Sample of graphs provided by DAX software. (Note: The verticle axis on the graph corresponds to the rectifier output voltage.) 


\begin{tabular}{|c|c|c|}
\hline \multicolumn{3}{|l|}{ ** READINGS ** } \\
\hline ID $:$ : & ID1 & ID2 \\
\hline PC Date/Time: $08-9-96$, & 16:36 Brd Date/Time: & $08 / 09 / 96,16: 42$ \\
\hline Anode Voltage: & 17.1 & \\
\hline Current: & 0 & \\
\hline Ref. Cell \#1: & 2.806 & \\
\hline Ref. Cell \#2: & 1.197 & \\
\hline Ref. Cell \#3: & 0.639 & \\
\hline Line Volt: & 111.6 & \\
\hline Battery: & 9.4 & \\
\hline Temp: & 37 & \\
\hline Opto In: & Off & \\
\hline Jumper 1 : & On & \\
\hline \multicolumn{3}{|l|}{ ** DEPOL1 ** } \\
\hline ID 1: & ID2: & ID2 \\
\hline PC Date/Time: $08-9-96$ & 16:37 Brd Date/Time: & $08 / 09 / 96.16: 42$ \\
\hline Type: & NORMAI & \\
\hline Start Delay: & 10 & \\
\hline Depolarized Time: & 1 & \\
\hline \multicolumn{3}{|l|}{ Ref. Cell } \\
\hline On: & 17.4 & \\
\hline Instant Off: & 3.1 & \\
\hline Depolarized: & 2.4 & \\
\hline \multicolumn{3}{|l|}{ Anode } \\
\hline On: & 0 & \\
\hline Instant Off: & 0 & \\
\hline Depolarized: & 0 & \\
\hline \multicolumn{3}{|l|}{ Current } \\
\hline On: & 2.859 & \\
\hline Instant Off: & 1.238 & \\
\hline Depolarized: & 1.143 & \\
\hline
\end{tabular}

Figure 15. Sample of SMART data imported into Microsoft Excel. 


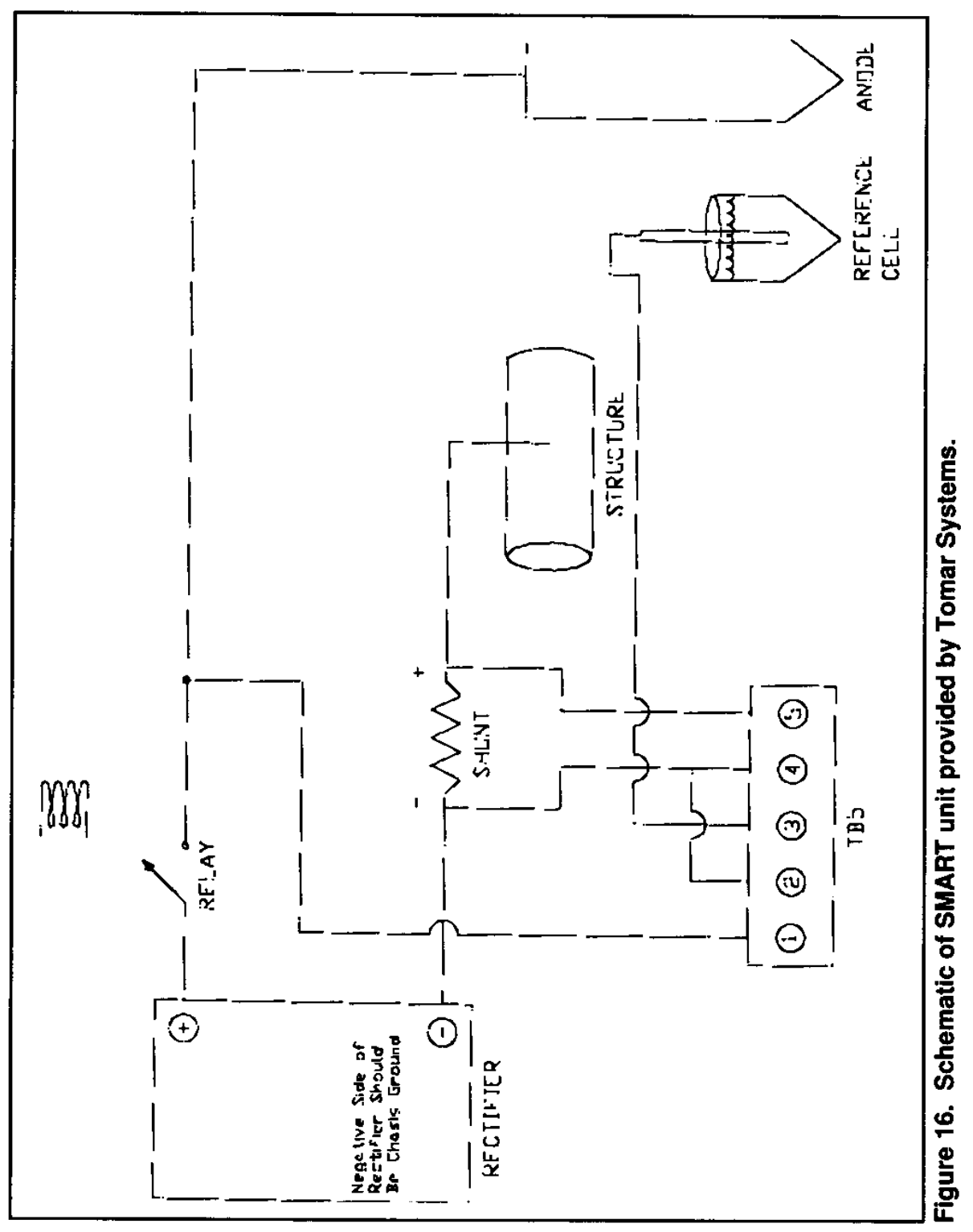

Table 3. Rectifier tap settings at USACERL test site.

\begin{tabular}{|c|c|}
\hline Dates & Rectifier Tap Setting \\
\hline 4 Mar - 3 May 1996 & B3 \\
\hline 6 May - 17 May 1996 & D3 \\
\hline 30 May - 14 Jun 1996 & A3 \\
\hline 21 Jun - 5 Jul 1996 & A5 \\
\hline 8 Jul - 26 Jul 1996 & D2 \\
\hline 29 Jul - 16 Aug 1996 & C2 \\
\hline
\end{tabular}




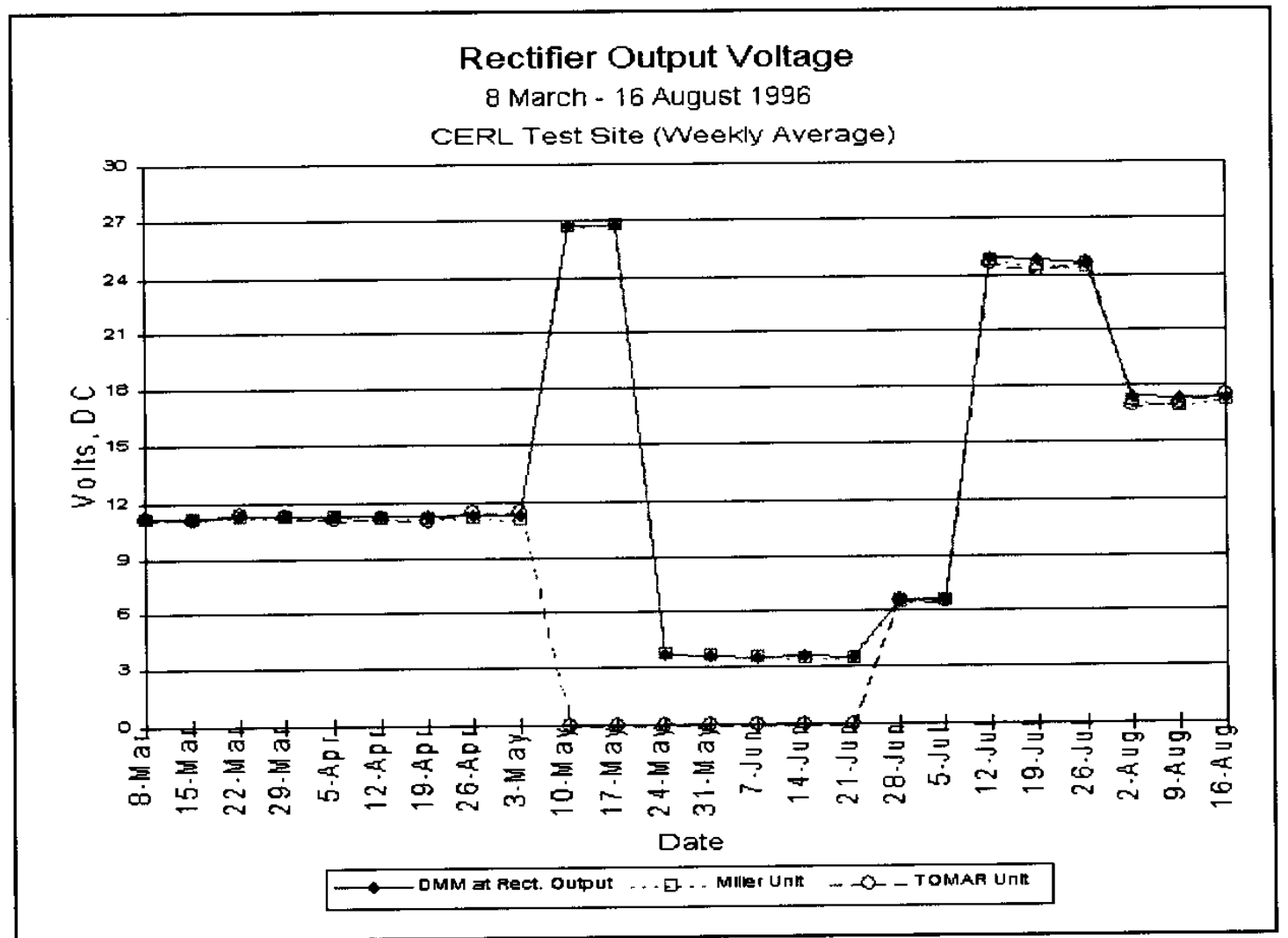

Figure 17. Weekly average rectifier output voltage at USACERL test site.

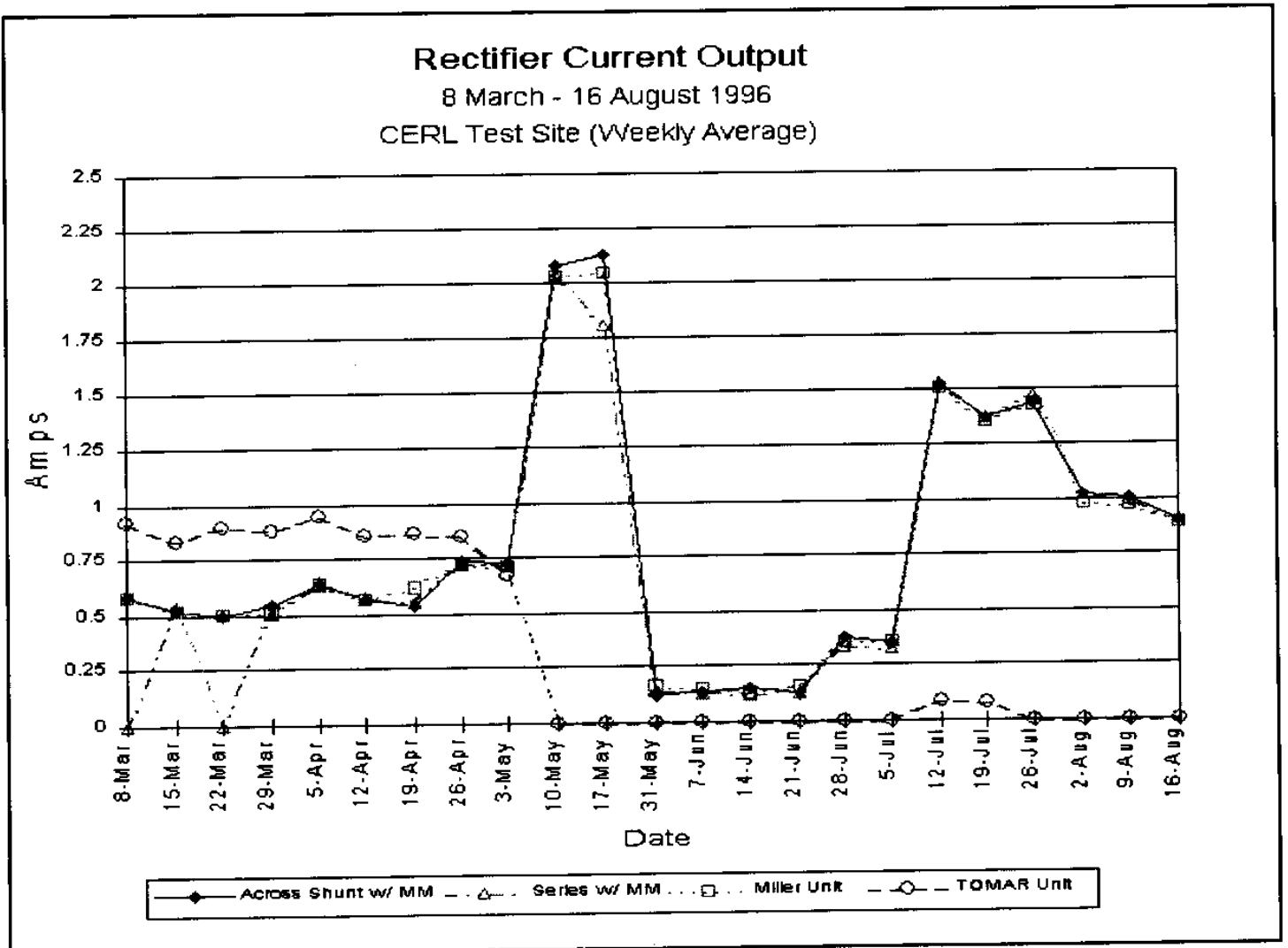

Figure 18. Weekly average rectifier output current at USACERL test site. 


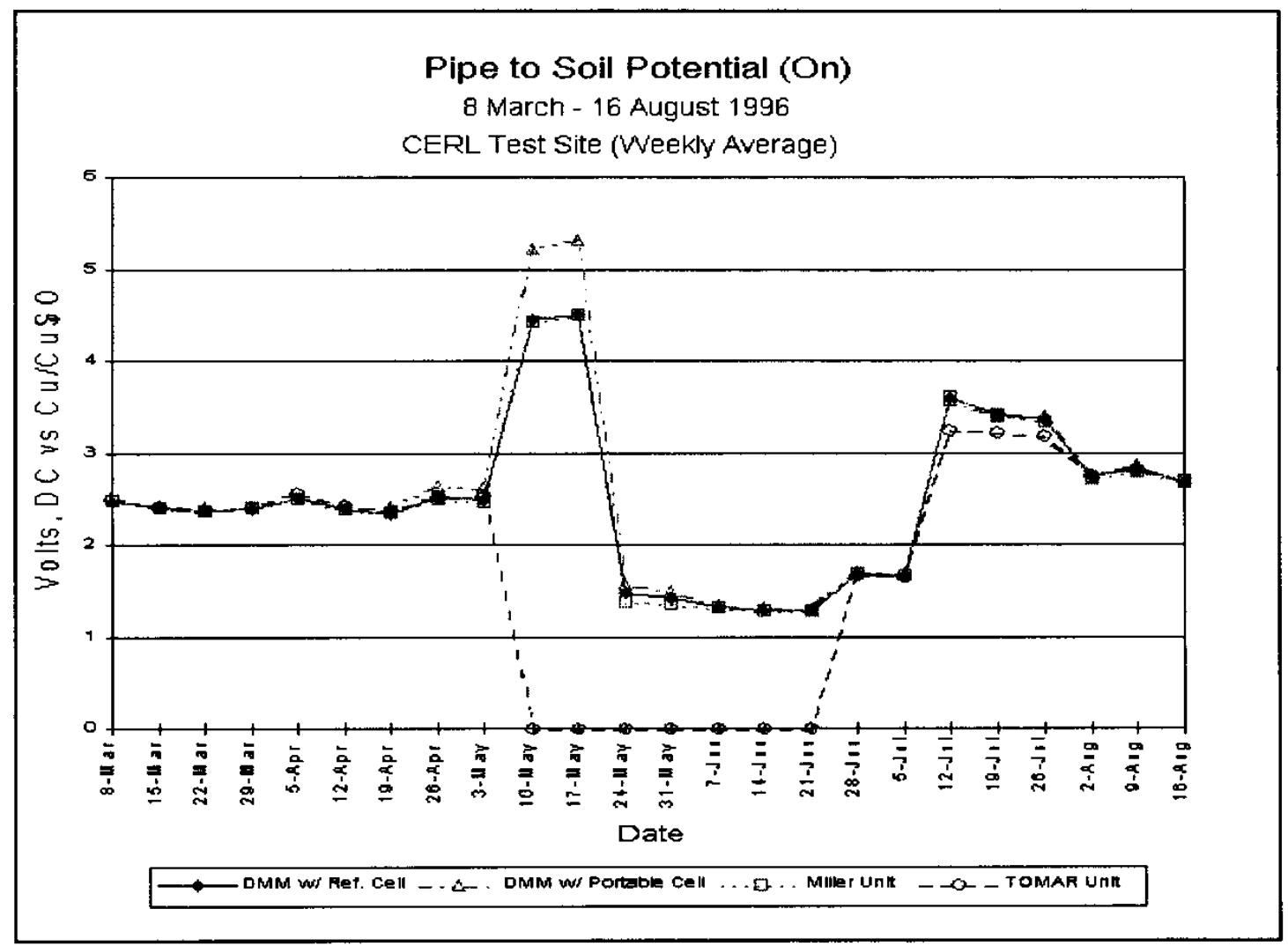

Figure 19. Weekly average pipe to soil "on" potentials at USACERL test site.

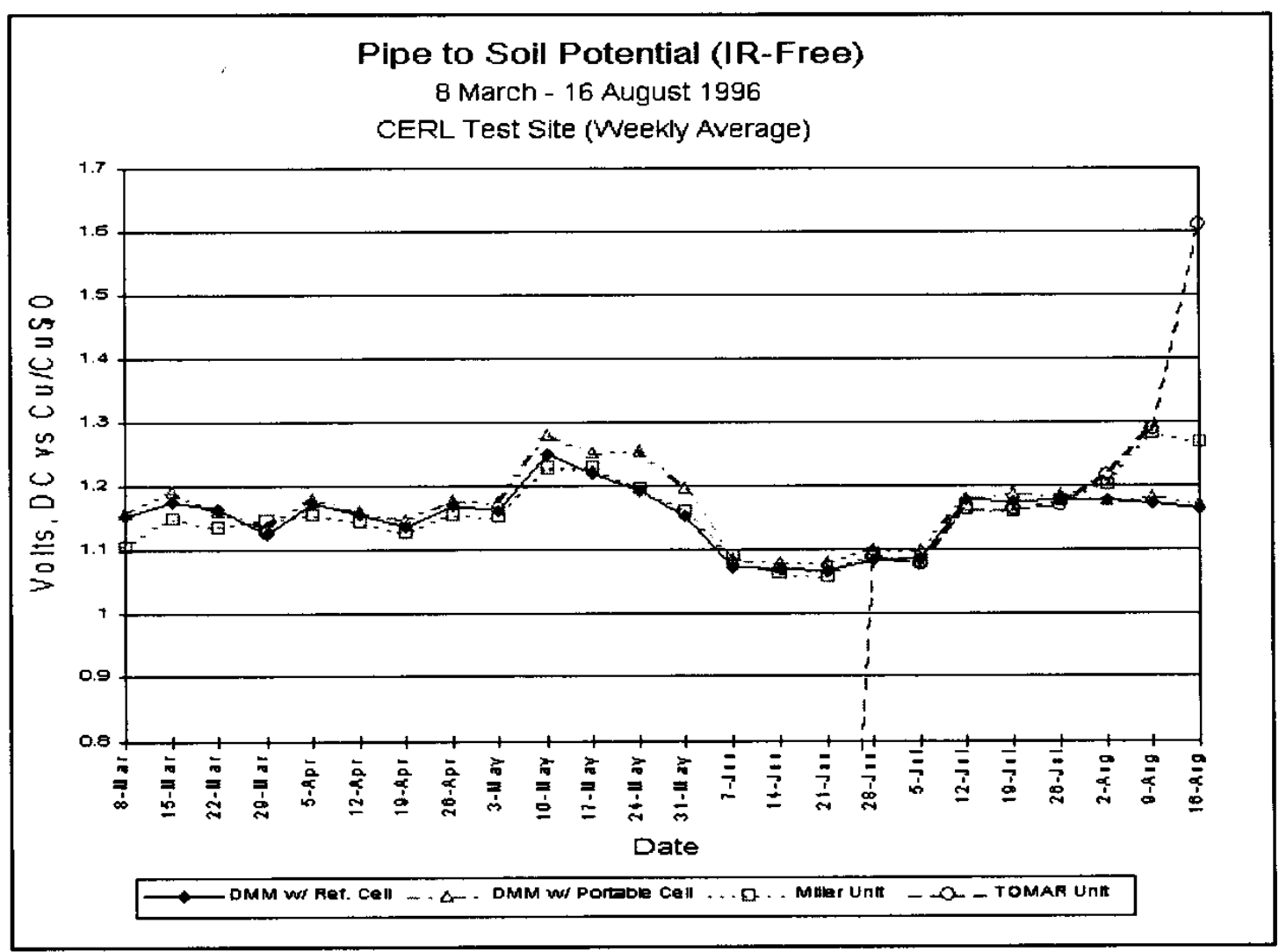

Figure 20. Weekly average pipe to soil IOPs at USACERL test site. 
Table 4. Readings from DAX unit at Building \#11050, 14 December 1995.

\begin{tabular}{|c|c|c|}
\hline CIRCUIT & DAX UNIT & INDEPENDENT METER \\
\hline Rectifier Output Voltage & 59.4 & 58.8 \\
\hline Rectifier Output Amperage & 0.86 & 1.05 \\
\hline Pipe-to-Soil Potential "ON" (volts) & 1.16 & 1.20 \\
\hline Pipe-to-Soil Potential "OFF" (volts) & 1.10 & 1.10 \\
\hline \multicolumn{3}{|c|}{$\begin{array}{l}\text { Rectifier \#49, Serial \# } 931060 \\
\text { Rectifier Shut Rating: } 50 \mathrm{mv}=15 \mathrm{a} \\
\text { NOTE: The data supplied by the DAX unit were not collected at the same time } \\
\text { as the independent meter data were collected. The small differences in data } \\
\text { readings are not unexpected nor do they indicate that the DAX unit is } \\
\text { inaccurately recording data. }\end{array}$} \\
\hline
\end{tabular}

Table 5. Readings from SMART unit at Building \#4405, 14 December 1995.

\begin{tabular}{|l|c|c|}
\hline \multicolumn{1}{|c|}{ CIRCUIT } & SMART UNIT & INDEPENDENT METER \\
\hline Rectifier Output Voltage & 37.4 & 54.7 \\
\hline Rectifier Output Amperage & 37.2 & 11.36 \\
\hline Pipe-to-Soil Potential "ON" (volts) & 0.80 & 1.16 \\
\hline $\begin{array}{l}\text { Pipe-to-Soil Potential "OFF" (volts) } \\
\text { Rectifier \#12, Serial \#931066 } \\
\text { Rectifier Shunt Rating: 50mv = 15A } \\
\text { NOTE: The data collected by the SMART unit were substantialiy inaccurate, as } \\
\text { shown by the independent meter data that was collected. Preset calibration } \\
\text { factors in the software are the suspected reason for the inaccuracy. }\end{array}$ \\
\hline
\end{tabular}

Table 6. Readings from DAX unit at Building \#11050 (Guthrie, Clinic), 18 June 1996.

\begin{tabular}{|l|c|c|}
\hline CIRCUIT & DAX UNIT & INDEPENDENT METER \\
\hline Rectifier Output Voltage & 58.4 & 58.3 \\
\hline Rectifier Shunt Reading (millivolts) & 2.3 & 2.2 \\
\hline Rectifier Output Amperage & 0.69 & 0.66 \\
\hline Pipe-to-Soil Potential "ON" (volts) & 1.068 & 1.078 \\
\hline $\begin{array}{l}\text { Pipe-to-Soil Potential "OFF" (volts) } \\
\text { Rectifier \#49 }\end{array}$ & 0.989 & 0.991 \\
\hline Rectifier Shunt Rating: 50mv = 15a & & \\
\hline
\end{tabular}


Table 7. Readings from DAX unit at Building \#10030 (Unit Chapel), 18 June 1996.

\begin{tabular}{|l|c|c|}
\hline \multicolumn{1}{|c|}{ CIRCUIT \#1 } & DAX UNIT & INDEPENDENT METER \\
\hline Rectifier Output Voltage & 56.5 & 56.8 \\
\hline Rectifier Shunt Reading (millivolts) & 22.10 & 22.0 \\
\hline Rectifier Output Amperage & 6.63 & 6.60 \\
\hline Pipe-to-Soil Potential "ON" (volts) & 1.647 & 1.65 \\
\hline Pipe-to-Soil Potential "OFF" (volts) & 1.417 & 1.42 \\
\hline \multicolumn{1}{|c|}{ CIRCUIT \#2 } & DAX UNIT & INDEPENDENT METER \\
\hline Rectifier Output Voltage & 57.4 & 57.8 \\
\hline Rectifier Shunt Reading (millivolts) & 8.80 & $\mathbf{8 . 8 0}$ \\
\hline Rectifier Output Amperage & 2.64 & 2.64 \\
\hline Pipe-to-Soil Potential "ON" (volts) & 1.647 & 1.65 \\
\hline Pipe-to-Soil Potential "OFF" (volts) & 1.419 & 1.42 \\
\hline Rectifier \#41 & & \\
Rectifier Shunt Rating: 50mv = 15a & & \\
\hline
\end{tabular}

Table 8. Readings from SMART unit at Building \#4405, 7 August 1996.

\begin{tabular}{|l|c|c|}
\hline \multicolumn{1}{|c|}{ CIRCUIT } & SMART UNIT & INDEPENDENT METER \\
\hline Rectifier Output Voltage & $0.0^{*}$ & 42.8 \\
\hline Rectifier Output Amperage & $107.9^{*}$ & 10.3 \\
\hline Pipe-to-Soil Potential "ON" (volts) & $1.857^{*}$ & 1.798 \\
\hline $\begin{array}{l}\text { Pipe-to-Soil Potential "OFF" (volts) } \\
\text { Rectifier \#12, Rectifier Shunt Rating: } \\
\text { Tomar Shunt Rating: 50mv=20a }\end{array}$ & $1.588^{*}$ & 1.499 \\
\hline
\end{tabular}

Table 9. Readings from SMART unit at Building \#10612, 7 August 1996.

\begin{tabular}{|l|c|c|}
\hline CIRCUIT & SMART UNIT & INDEPENDENT METER \\
\hline Rectifier Output Voltage & $41.1^{*}$ & 60.0 \\
\hline Rectifier Output Amperage & $0.44^{*}$ & 1.80 \\
Pipe-to-Soil Potential "ON" (volts) & $0.916^{*}$ & 1.047 \\
\hline $\begin{array}{l}\text { Pipe-to-Soil Potential "OFF" (volts) } \\
\text { Rectifier \#19, Rectifier Shunt Rating: 50mv=15a }\end{array}$ & 0.760 \\
\hline $\begin{array}{l}\text { Tomar Shunt Rating: 50mv=20a } \\
\text { * The SMART unit readings are in error. The relay switch for current interruption sticks in } \\
\text { the open position. }\end{array}$ & $0.654^{*}$ \\
\hline
\end{tabular}




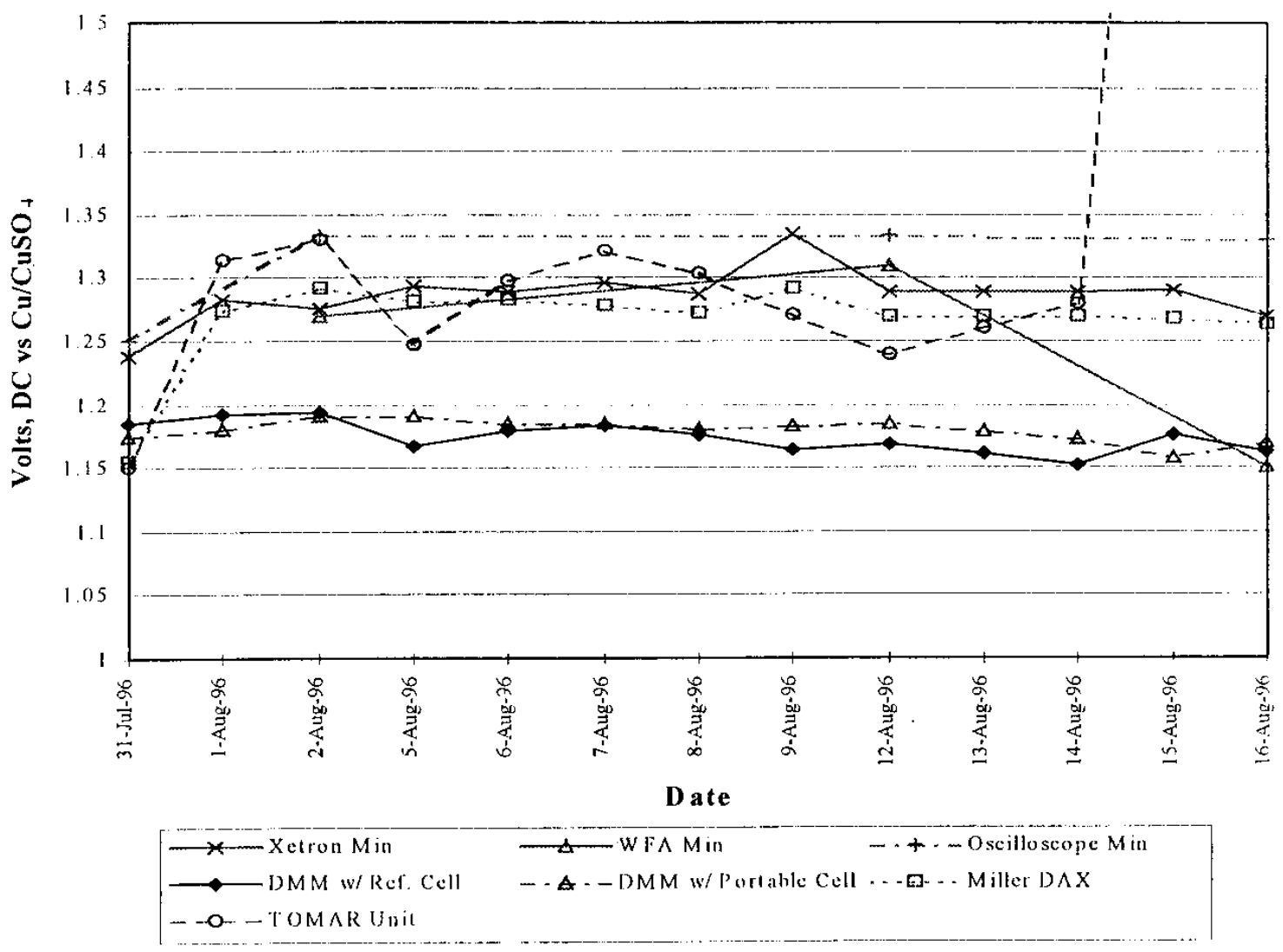

Figure 21. IR-free potentials at USACERL test site using various instruments. 
Table 10. RMU software feature comparison.

\begin{tabular}{|c|c|c|c|c|c|c|c|}
\hline \multirow[b]{2}{*}{ FEATURE } & \multirow{2}{*}{$\begin{array}{l}\text { Weighting } \\
\text { Factor }\end{array}$} & \multicolumn{2}{|c|}{$\begin{array}{c}\text { DAX } \\
\text { (M.C. Miller) }\end{array}$} & \multicolumn{2}{|c|}{$\begin{array}{l}\text { SMART } \\
\text { (Tomar) }\end{array}$} & \multicolumn{2}{|c|}{$\begin{array}{c}\text { RAMS } \\
\text { (Good-All) }\end{array}$} \\
\hline & & Rating & Score & Rating & Score & Rating & Score \\
\hline Software manual & 1 & 3 & 3 & 5 & 5 & 3 & 3 \\
\hline Software manual (novices) & 1 & 1 & 1 & 5 & 5 & 1 & 1 \\
\hline Software manual (experts) & 1 & 3 & 3 & $\underline{5}$ & 5 & 3 & 3 \\
\hline Technical support (software) & 5 & $\underline{5}$ & 25 & 3 & 15 & 1 & $\underline{5}$ \\
\hline Toll free number & 1 & $\underline{5}$ & 5 & 5 & 5 & 1 & 1 \\
\hline Software operation & 5 & 4 & 20 & 2 & 10 & $1^{\mathrm{A}}$ & $5^{\mathrm{A}}$ \\
\hline Software loading & 1 & 5 & 5 & 5 & $\underline{5}$ & 3 & 3 \\
\hline Software configuration & 2 & 5 & 10 & 2 & 4 & $1^{A}$ & $2^{A}$ \\
\hline Software versatility & 5 & 5 & 25 & 2 & 10 & $1^{\mathrm{A}}$ & $5^{\mathrm{A}}$ \\
\hline Software appearance & 2 & 5 & 10 & 2 & 4 & 5 & 10 \\
\hline Help function & 2 & 5 & 10 & 5 & 10 & 1 & 2 \\
\hline Ease of operation (single unit) & 2 & 4 & 8 & 5 & 10 & $1^{A}$ & $2^{A}$ \\
\hline Ease of operation (multiple units) & 4 & 5 & 20 & $\underline{2}$ & 8 & $1^{A}$ & $4^{A}$ \\
\hline Data report format & 3 & 5 & 15 & 2 & 6 & $1^{A}$ & $3^{A}$ \\
\hline Exportability to MS Excel & 2 & 5 & 10 & 2 & -4 & $1^{A}$ & $2^{A}$ \\
\hline Spreadsheet formatting & 2 & 5 & 10 & 2 & 4 & $1^{A}$ & $2^{A}$ \\
\hline Alarm capability & 5 & $3^{\mathrm{B}}$ & $15^{\mathrm{B}}$ & $3^{c}$ & $15^{\mathrm{C}}$ & $3^{A}$ & $15^{A}$ \\
\hline Synchronized interruption & 5 & $3^{0}$ & $15^{\mathrm{D}}$ & 1 & 5 & $1^{A}$ & $5^{A}$ \\
\hline Un-install feature & 1 & 5 & 5 & 1 & 1 & 1 & 1 \\
\hline Software Score & & & 215 & & 131 & & 74 \\
\hline $\begin{array}{l}\text { Notes: } \\
\text { A Unable to evaluate due to non-or } \\
\text { BAlarms available in latest DAXIT } \\
\text { CUnable to verify due to malfuncti } \\
\text { ONext version of DAXIT software } \\
\text { Weighting factors: } 10=\text { most imp } \\
\text { Grading scale: } 5=\text { best; } 1=\text { unac } \\
\text { Scoring range: } 250=\text { maximum; }\end{array}$ & $\begin{array}{l}\text { sorational cor } \\
\text { software vers } \\
\text { on in SMART } \\
\text { to have this } f \in \\
\text { ortant; } 1=\text { le } \\
\text { ceptable. } \\
50=\text { minimun }\end{array}$ & $\begin{array}{l}\text { tion of } R \\
n, \text { unable } \\
\text { it. } \\
\text { ure. } \\
\text { importa }\end{array}$ & $\begin{array}{l}\text { unit. } \\
\text { verify du }\end{array}$ & $g$ this eve & ation. & & \\
\hline
\end{tabular}


Table 11. RMU hardware feature comparison.

\begin{tabular}{|c|c|c|c|c|c|c|c|}
\hline \multirow[b]{2}{*}{ FEATURE } & \multirow{2}{*}{$\begin{array}{l}\text { Weighting } \\
\text { Factor }\end{array}$} & \multicolumn{2}{|c|}{$\begin{array}{c}\text { DAX } \\
\text { (M.C. Miller) }\end{array}$} & \multicolumn{2}{|c|}{$\begin{array}{l}\text { SMART } \\
\text { (Tomar) }\end{array}$} & \multicolumn{2}{|c|}{$\begin{array}{c}\text { RAMS } \\
\text { (Good-Ali) }\end{array}$} \\
\hline & & Rating & Score & Rating & Score & Rating & Score \\
\hline Hardware manual & 2 & 4 & 8 & 3 & 6 & 1 & 2 \\
\hline Ease of installation & 3 & 4 & 12 & 3. & 9 & 1 & 3 \\
\hline Safety (high voltage exposed?) & 5 & 1 & 5 & 1 & 5 & 1 & 5 \\
\hline Safety warning labels & 3 & 1 & 3 & 1 & 3 & 1 & 3 \\
\hline Technical support (hardware) & 5 & 5 & 25 & 2 & 10 & 1 & 5 \\
\hline Interrupter relay & 5 & 5 & 25 & 1 & 5 & $1^{A}$ & $5^{\mathrm{A}}$ \\
\hline Data accuracy & 10 & 5 & 50 & 1 & 10 & $1^{A}$ & $10^{\mathrm{A}}$ \\
\hline Reliability & 10 & 4 & 40 & 2 & 20 & $1^{\mathrm{A}}$ & $10^{\mathrm{A}}$ \\
\hline Surge/lightning protection & 5 & 5 & 25 & 2 & 10 & $1^{A}$ & $5^{\mathrm{A}}$ \\
\hline Remote programming & 2 & 5 & 10 & 1 & 2 & $1^{A}$ & $1^{A}$ \\
\hline Hardware Score & & & 203 & & 80 & & 50 \\
\hline Software Score (Table 10) & & & 215 & & 131 & & 74 \\
\hline OVERALL SCORE & & & 418 & & 211 & & 124 \\
\hline \multicolumn{8}{|c|}{$\begin{array}{l}\text { Notes: } \\
\text { A Unable to evaluate due to non-operational condition of RAMS unit. } \\
\text { Weighting factors: } 10=\text { most important; } 1=\text { least important. } \\
\text { Grading scale: } 5=\text { best; } 1=\text { unacceptable. } \\
\text { Scoring range: } 250=\text { maximum; } 50=\text { minimum. } \\
\text { Maximum overall score }=500 ; \text { Minimum overall score }=100 \text {. }\end{array}$} \\
\hline
\end{tabular}




\section{Conclusions and Recommendations}

\section{Conclusions}

Three different commercially available impressed current $\mathrm{CP}$ remote monitoring systems were field tested at USACERL and Fort Drum during this FEAP demonstration. The three systems were evaluated on the basis of measurement accuracy, hardware reliability and safety, quality of software, ease of hardware and software installation and configuration, and quality of instruction manuals. Shown in descending order, the final rankings were:

\section{M.C. Miller DAX System}

2. Tomar Systems SMART System

3. Good-All RAMS System.

The M.C. Miller DAX was the only evaluated RMU that was found to be fully operational, accurate, and reliable during the demonstration. The DAX software was rated excellent, and additional software upgrades promised by the manufacturer should make this an especially powerful and efficient RMU system.

The Tomar Systems SMART unit was not fully functional and did not regularly provide accurate and reliable data during the test period. It sometimes provided inaccurate or fluctuating data, and several hardware problems impacted the unit's reliability. The SMART unit may provide an acceptable level of service for Army locations with a limited number of RMUs, but only after modifications are made by the manufacturer to fix the problems noted in the text. The SMART software offers fewer features than the DAX software, but it is considered functional. However, software functionality improves dramatically if only a small number of RMUs are monitored.

The Good-All Electric RAMS unit is not yet operational. It is not expected that the RAMS RMU will be available for use in the near future. The software appears to be powerful, but it could not be fully evaluated without an operational RMU.

It should be noted that new remote monitoring units have been introduced onto the market by a variety of manufacturers since this project was initiated in 1995 . The 
newer RMUs are being produced by several companies, including J.A. Electronics, CPS, Universal, and Metretek. In addition, there are RMUs that are manufactured outside the United States, such as the Corexco units.

\section{Recommendations}

Because only one of the RMUs tested can be considered adequate for Army use at this time, it is important to track the market for new candidate RMUs so DPWs have more than one product to choose from. Considering the problems that may arise from the installation of an inadequate remote monitoring system, it is recommended that new candidate RMUs be fully tested according to the procedures documented in Chapter 4 of this report before they are considered for Army use.

It is recommended that the DAX RMU be considered acceptable for Army use, but one caveat must be observed: because the DAX system did not have a working CP alarm function during the demonstration period, the user must regularly interrogate all RMUs to ensure that problems with the CP system are detected in a timely manner. 


\section{References}

Code of Federal Regulations (CFR), title 40, parts 280-281.

Code of Federal Regulations (CFR), title 49, part 192, subpart I.

Engineer Technical Letter (ETL) 1110-3-440, Cathodic Protection (Headquarters, Department of the Army [HQDA], 20 August 1992).

Good-All Electric, RAMS: Remote Access Monitoring System (Fort Collins, CO, 1995).

Hock, V.F., L.F. Setliff, W.A. Houtz, M. Noble et al., Off-Potential Measurement Systems for Impressed Current Cathodic Protection, Technical Report FM-94/16 (USACERL, September 1994).

Husock, B. Evaluation of Cathodic Protection Criteria, ESL TR-79-14 (Headquarters, Air Force Engineering and Services Center [HQAFESC], Tyndall Air Force Base, FL, April 1979).

M.C. Miller Company, Inc., Daxit User's Manual (Ringwood, NJ, 1996).

M.C. Miller Company, Inc., Data Acquisition Communication and Control: DAX 10XX Series Reference Guide, (Ringwood, NJ, 1995).

Military Handbook (MIL-HDBK) 1004/10, Electrical Engineering Cathodic Protection (Department of Defense, 31 January 1990).

Myers, J.R., Fundamentals and Forms of Corrosion (Air Force Institute of Technology, 1974).

Standard Recommended Practice RP0169-96, Control of External Corrosion on Underground or Submerged Metallic Piping Systems (NACE International, 1996).

Tomar Systems, Inc., SMART Monitor/Controller Users Manual: Installation and Checkout Guidelines (Eden Prairie, MN, 1995). 


\section{Appendix A: Manufacturer's Brochure for DAX RMU}




\section{Get your data across with ...}

\section{DAX Remote Monitoring}

The Next Generation of Cathodic Protection Data Acquisition Communication and Control

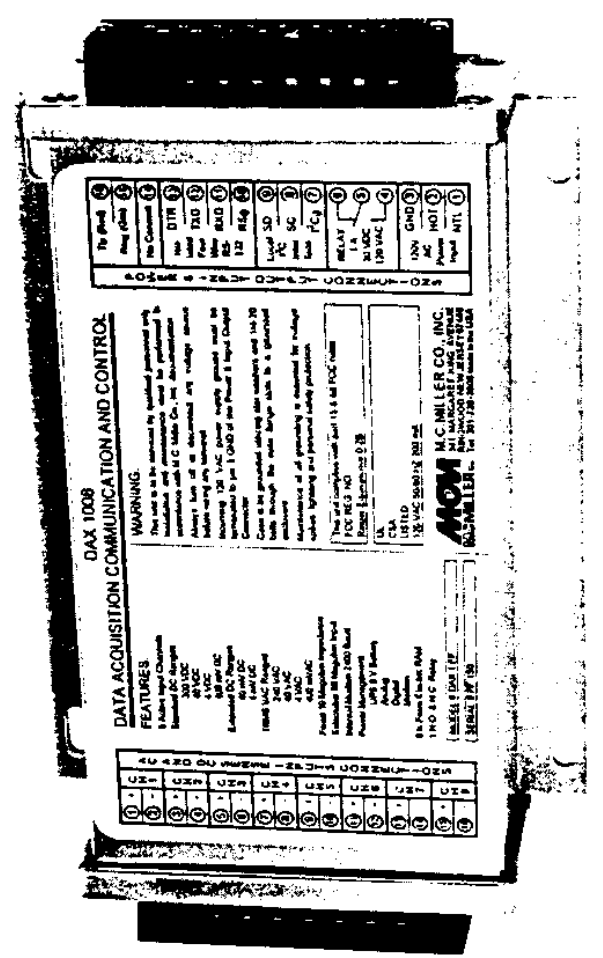

\section{Do You Need}

a Remote monitoring units built with only the features which you need?

a Units that withstand the extremes of environments? Temperature, Humidity, Hot, Cold, Wet and Dry?

t. Lightning, surge, and voltage spike protection?

- AC and DC Voltage Range? Extended Ranges?

a A Positive and Negative terminal for each channel?

If the answer is YES, you can make your task a lot easier - and with more dependable results - by relying on the M.C. Miller Co. for Data Acquisition Communication and Control (DAX for short).

\section{Features To Choose From}

The DAX has been constructed so that any or all of these features may be added to the standard configuration.

a One to Eight voltage input channels can populate the DAX. You only pay for the number of channels which are installed.

- Extended voltage ranges can be installed to measure down to the lowest millivoit range for critical $\mathbb{R}$ drop testing. The $\pm 40.00 \mathrm{mV}$ and $\pm 4.000 \mathrm{mV} \mathrm{DC}$ ranges allow accurate readings with resolution of 0.000001 Volt.

- AC Voltage measurements $240.0 \mathrm{~V} \mathrm{AC}$

$40.00 \mathrm{VAC}$

$4.000 \mathrm{~V} \mathrm{AC}$

400.0 mVAC

a Selectable input impedance Standard readings are recorded at 10 megohm. An extended range of up to 50 megohm can be added for variable source impedance.

a Upgrade memory from $8 \mathrm{~K}$ to $1 \mathrm{Meg}$, utilizing non volatile ferroelectric RAM

x Unintermuptable Power Supply. $9 \mathrm{~V}$ internal battery supplies backup power during primary power outage - power enough to make hundreds of phone calls and continue data logging.

- Primary power options: $120,24050 / 60 \mathrm{~Hz}$ VAC $12,24,48$ VDC Regulated 5 VDC

\section{Outstanding} Standards

The following are the standard features of the DAX.

- Standard voltage ranges:

$\pm 300.0 \mathrm{VDC}$

$\pm 40.00 \mathrm{VDC}$

$\pm 4.000 \mathrm{VDC}$

$\pm 400.0 \mathrm{mVDC}$

a Each channel has a positive and negative terminal.

- Fixed and auto ranging voltage ranges.

a 10 megohm input impedance.

a Call back on alarm set points, with user defined hysteresis.

a Complete data logging capability.

- 1 N.O., 1 N.C. Relay

a Isolated RS-232 Port

- Internal 2400 or 9600 baud Hayes ${ }^{\Phi}$ compatiole modem.

a Up to 16 DAX attached to the same phone line.

a UL 1950, CSA 950 certified

a Industrial grade components.

- Operating temperature range $-40^{\circ}$ to $185^{\circ} \mathrm{F}$

- NEMA 6 watertight enclosure, 3 feet for 30 minutes submersion.

4. Sunge, spike and lightning protection on channel inputs, power supply connections, phome line interface, and RS-232 terminals.

- Firmware features may be upgraded over the modern - no IC's to manually replace.

- $\mathrm{I}^{2} \mathrm{C}$ Bus for future expansion products.

This has been achieved by designing specifically for the cathodic protection corrosion industry, employing the most knowledgeable personnel, and utilizing only high grade incustrial components for our products.

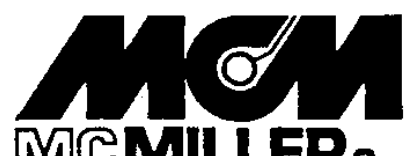

M.C.MILLER Co.,Inc. 341 Margaret King Ave. Ringwood, N.J. 07456 Phone: 201-728-3800 NACN LE: Co. Made in the U.S.A. 
Get your data across with ...

\section{Remote Access To Cathodic Protection}

Products Joining Telecommunication With Data Acquisition And Control

The M.C. Miller Co.. Inc. is actively creating the latest technological advances in remote data collection. The device is called DAX an acronym for Data Acquisition and Communication System. It represents a symbiotic merging between 50 years of quality $\mathrm{CP}$ measurements with the latest advances in telecommunications. The M.C.Miller Co. will deliver the most dependable equipment addressing the specific needs of CP monitoring. Designed to withstand the extremes of weather. rain, heat, cold and lightning. No off-the-shelf generic equipment cheaply repackaged will be used. All components will be carcfully chosen to create a product which will withstand the environment and continue to supply reliable voltage readings.

$\mathrm{D}$

AX is a full featured device which will allow cathodic protection facilities to be interrogated for P/S, I. AC. DC IR Free. etc. from the office. Install the unit in the field (it's small enough to fit inside most rectifiers) by connecting AC or DC power, two wires from the phone line or cellular phone, two wires to an external relay to perform instant off readings and leads to the electrodes. shunts and DC output. DAX is now ready to be called from the office or initiate a call itself if voltages fall out of user defined set points. In fact the DAX has onboard UPS so if power is lost it can call the office to report on the power outage.

$\mathrm{D}$ ifferential inputs versus single ended input. Each voltage reading is done with two terminals: a positive and a negative. Two terminals are used for each of the eight channels. This differential input allows multiple rectifier, multiple IR drop Test spans. multiple reverse current switches, or any combination of things which have different negative potentials to be monitored from a single DAX. Single ended input devices (which the dax is not) have a common or single negative terminal for all 8 channels. Single ended inputs are cheaper to produce but cause great difficulty in obtaining accurate readings. For example. if one rectifier is protecting two pipelines the potential between the two is different and therefore the negative is not common.

Toltage Ranges to choose from. The DAX has been $\checkmark$ designed for optimum flexibility when choosing the voltage range for a particular application. All eight channels can be auto ranging or remotely locked into a particular range. Any or all channels can have different range settings. The options are as follows.

$$
\begin{array}{ll} 
\pm 300.0 \vee D C \text { or AC } & \pm 400.0 \mathrm{mVDC} \text { or AC } \\
\pm 40.00 \vee D C \text { or AC } & \pm 40.00 \mathrm{mVDC} \text { only } \\
\pm 4.000 \text { VD or AC } & \pm 4.000 \mathrm{mVDC} \text { only }
\end{array}
$$

Tnut impedance of each channel is normally fixed at $10 \mathrm{Megohms}$. This is the input impedance of most commercially available digital voltmeters and adequate to overcome most contact resistance between electrode and soil. The 10 Megohm of the DAX will suit most applications but there are occasions when the soil or concrete is extremely dry or high in resistance. In these instances a higher input resistance is required. The DAX can be configured for an additional input impedance of $50 \mathrm{Megohms}$. The user specifies the second level of impedance when the unit is purchased This optional input impedance is in addition to the standard 10 Megohms and can be used to take two comparative readings one at $10 \mathrm{Megohms}$ and the other at 50 Megohms thercby proving the existence of external high resistance (indicated by the voltage increase when the impedance is switched from 10 to 50 Megohms) and overcoming its effects by using the much larger value of 50 Megohms.

Tdustrial grade hardware and components are used exclusively in the DAX. No general commercial parts from Radio Shack or Digi-Key because the parts are made to operate within a small envelope of temperature. vibration and relative humidity. Their product temperature range is +32 to $104^{\circ} \mathrm{F}$. The $\mathrm{DAX}$ is -40 to $+185^{\circ} \mathrm{F}$

Curge, lightning. spike, and over voltage protection has been at the forefront of all design decisions. We realize that if the remote monitoring unit is to do its job it cannot require service every time a thunderstorm is in the arca. The function of the unit is to reduce trips to a remote location, and those trips had better not be to repair a M.C. Miller Co. DAX. We also know that electric and gas utilities often do not use watt meters. and hook directly to line voltage. This removes any surge suppression created by the watt meter. circuit breaker and length of feeder cable. In fact by UL guidelines this condition is the most susceptible to surges and considered the highest class I fault prone condition. The DAX is constructed for these worst case conditions. The AC line power has capability to withstand repeated spikes of 9.000 Amps at 1,000 volts. The eight input channels each have independent surge supprcssion staring at +20 volts and up to 250 Amps. The phone line coming into the DAX is another entry way for surges and possible damage to the unit. All retail modems are constructed for UL zone II inside a building spike protection. Not the DAX. It is a commercial modem with a temperature range of -10 to $+185^{\circ} \mathrm{F}$ with surge protection of $500 \mathrm{Amps} 1.500 \mathrm{~V}$. The enclosure of the DAX is aluminum and fully shiclds against any Electromagnetic interference caused by the noisy tansformers located inside the rectifier. The aluminum case is an integral part of the spike 
protection scheme in that when the over voltage devices fire, current and voltage are drained to the case. This makes it imperative that when the units are installed they be properly grounded, either by bolting the DAX to the rectifier case or with a grounding wire to the slots provided along the side of the DAX case. The M.C. Miller Co. has given particular attention to the four areas of surge protection: the power supply line feeding the unit; the phone lines used to communicate: the individual channels monitoring the potentials; and finally the enclosure itself. A hardened unit for a harsh environment.

$\mathrm{U}$ nderwriters Laboratory. The highest of safety standards are required to obtain UL listing and approval. The M. .. Miller Co., Inc. has made every effort to comply with or exceed UL recommendations for safety. The DAX is 1950 UL listed and approved. The Dax has passed all tests for safety from personal shock hazards and for over voltage faults. This means that redundant systems for hazards have been put in place to protect against fire and personal energy. There are three reasons for UL listing. It is absolutely essential that customers be assured the product is safe and will not cause harm to personnel and equipment. Electricians often will not install a piece of electrical equipment unless it is UL listed. One of the biggest reasons is some local and state building codes and fire inspectors will not authorize the use of electrical equipment that is not UL listed.

$D^{\circ}$ ower supplies deliver the energy to operate the DAX. There are a variety of circumstances which arise in the field where different types of voltages are available. In most instances there is 120 VAC or 240 VAC single phase (from which 120 VAC can be split off) available. For this reason the DAX is normally configured with an internal 120 VAC to 5 VDC regulated transformer. This transformer is packed inside the DAX and the installer need only attach 120 VAC directly to the terminal block of the DAX. Following is a list of other commonly used power supplies which can be installed in place of the $120 \mathrm{VAC}$ transformer. $240 \mathrm{VAC}, 3$ phase. 48 VDC, 24 VDC, and 12 VDC can be mounted inside the DAX. These supplies allow any of the above mentioned voltages to be connected directly to the terminals of the DAX In an effort to be competitive and keep the cost to a minimum, no power supply at ail may be installed inside the DAX. Instead an external 5 VDC regulated wall transformer may be wired directly to the terminals. This is an acceptable solution as long as the limitations of the wall transformer are not exceeded, the most obvious being a temperature range of $32^{\circ}$ to $104^{\circ} \mathrm{F}$, and mean time between failures.

U PS or uninterruptable power supply is employed in the DAX. This power supply comes on when the primary power to the unit is lost. This can often happen because of power failures or tripped circuit breakers. When the UPS comes on, the unit continues to monitor external voltages and other tasks which it would normally perform while under primary power. One of the smart tasks which is performed is to look to see the amount of time the user has requested before reporting a primary power fault condition. In other words, the DAX senses primary power has been lost. switches to secondary power and waits an hour or two to see if the power comes back on. If power comes back no report is made, but if power is not restored in the allotted time the unit makes a call to the central office to report there has been a power failure. The user determines and sets the fault time duration value. This eliminates a call being initiated every time the power goes out for a few minutes. This duration time. which the user sets from the PC software, has been left a variable because in some instances a critical situation may result if notification is not given within a few minutes or in other cases the power can be out for a day or two without cause for concem. The UPS is composed of a standard 9 Volt transistor battery which can be found at almost any convenience store. Battery designs are not all the same. For instance the Eveready lead acid battery has a shelf life of four years and a energy density of $300 \mathrm{~mA}$ Hours, which will operate the DAX for about 3 years or 100 one-minute phone calls. The battery M.C. Miller Co., Inc. chooses to use is the lithium battery which can be found at most stores which have camera supplies. The battery has a shelf life of ten years and an energy density of $1200 \mathrm{~mA}$ hours. This battery will power the DAX for 300 one-minute phone calls. or nine years before it needs to be replaced. This brings us to the obvious question of how to know when the battery is to be replaced. The answer is that DAX has built in self diagnosis capability which periodically checks the battery voltage and reports the status during connect time with the central computer located in the office.

$\mathrm{P}$ ower Management is a behind-the-scenes feature which enhances the quality and longevity of the product. Power management turns on and off different systems of the DAX when required. There are four blocks which utilize power management: Analog level which does all the voltage monitoring; the modem block which handles the incoming and outgoing communications; and the digital and memory boards. Power management turns these blocks on when they are needed and off when they are not required. The reason for doing this? Mean Time Between Failures. Every component has an average operating life expectancy before it fails. Components are chosen with the longest MTBF as possible. The solution to the problem or a way to get more life is to only operate the blocks when required. For example, turn on the modem when making a call or receiving a call, the rest of the time leave it turned off. Another example is when sampling data only once a day the analog, digital. and memory boards can be powered up for a few seconds to take the sample and store it, then completely powered off for the rest of the day. All this is handled behind the scenes by the power management system. This is a far better method than letting all the components nu all the time, maximizing the efficiency of the components and ensuring longer life.

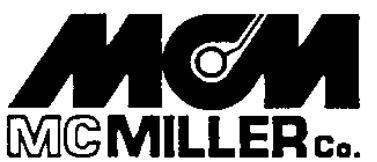

M.C.MILLER Co.,Inc. 341 Margaret King Ave. Ringwood, N.J. 07456 Phone: 201-728-3800 QRGMILLERco. Made in the U.S.A. 


\section{Appendix B: Supplemental RMU Installation Instructions (Prepared Onsite)}

\section{M.C. Miller DAX Units}

1. Remove rectifier negative cable (this is the structure lead). Splice the negative lead to \#12 AWG and route through RMU relay.

2. Use \#18 twisted pair wires to connect to terminals of RMU.

3. Connect red \#18 to left side of rectifier shunt and RMU terminal \#1 of channel \#1.

4. Connect black \#18 to right side of rectifier shunt and RMU terminal \#2 of channel \#1.

5. Connect red \#18 to positive (anode) terminal of rectifier and RMU terminal \#3 of channel \#2.

6. Connect black \#18 to negative (structure) terminal of rectifier and RMU terminal \#4 of channel \#2.

7. Splice \#18 red to reference cell lead and connect to terminal \#5 of channel \#3.

8. Splice \#18 black to separate pipe lead (running with reference cell lead) and terminal \#6 of channel \#3.

9. Connect $\mathrm{AC}$ power to fuses inside RMU unit. Use caution to match input voltage with RMU rating!

10. NOTE: Provide local disconnect for RMU unit, preferably disconnecting rectifier power as well.

\section{Tomar Systems SMART Units}

1. Remove rectifier Negative cable (this is structure lead). Splice to \#12 AWG and route to structure terminal in RMU (large right copper lug).

2. Route \#12 wire from left large lug in RMU labeled "Rect. Neg." and connect to lug marked "Negative" in rectifier.

3. Connect reference cell lead to RMU terminal marked "RC."

4. Connect \#12 (min.) wire to RMU terminal labeled "Pos." and connect in parallel to rectifier terminal marked "Positive."

5. Ground TOMAR case to earth ground using ground terminal in RMU with a mark resembling an upside down Christmas tree. 
6. Plug telephone wire into left most RJ-11 jack labeled "TEL JACK."

7. Connect separate pipe lead (running with reference cell lead) to RMU terminal marked "STR".

8. When all power is completed, connect white molded plastic connectors (male \& female) to complete battery backup connection.

9. NOTE: Provide local disconnect for RMU unit, preferably disconnecting rectifier power as well.

10. NOTE: These instructions are not necessarily per the manufacturer's installation manual. The manual pertains to the schematic connection diagram for the RMU "brains" unit itself. This contract specified additional components be provided, which the manufacturers's manual does not address. 


\section{Appendix C: Suggested Remote Monitoring Unit Relay}

A permanent relay switch should be installed with each remote monitoring system in order to gather IOP readings. The relay switches are the only mechanical components involved in remote monitoring. As a result, they are more susceptible to failure. It is important that a single type of proven high quality relay be used to prevent serious problems when performing IOP readings. One of the major problems encountered in the evaluation occurred due to a faulty relay. The relay tended to stick in the open position after IOP readings were taken via remote computer. The result of the open circuit was that cathodic protection current was unable to flow through the structure, thereby leaving the structure unprotected.

Problems of this nature were not present in units provided by vendors with a magnetic relay. The magnetic relay operated properly throughout a wide range of temperature extremes. The relay that did not function properly was a spring loaded solenoid type. The problems with using a spring solenoid under conditions expected with RMU deployment is that they are susceptible to problems created by dusty environments and temperature variations. The internal components, (i.e., spring) will expand or contract with varying temperature conditions resulting in interference in proper functioning. The dirt from a dusty environment will invade the internal components with the same result. A magnetic relay switch is not susceptible to the same environmental constraints and as a result is preferable for RMU deployment.

Therefore, it is recommended that a magnetic relay be procured and installed with each remote monitoring system with adjustments based on system voltage and current requirements. The relay that performed well during the demonstration was:

Manufacturer: Potter \& Brumfield

Model: PRD-5AYO-SPDT - General Purpose Relays, Type C - Power Relay

Ordering Code: Class Number - Class 8501

Type Number: C015

Voltage Code: V04 
The PRD is an Underwriters Laboratories - Canadian Standards Association (UL - CSA) listed, heavy-duty power relay designed for high inrush current applications. The relay has improved screw terminals eliminating the risk of terminal breakage upon installation. The PRD coil is housed in a plastic enclosure thereby preventing damage to the coil. The PRD has a life expectancy of 100,000 operations at full load. Life increases when operated at reduced loads or with appropriate arc suppression. The floating movable contact carrier provides excellent pressure and wipe between contact surfaces, thereby keeping voltage drop to a minimum between mating contacts. The contacts are made of silver-cadmium oxide, with the intent of providing additional contact life and resistivity to welding when used for heavy inductive loads.

Some additional specifications for the model PRD-5AYO-SPDT relay include:

Coil Specifications

Input Resistance (Ohms) Amp Rating

$240 \mathrm{~V} \quad 1200 \quad 25 \mathrm{~A} @ 277 \mathrm{~V} \mathrm{AC}$

Operating Voltage/ Voltage Range:

AC - 6 through 480 Volts, $+10 \% /-15 \%$ of nominal at $25^{\circ} \mathrm{C}$

Operating Temperature Range:

$-55^{\circ} \mathrm{C}$ to $80^{\circ} \mathrm{C}\left(-67^{\circ} \mathrm{F}\right.$ to $\left.176^{\circ} \mathrm{F}\right)$

The recommended relay is available from many authorized distributors. Ordering information must include class number, type number, and voltage code. Additional information about Potter \& Brumfield relays may be obtained and orders may be placed via the Internet at http://www.sumer.com/pab.htm. 


\section{Appendix D: Daily Rectifier Output Voltage Readings at USACERL Test Site}




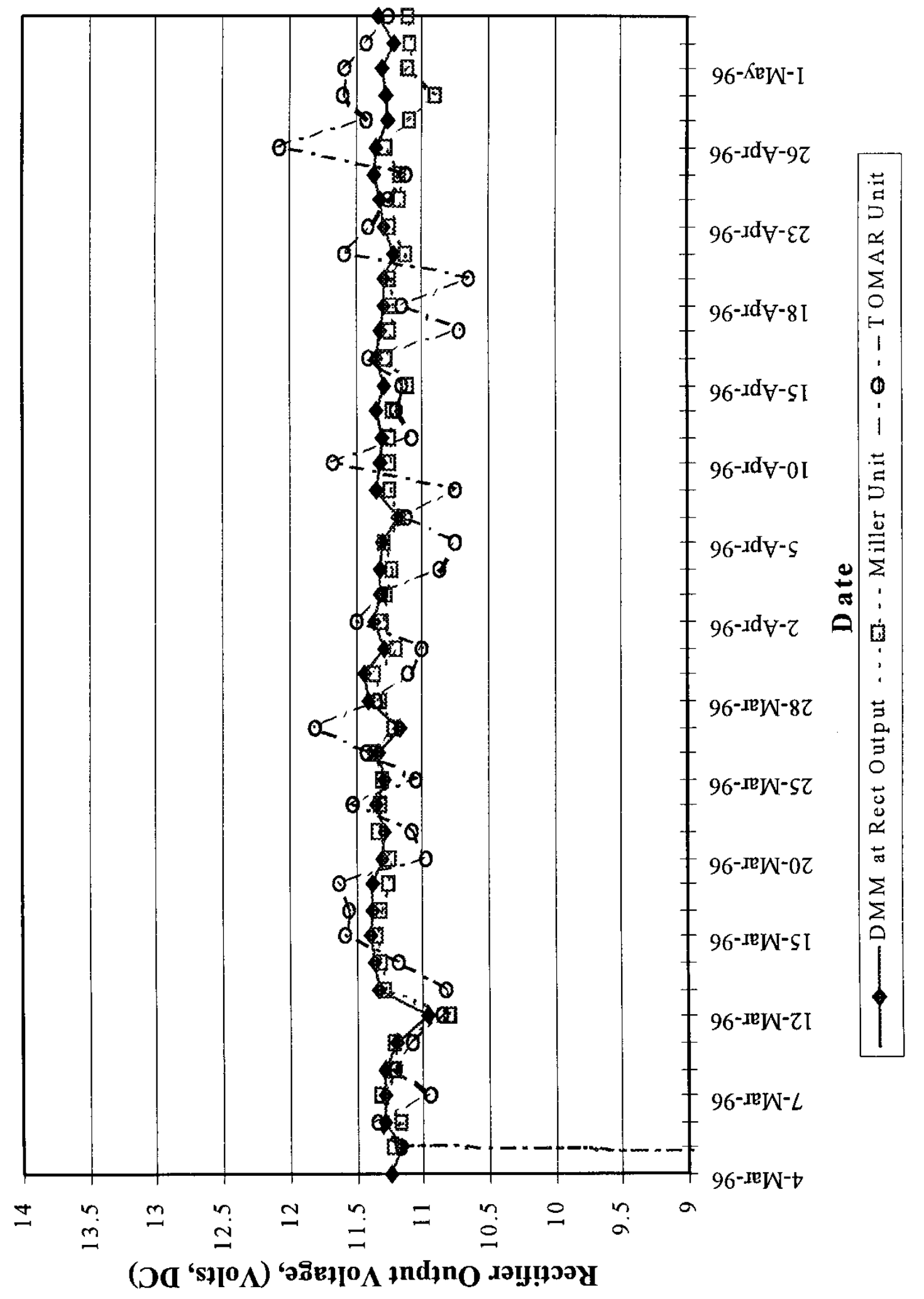

畕 


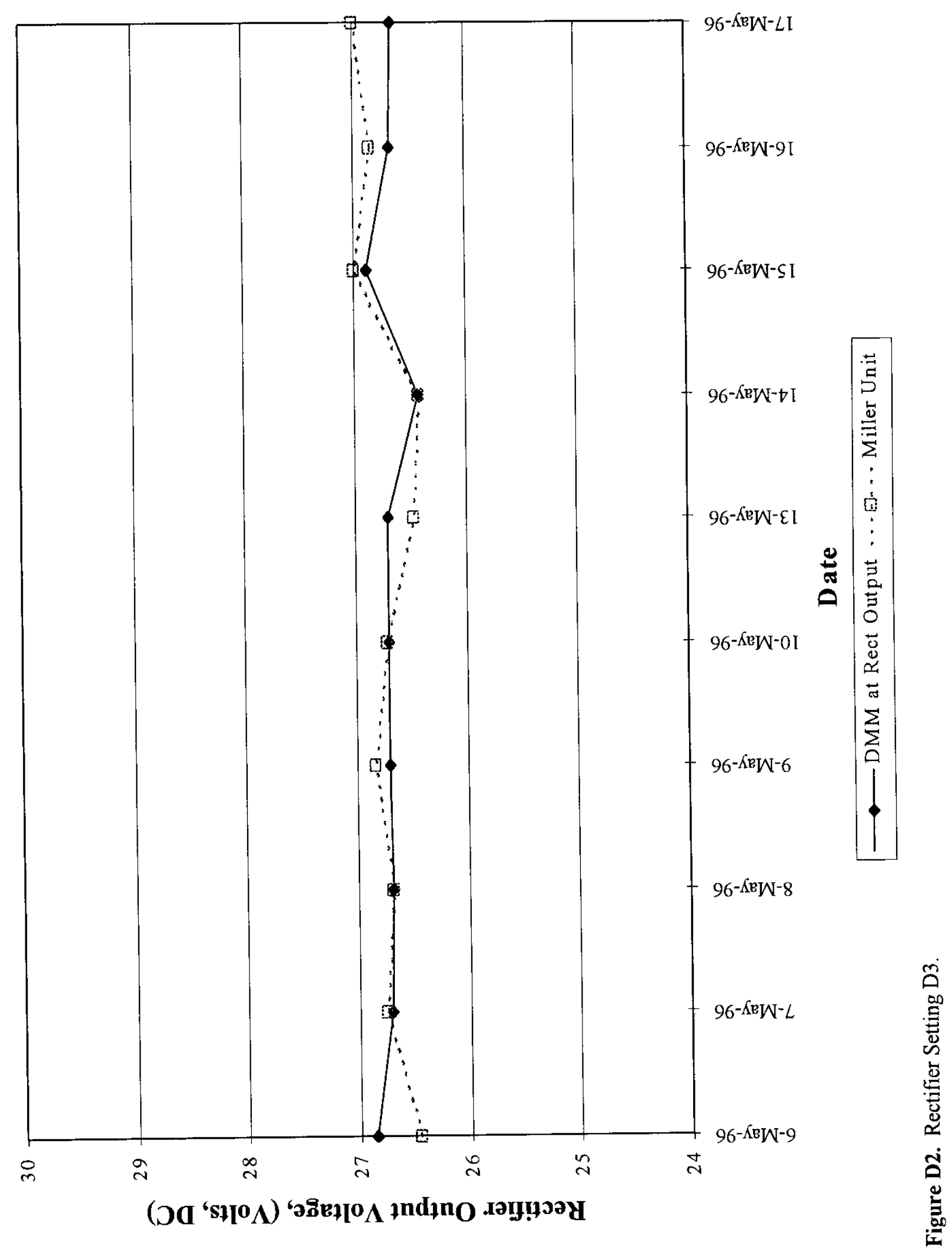




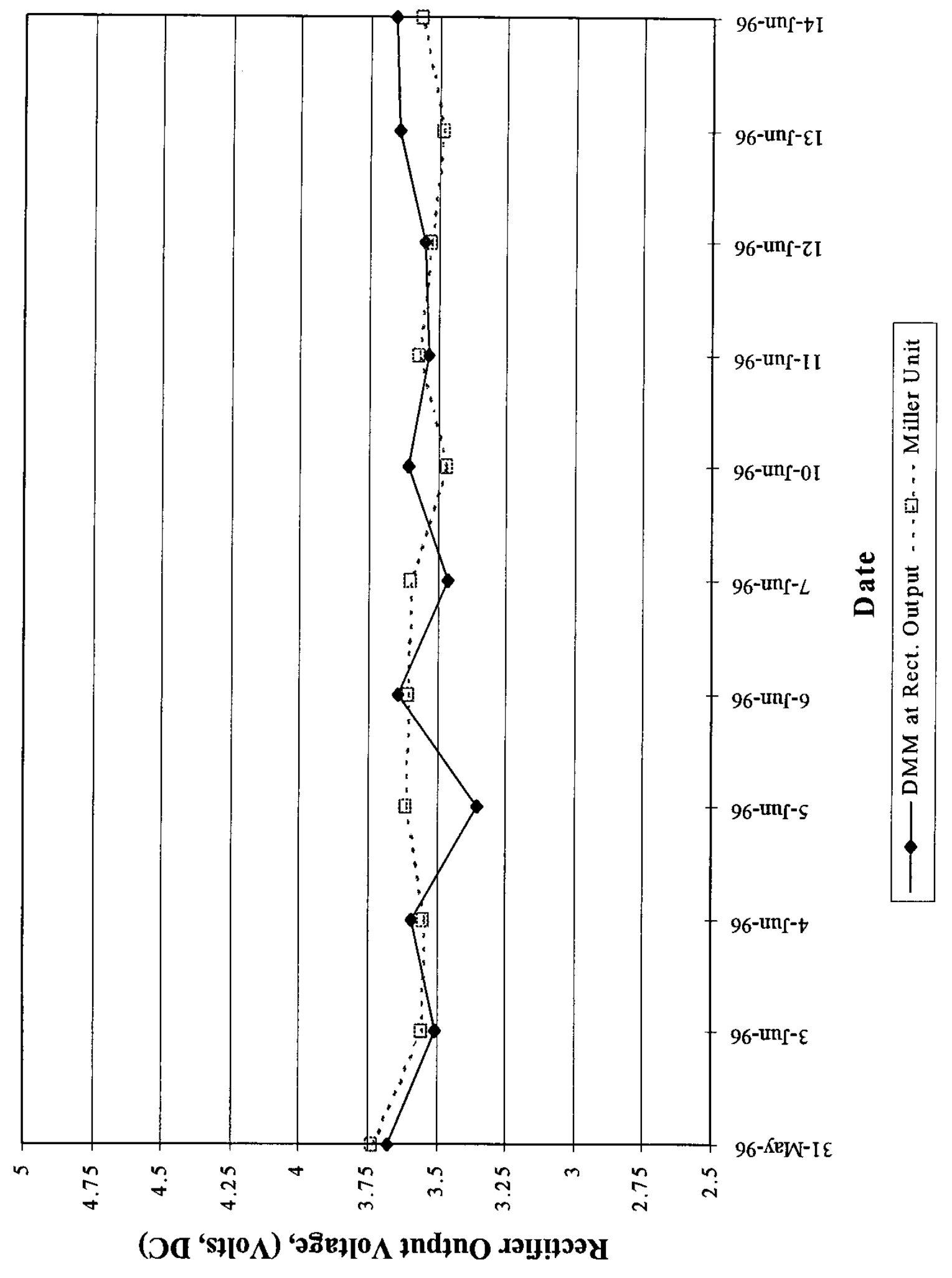

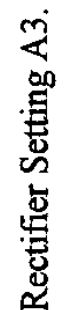

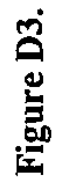




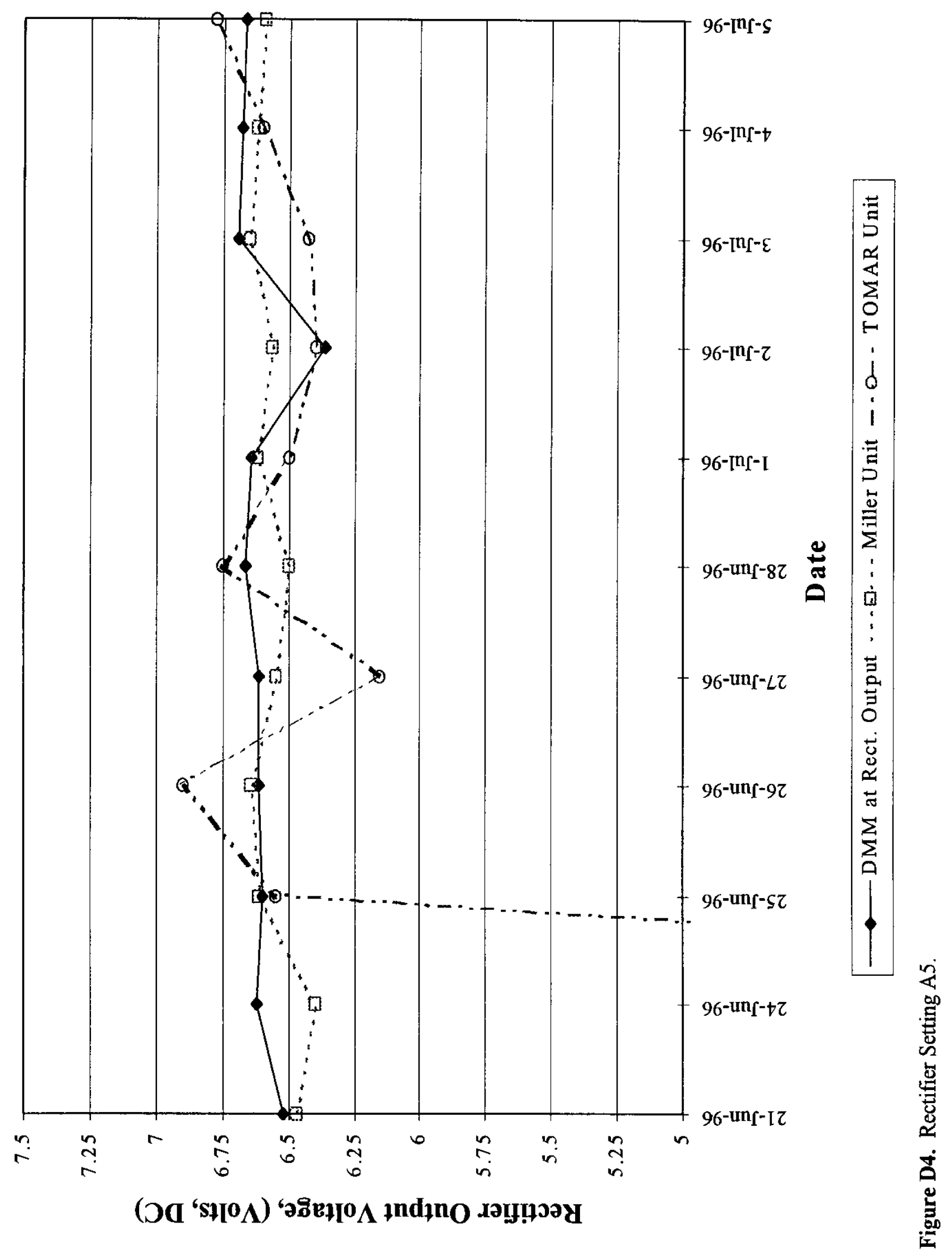




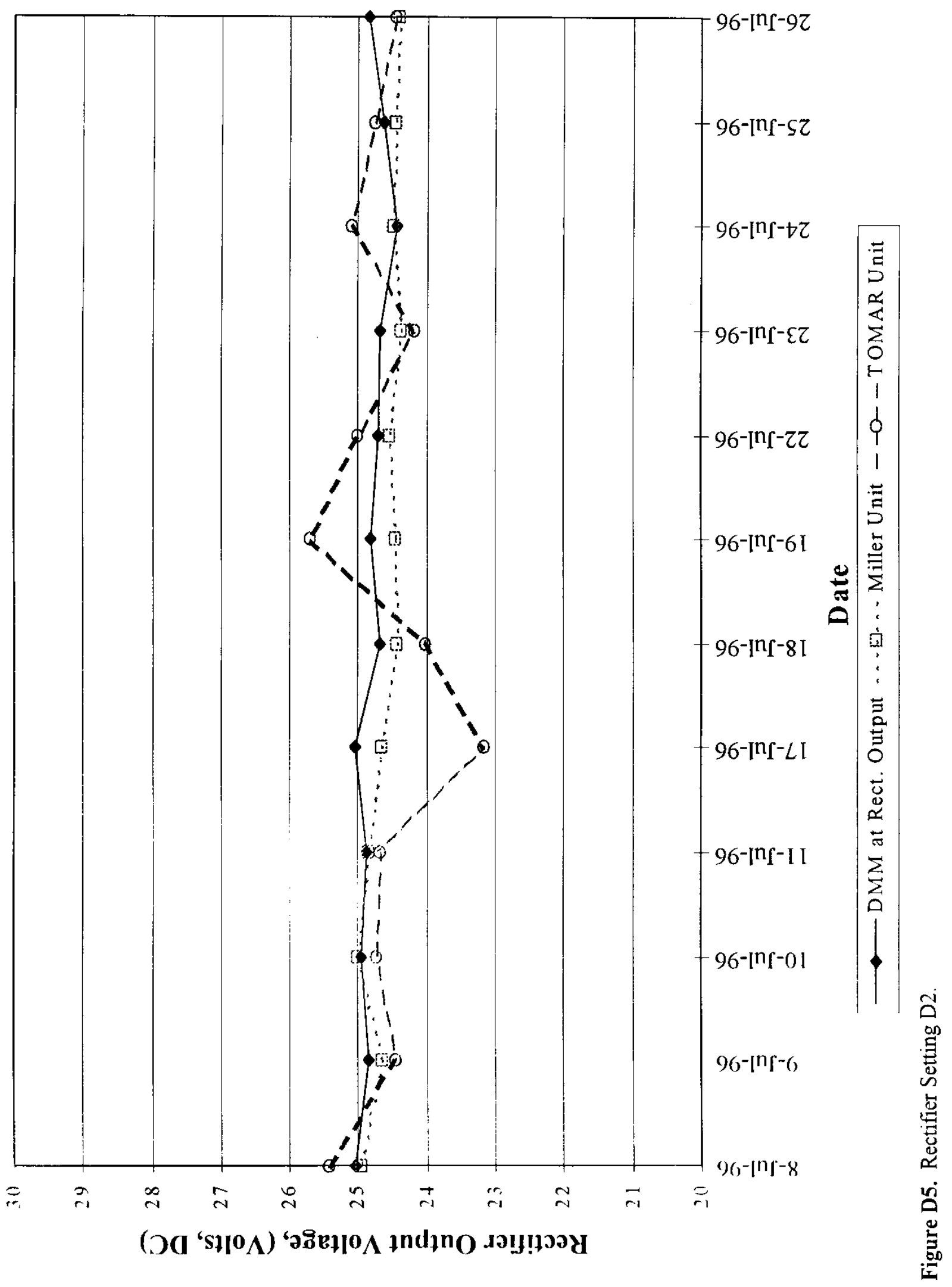




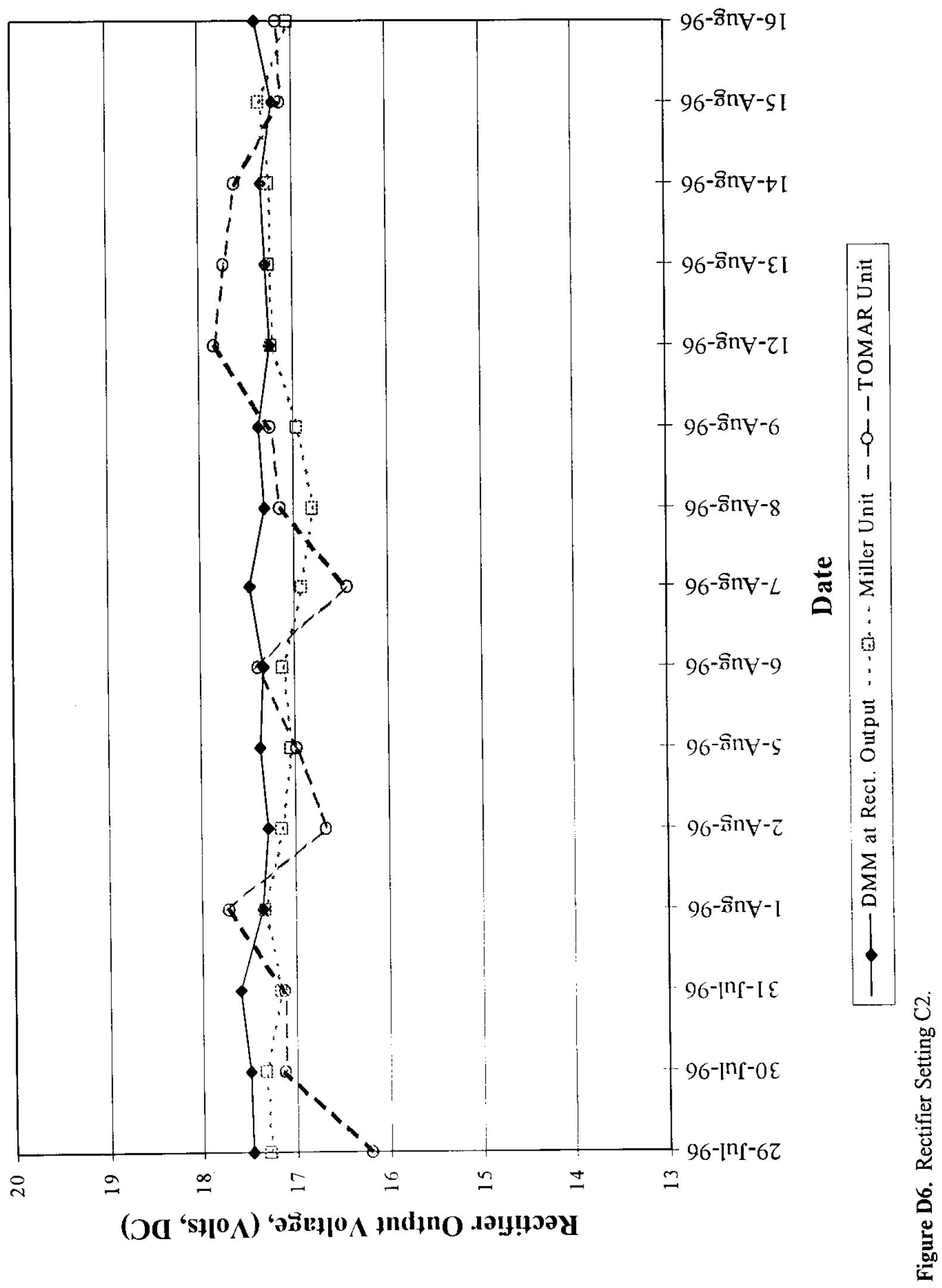




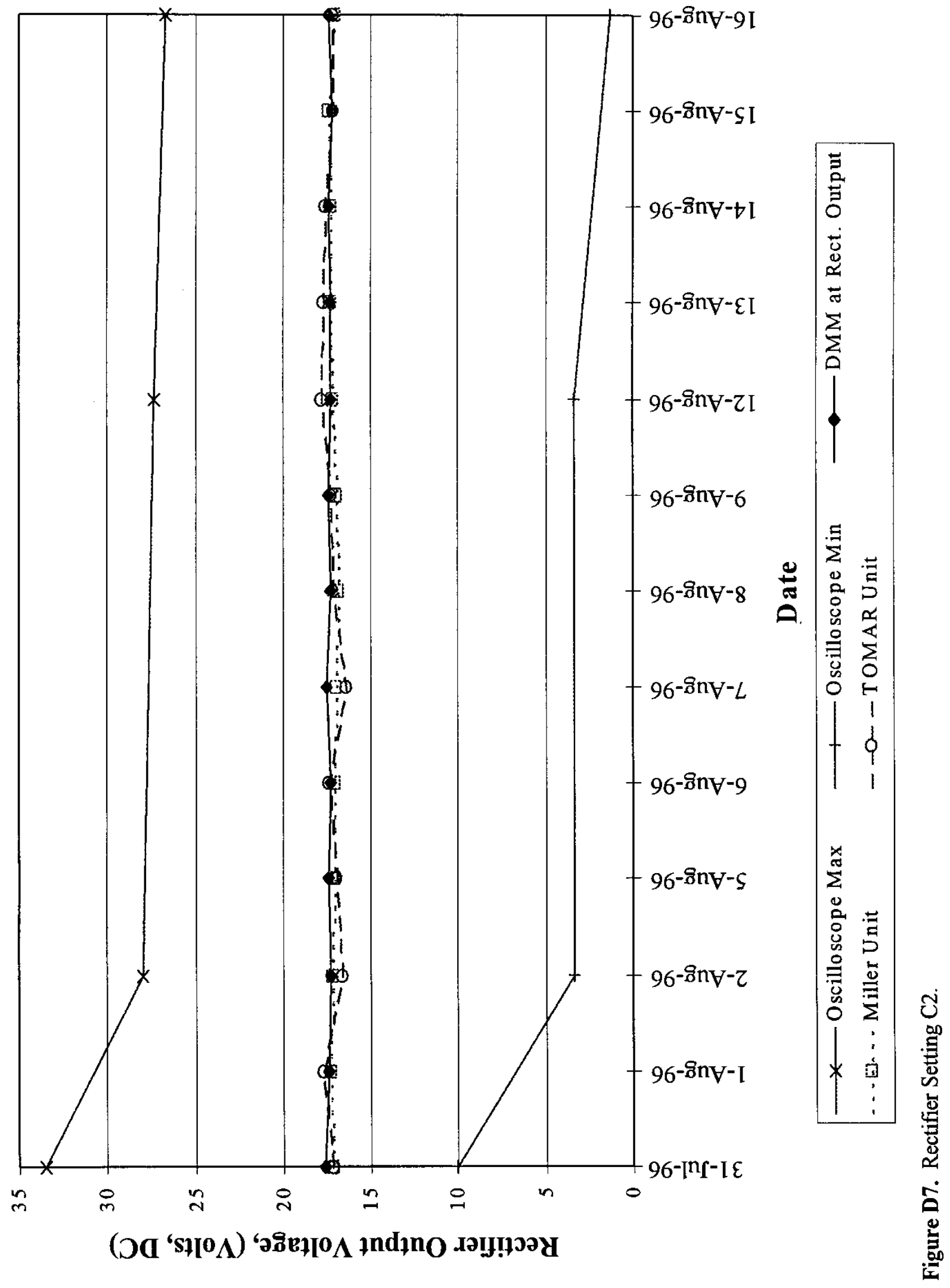




\section{Appendix E: Daily Rectifier Output Current Readings at USACERL Test Site}




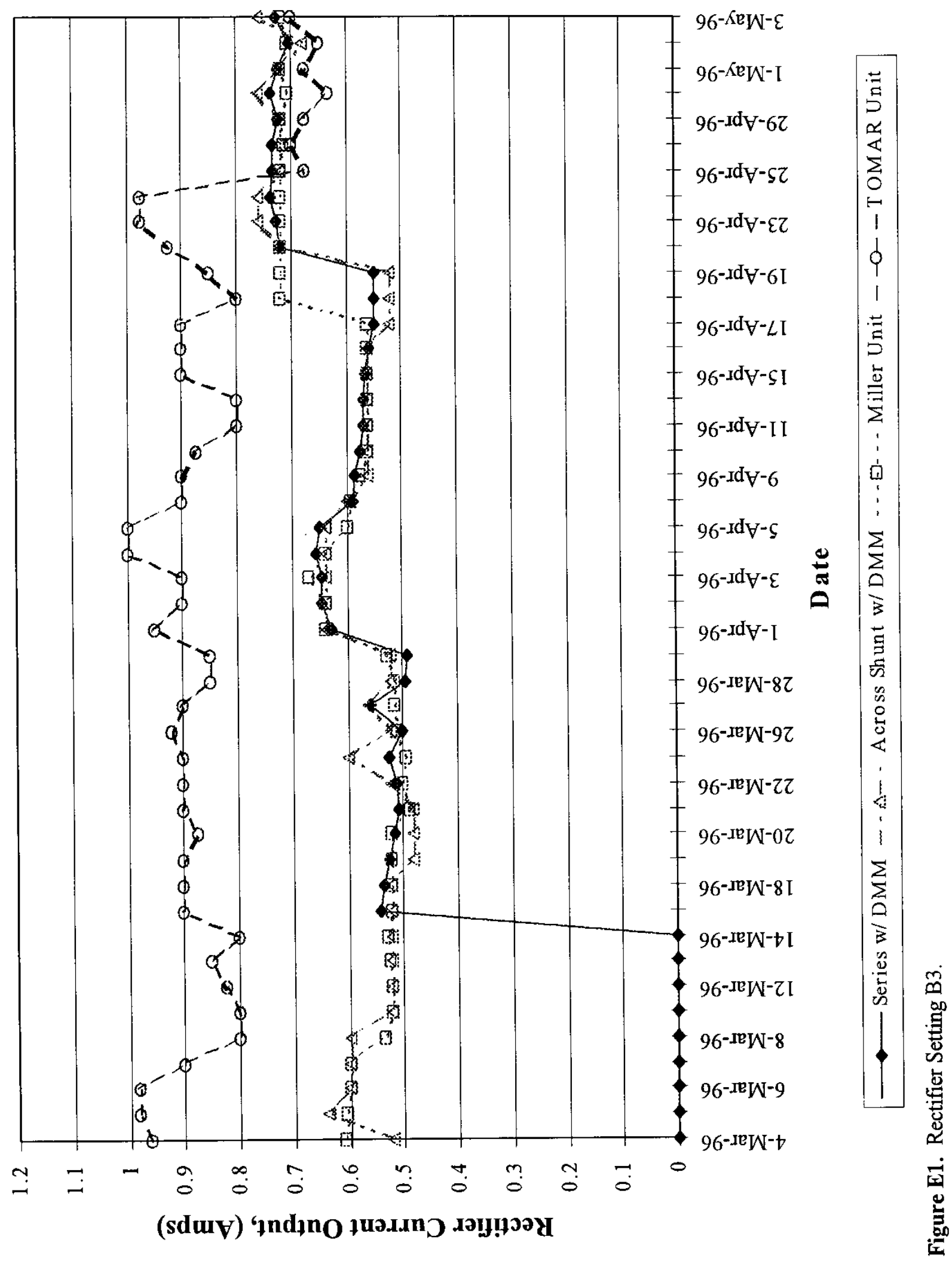




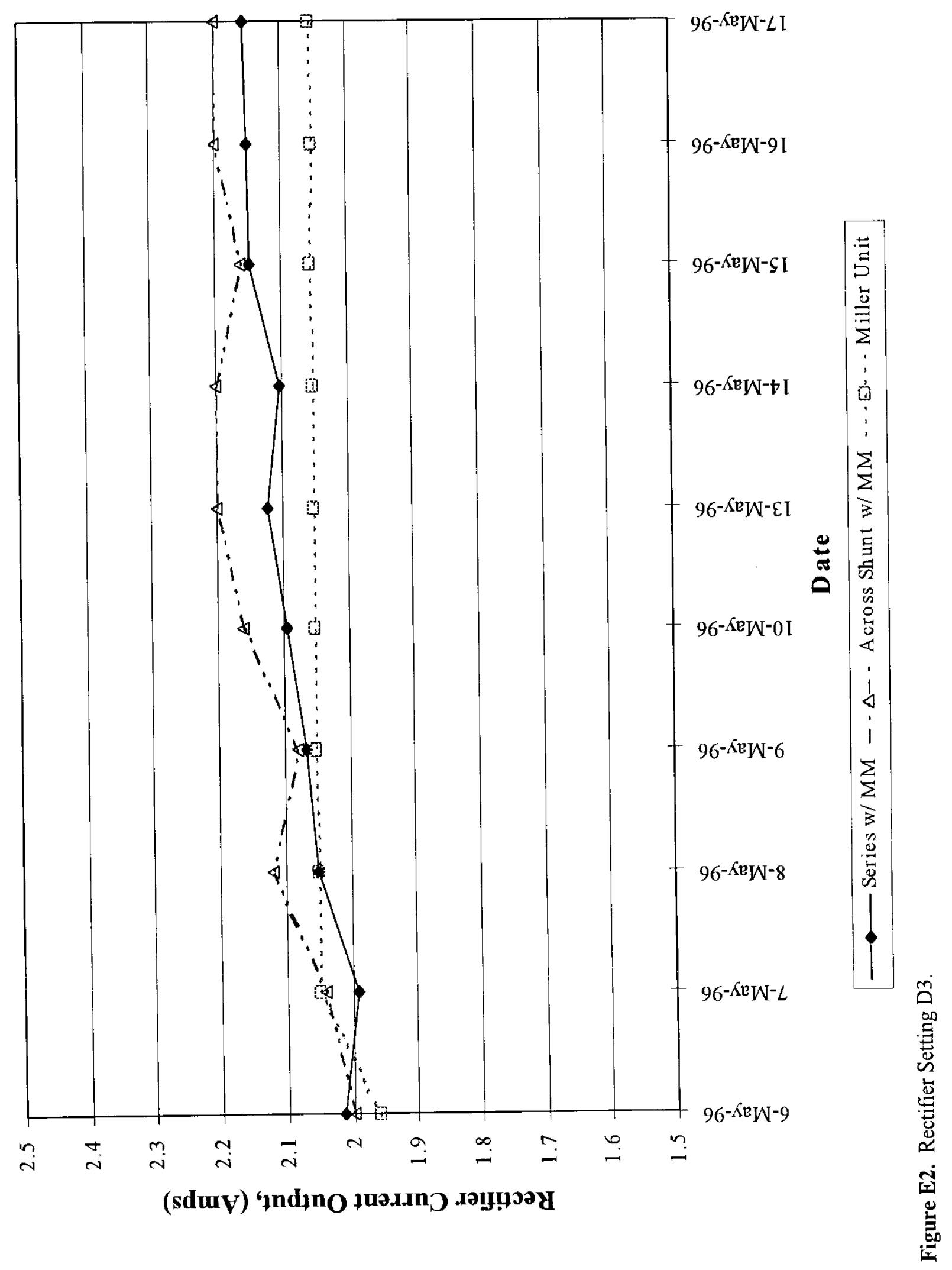




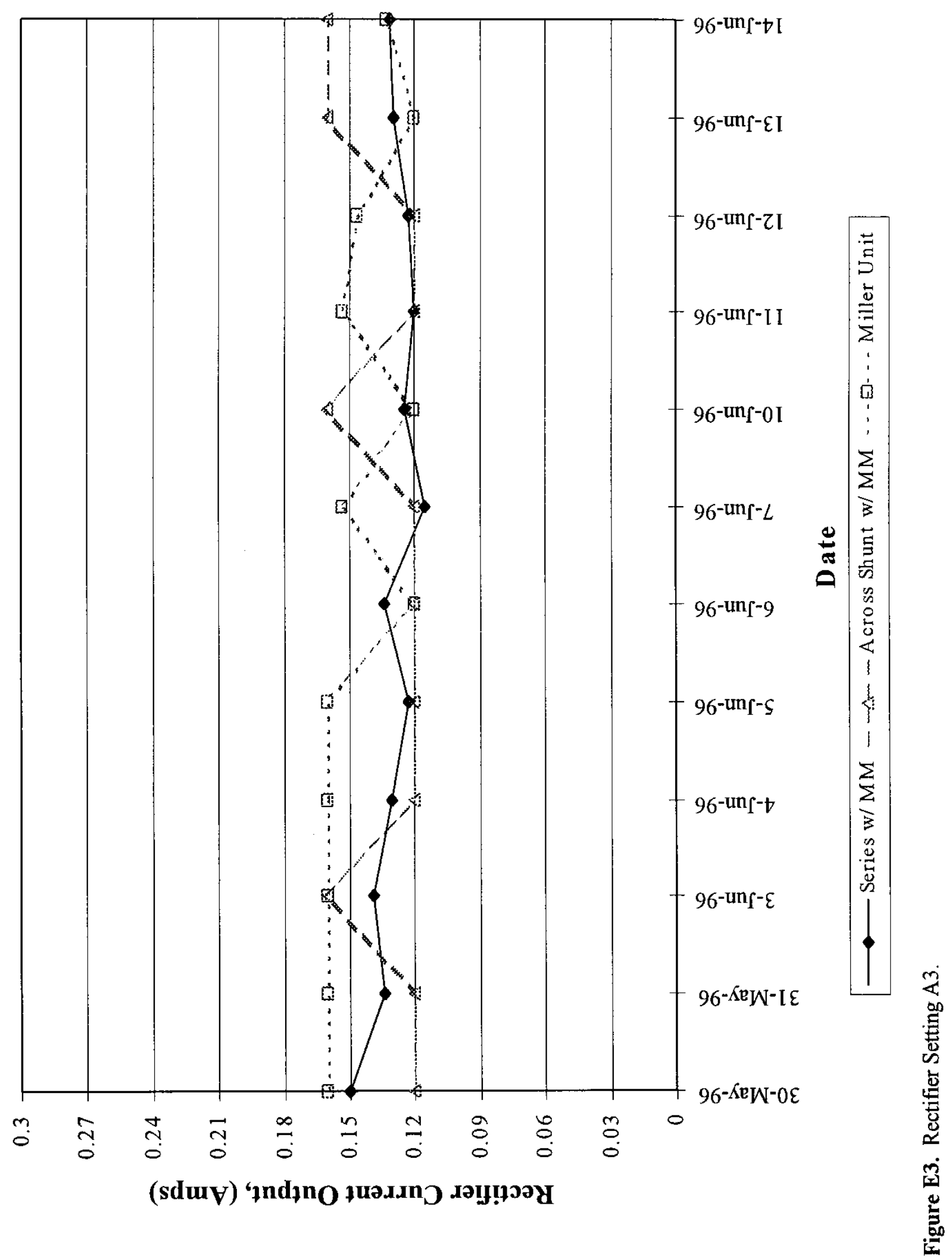




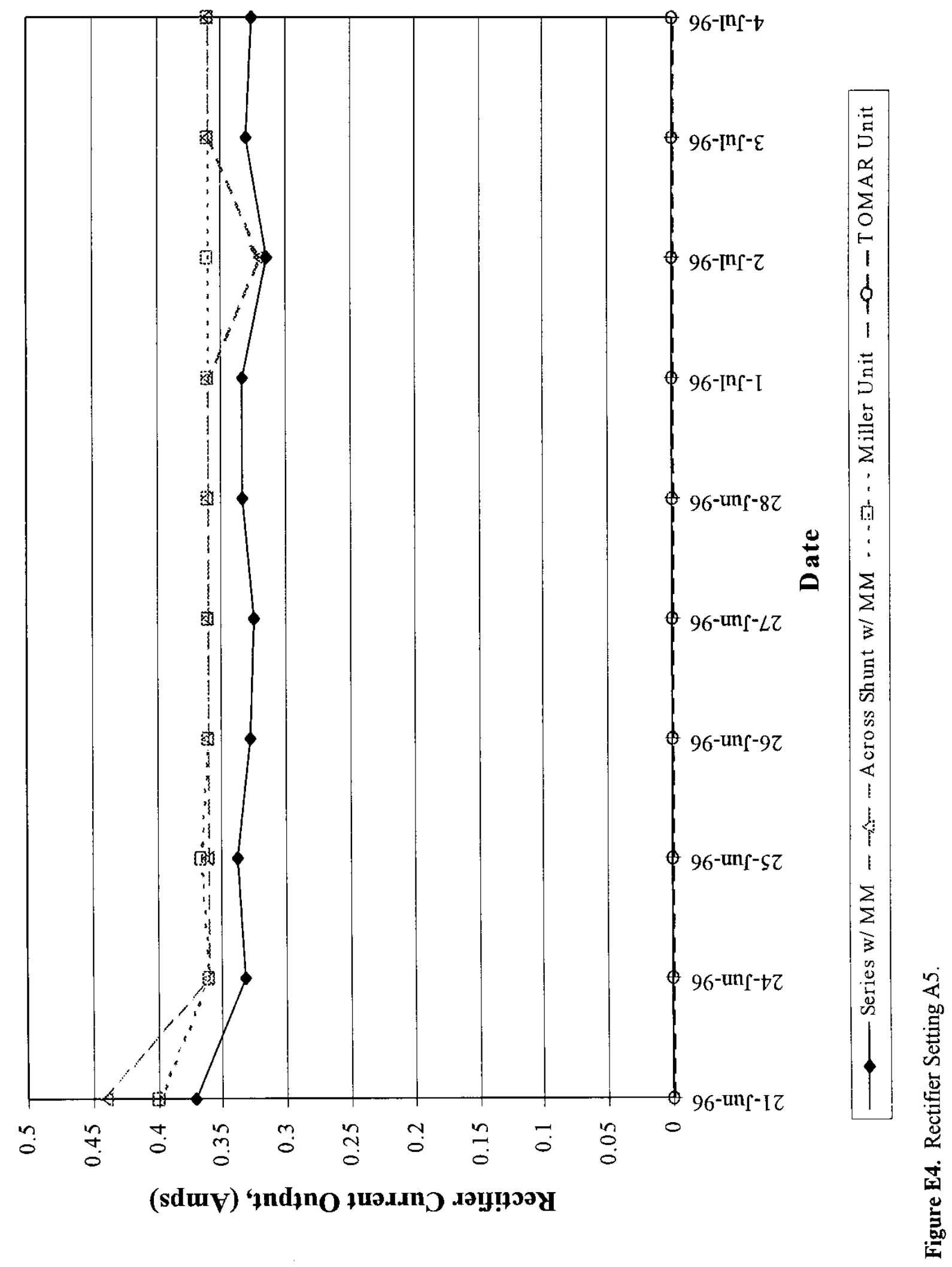




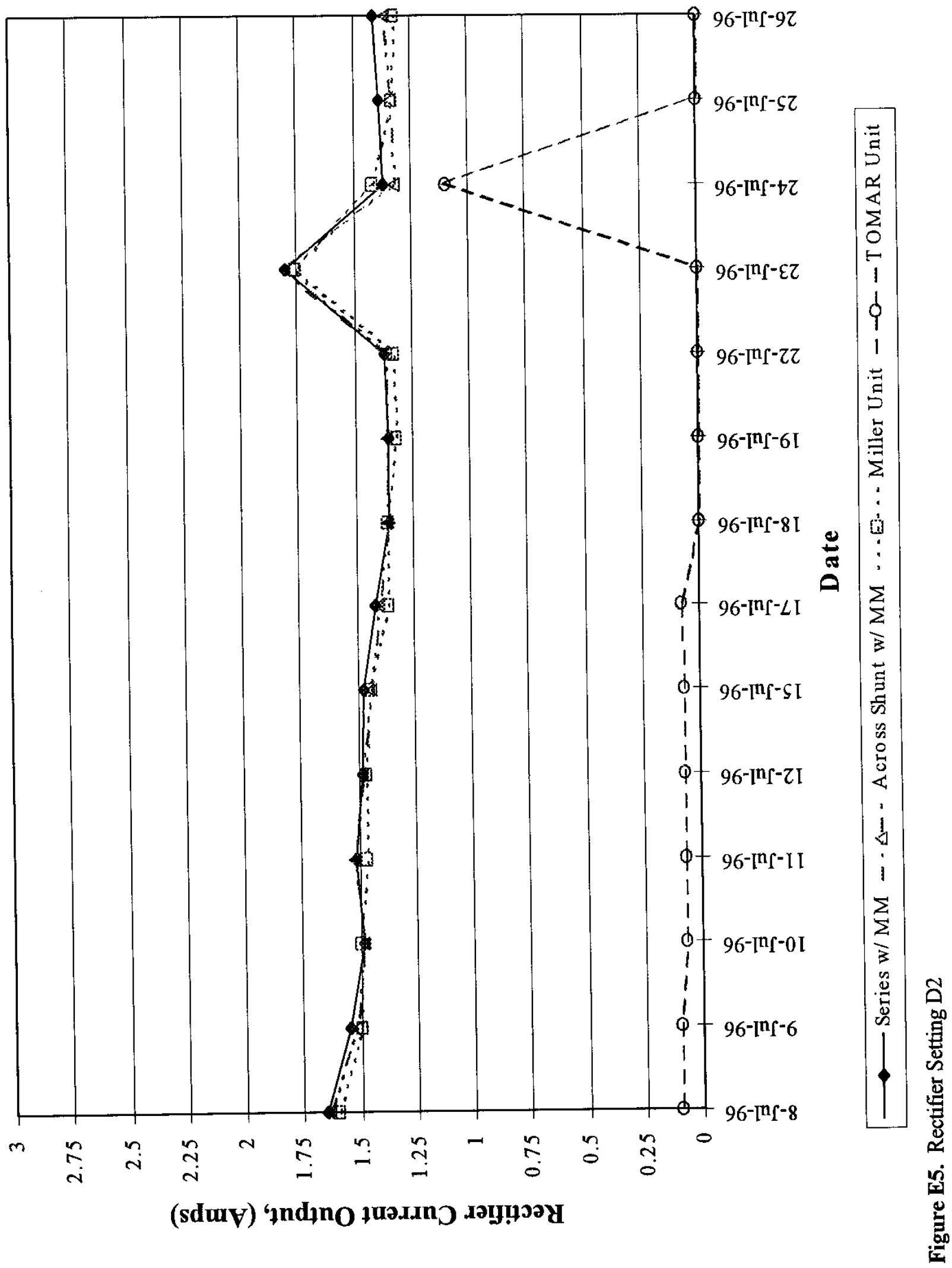




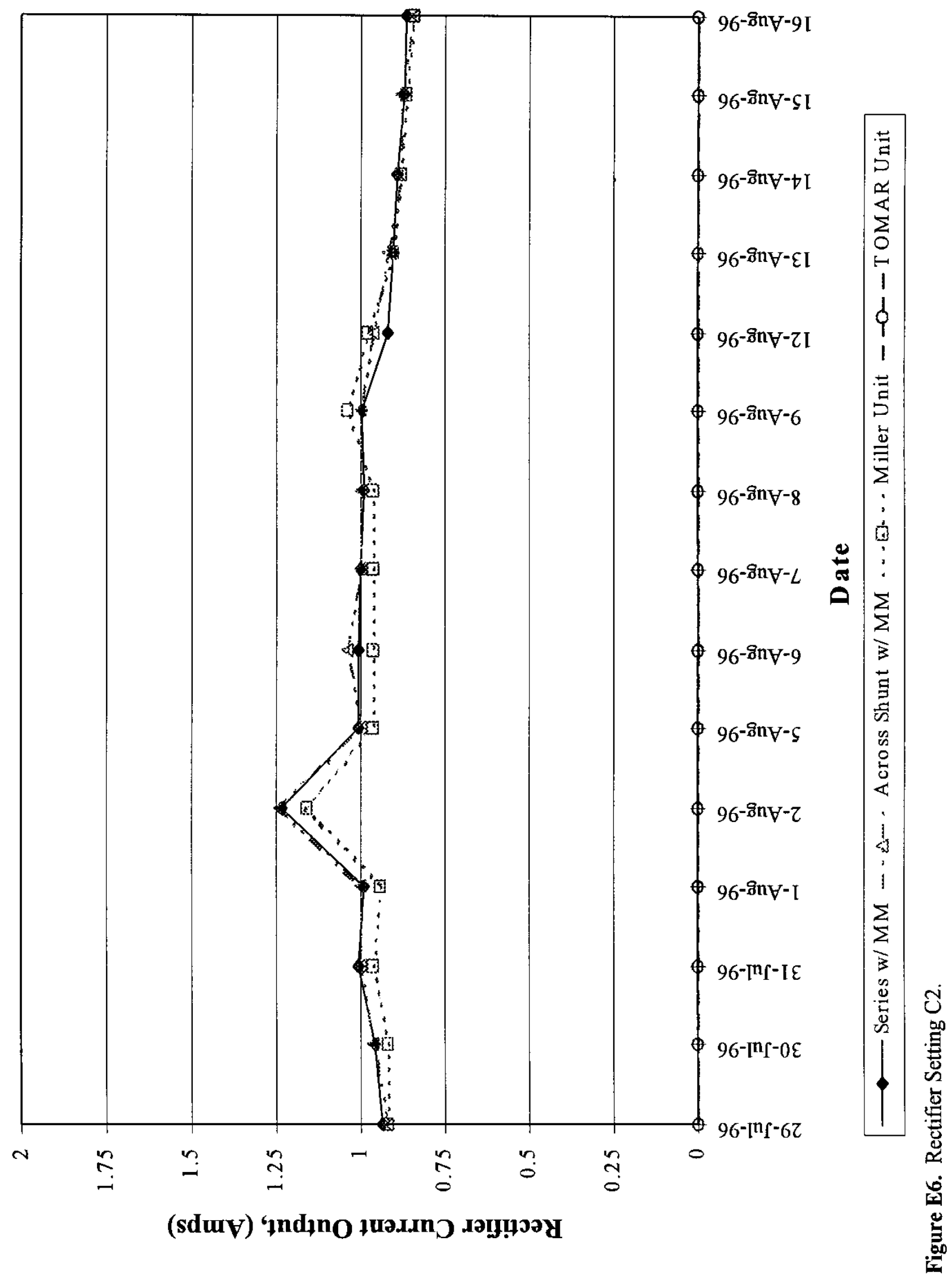




\section{Appendix F: Daily Pipe to Soil "On" Potential Readings at USACERL Test Site}




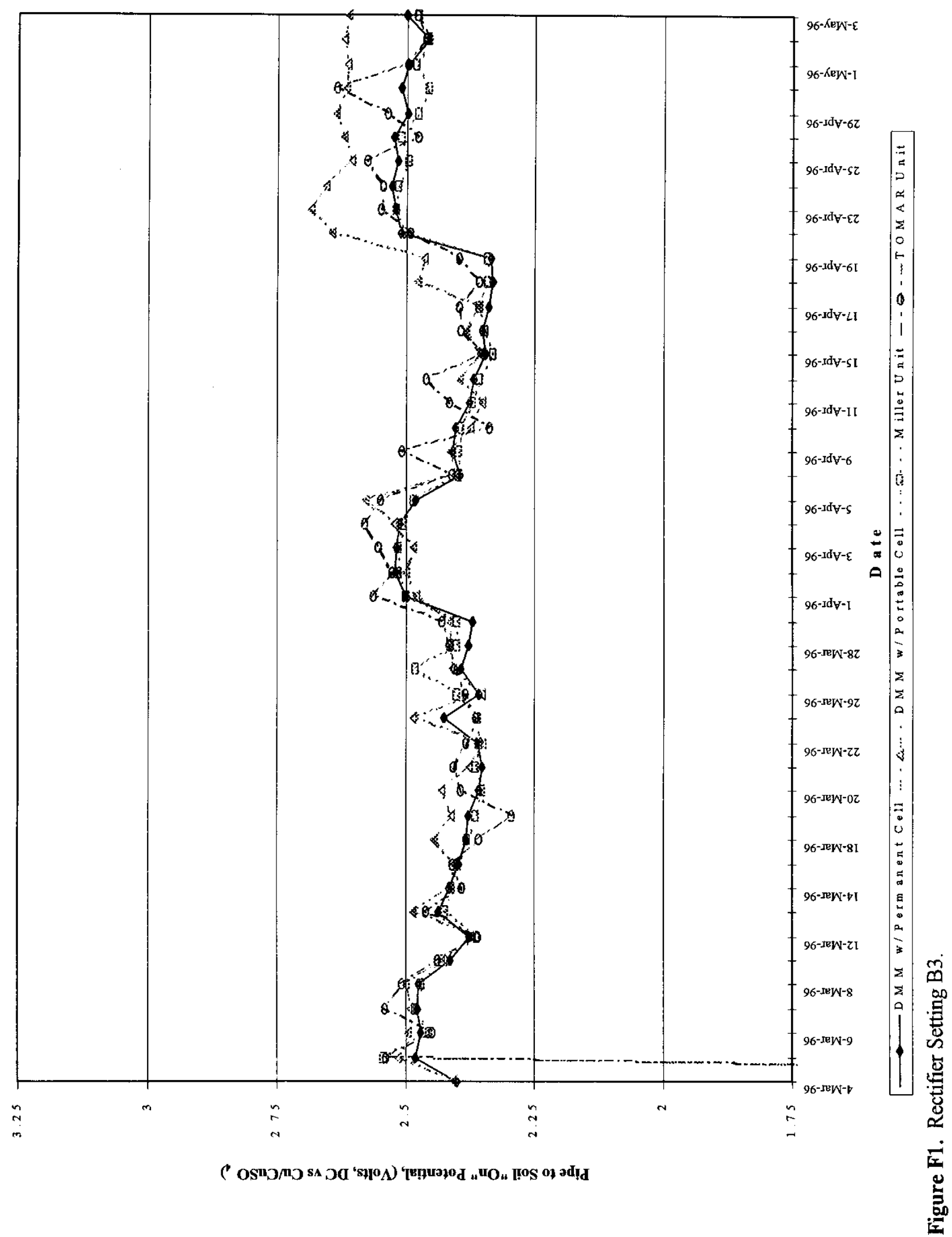




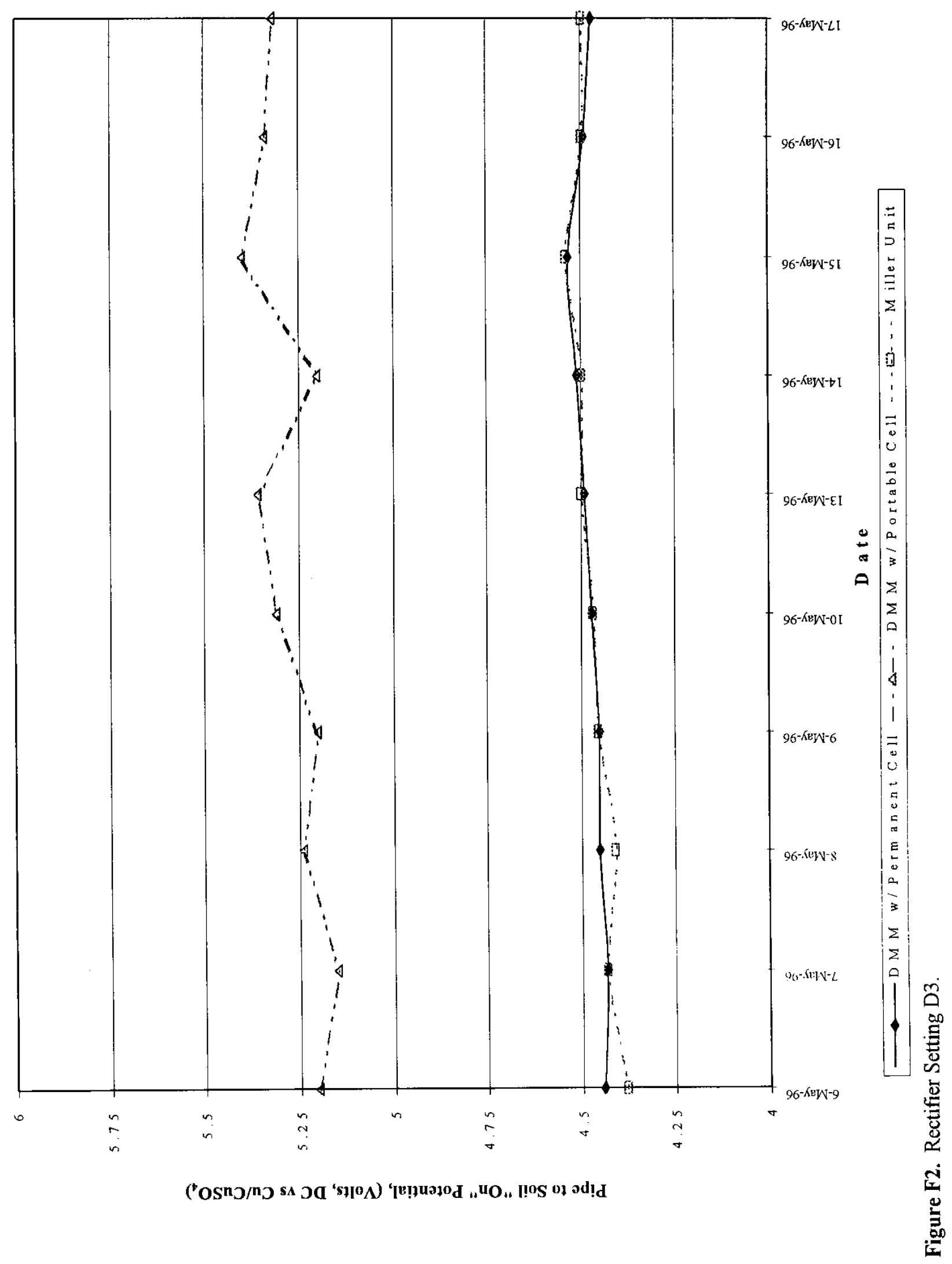


88

USACERL TR $97 / 76$

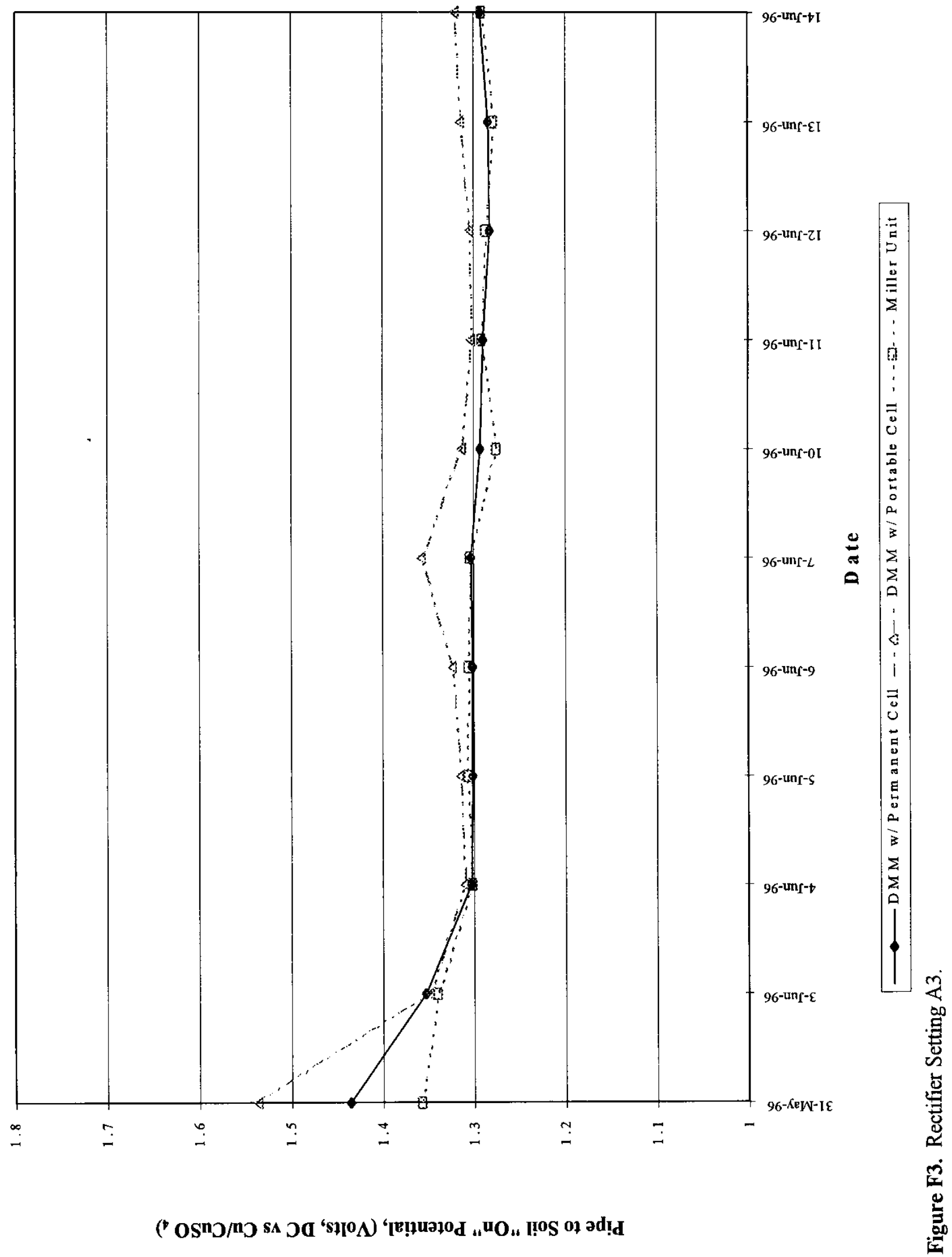




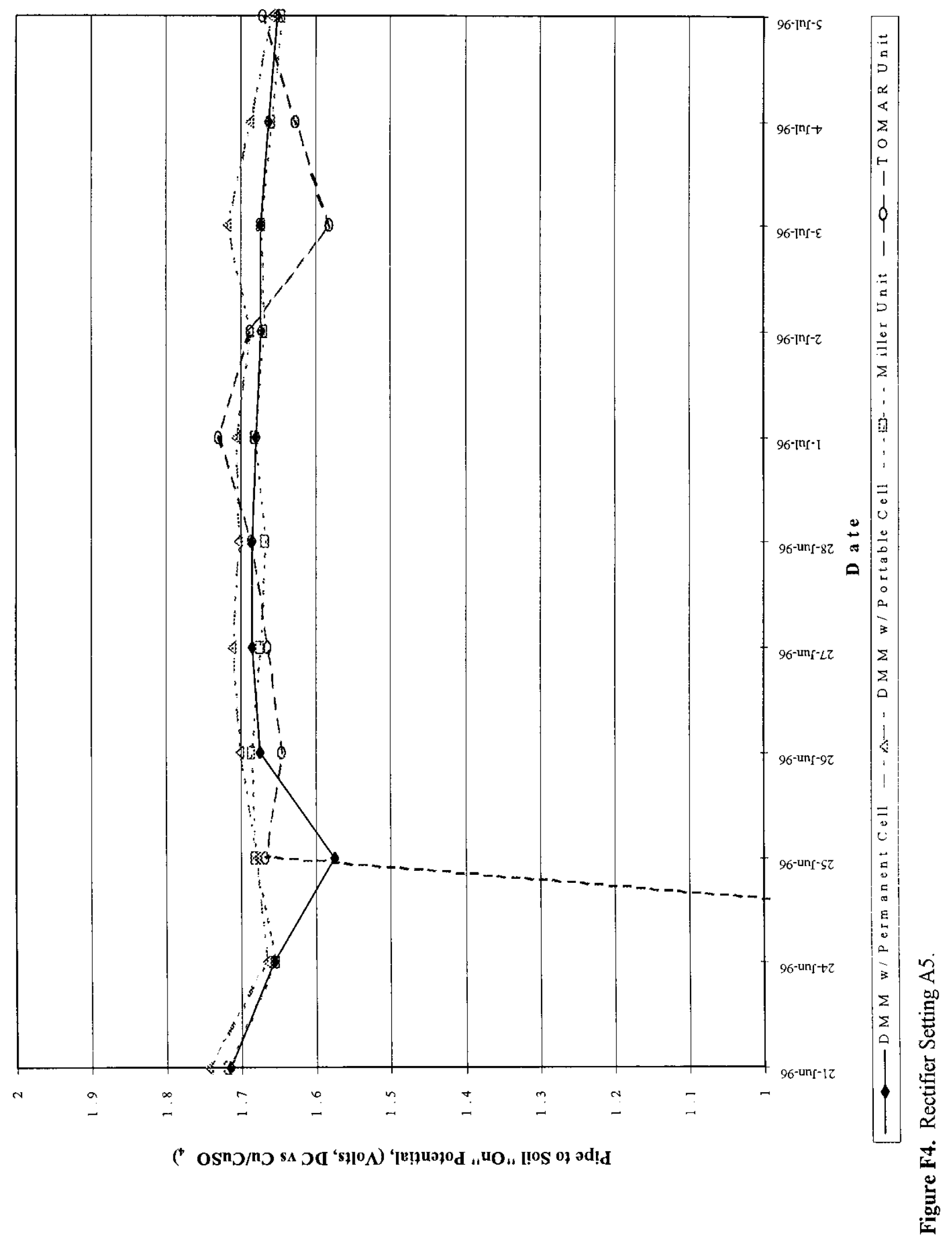




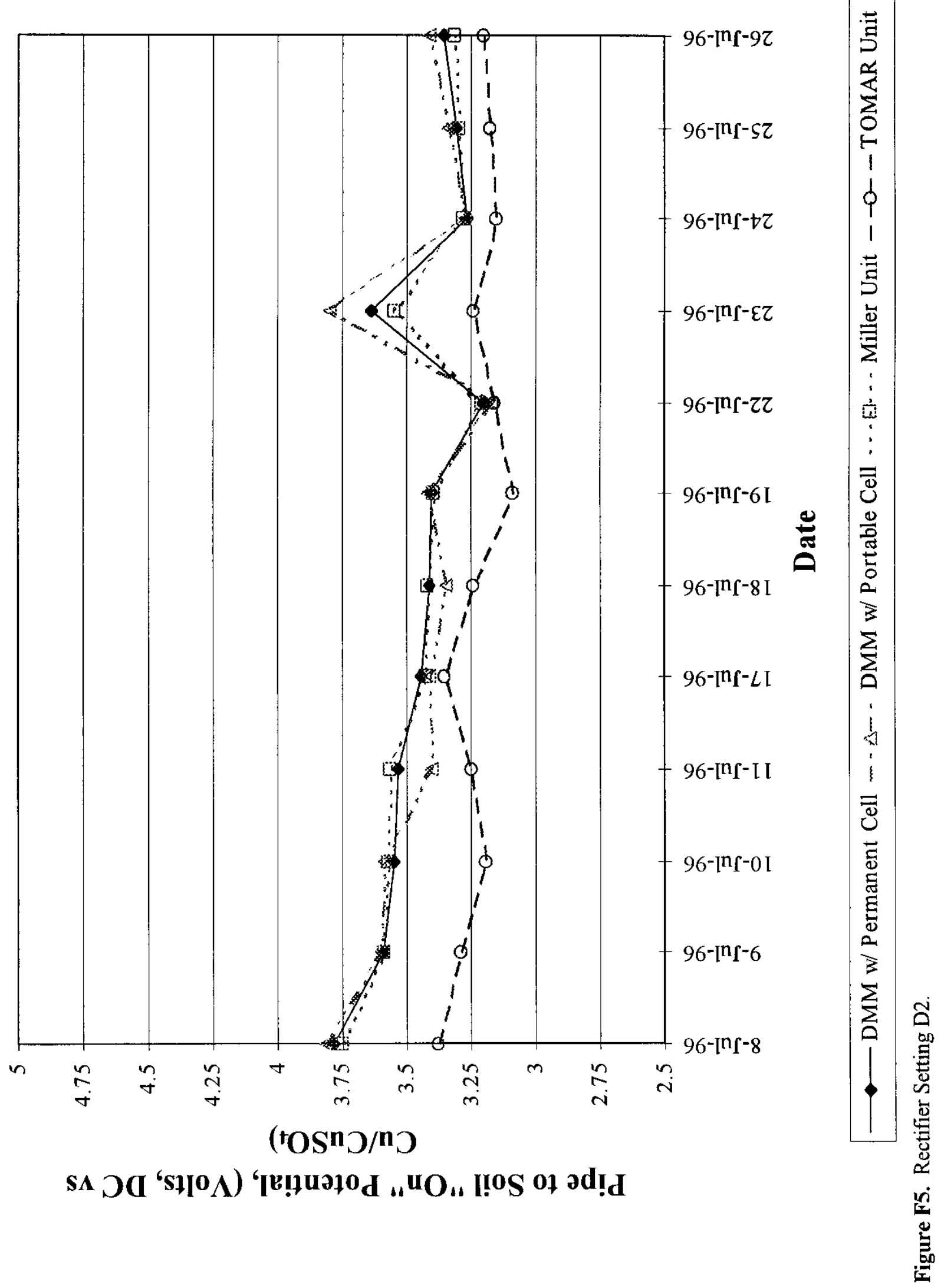




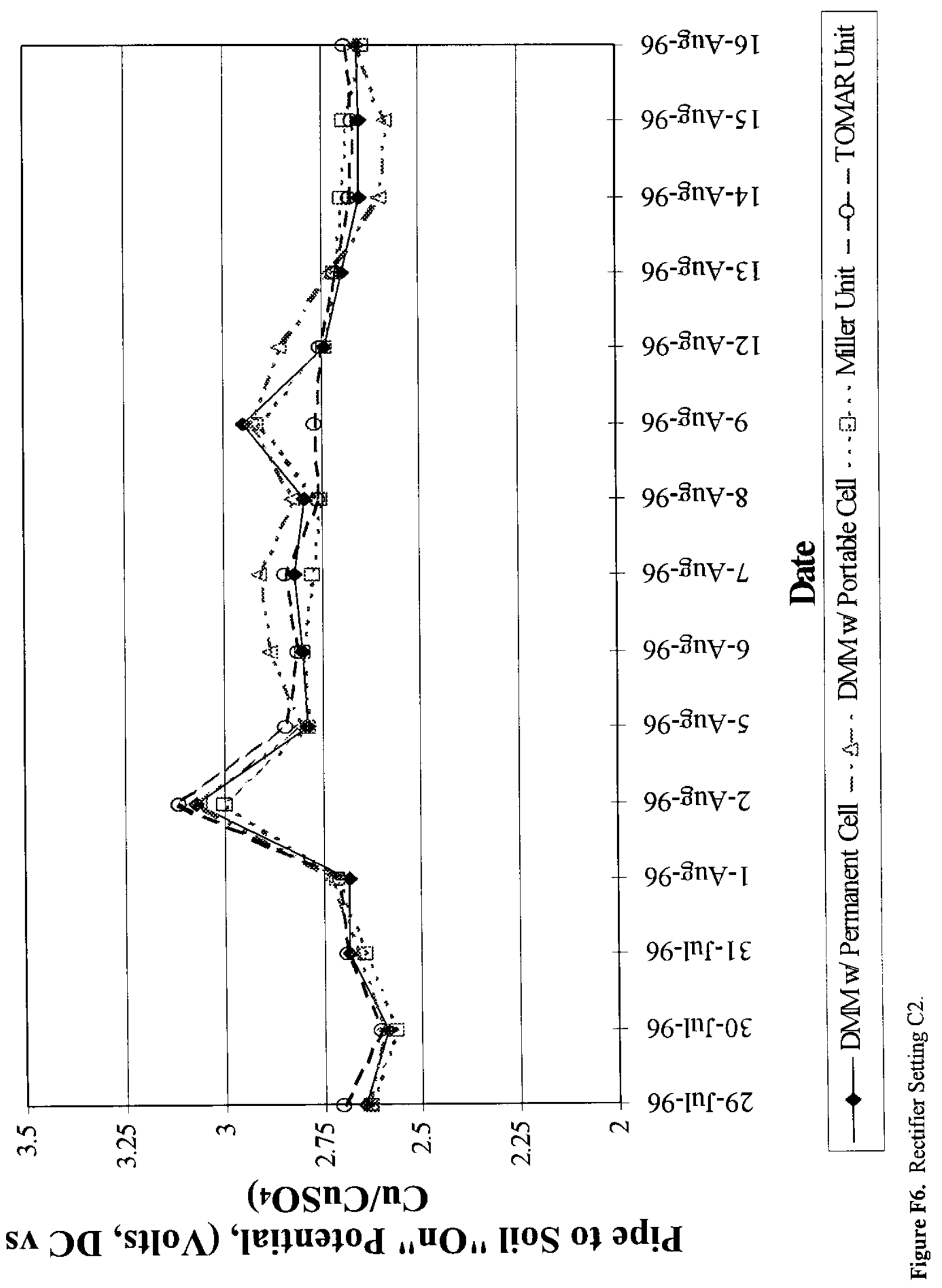




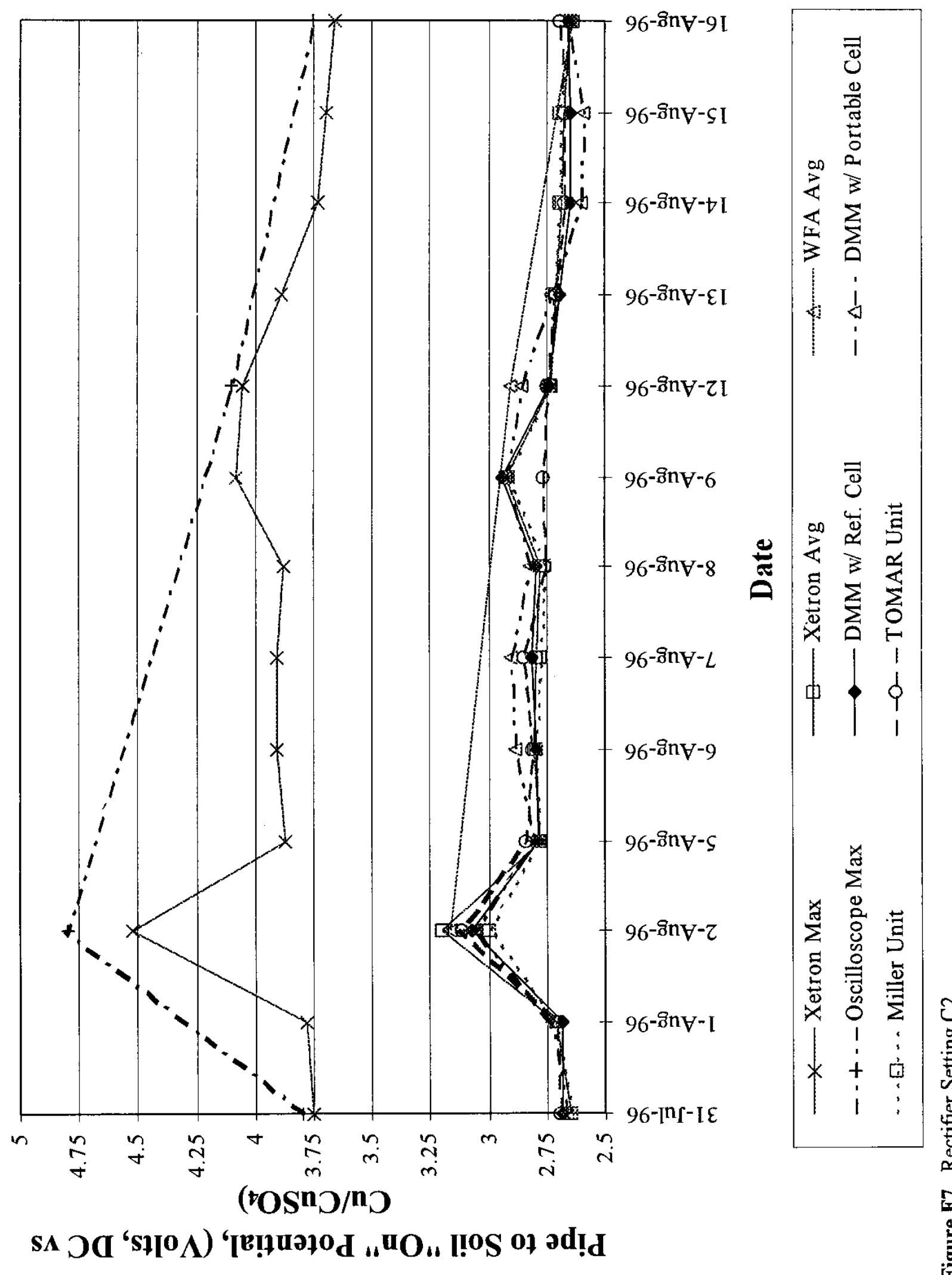

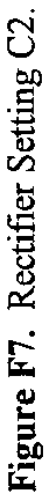




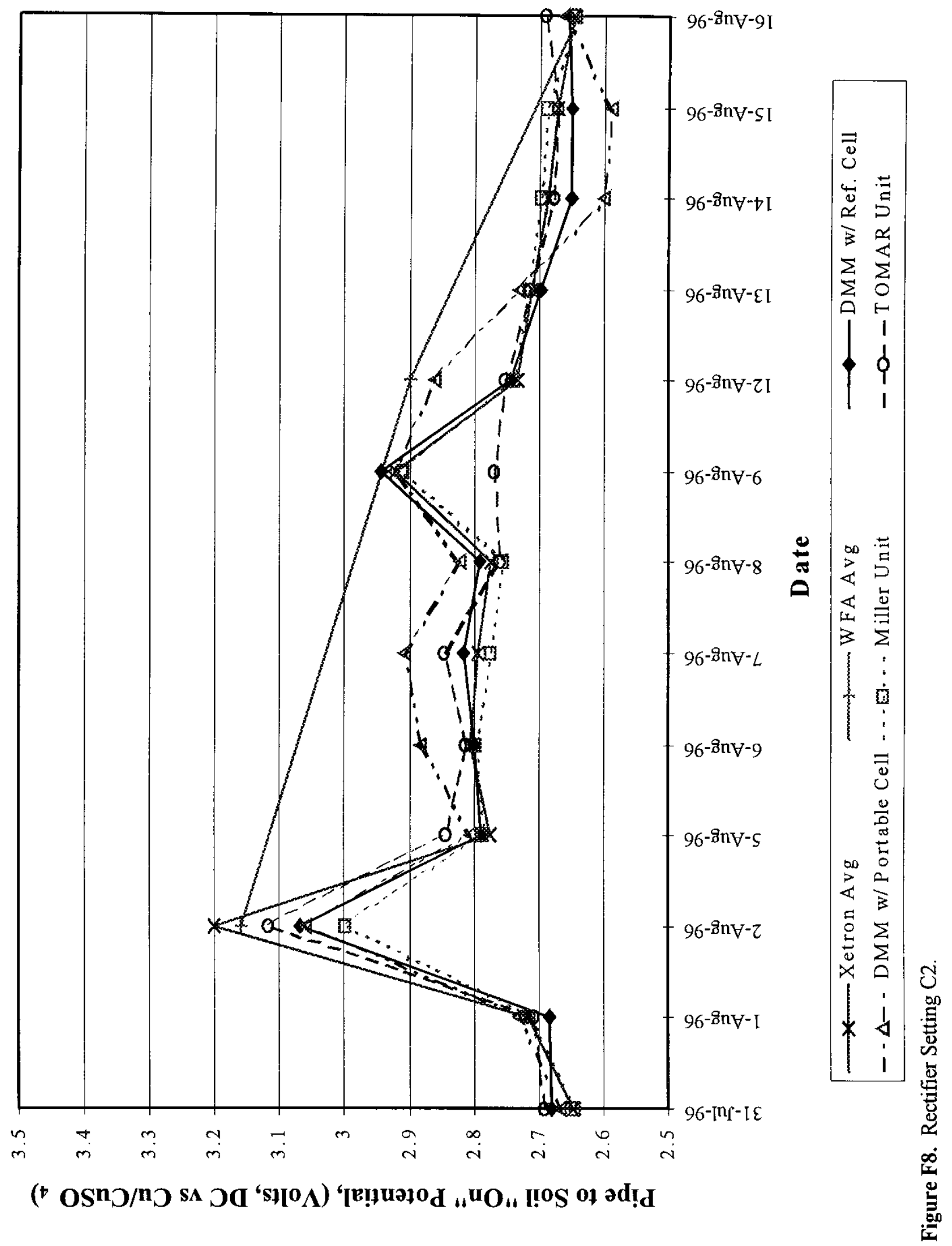




\section{Appendix G: Daily Pipe to Soil Instant Off Potential (IOP) Readings at USACERL Test Site}




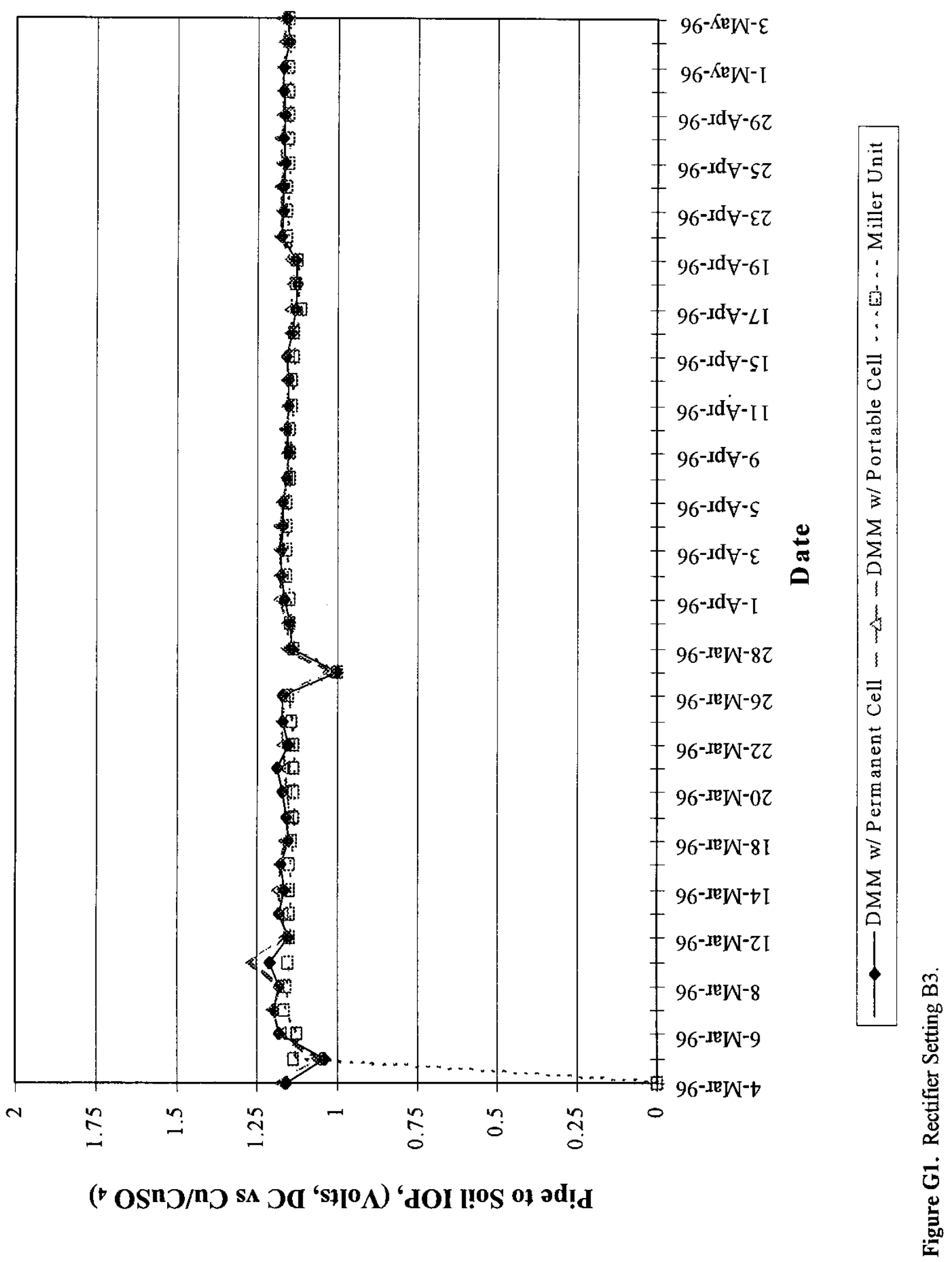




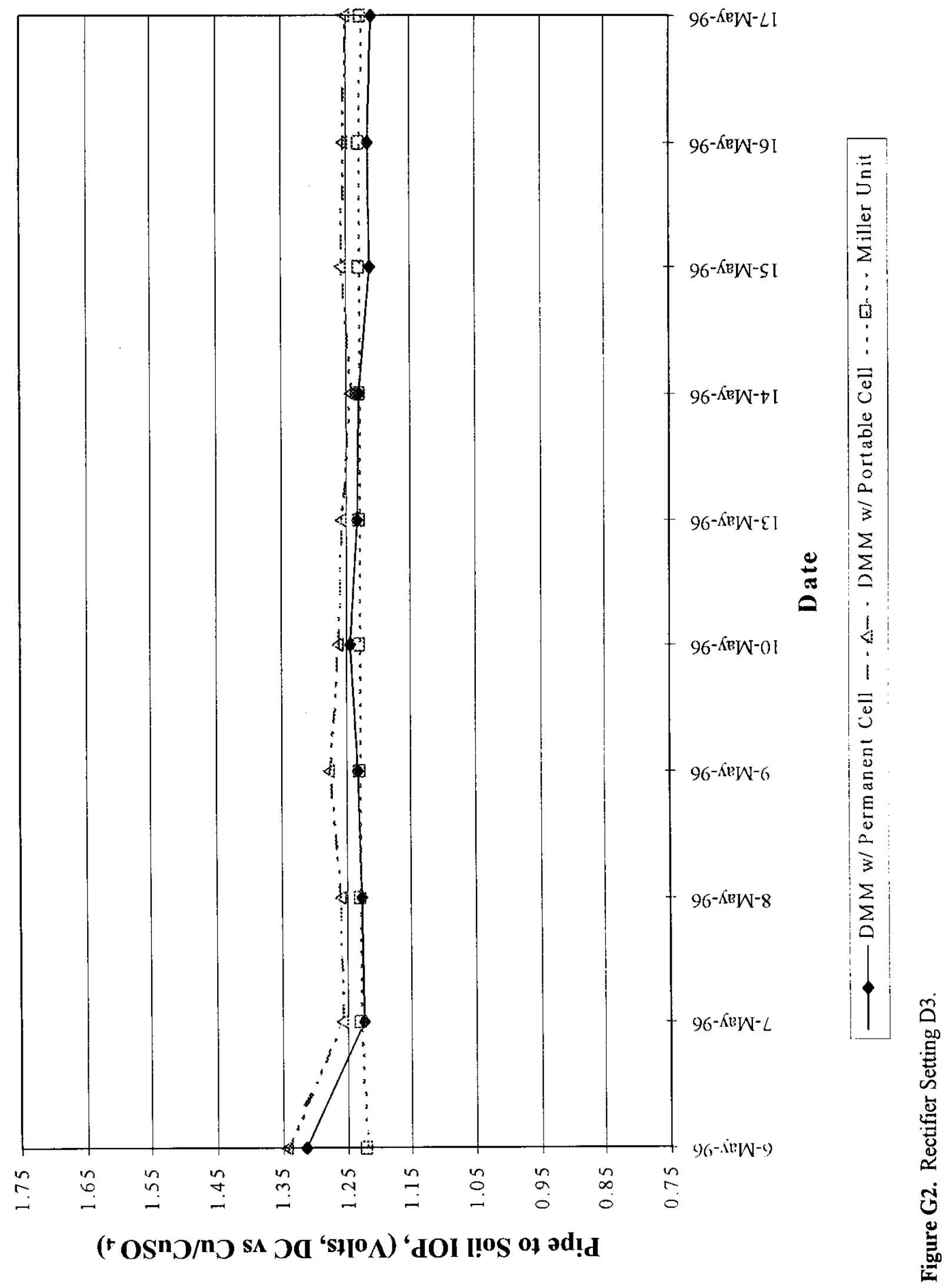




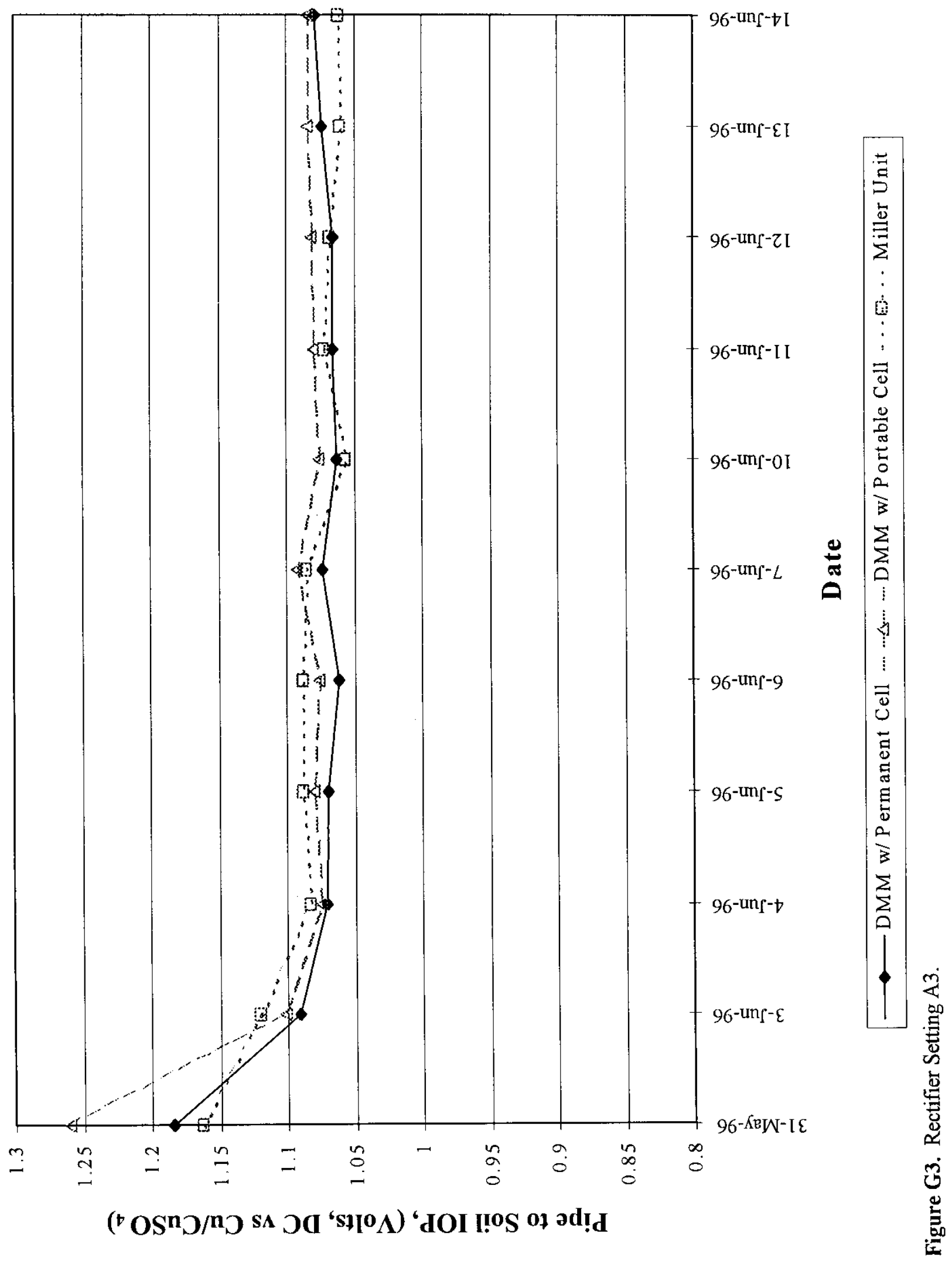




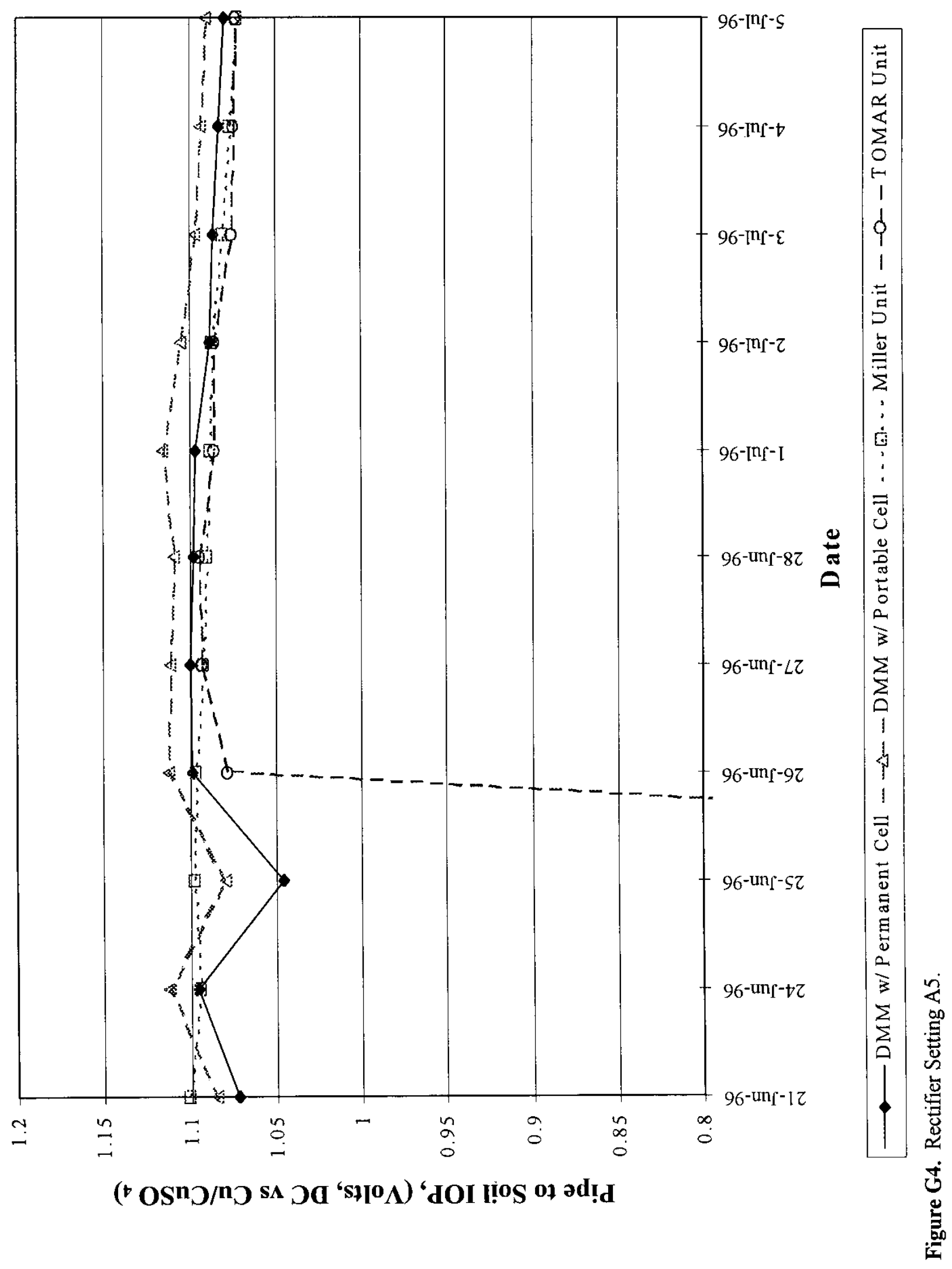




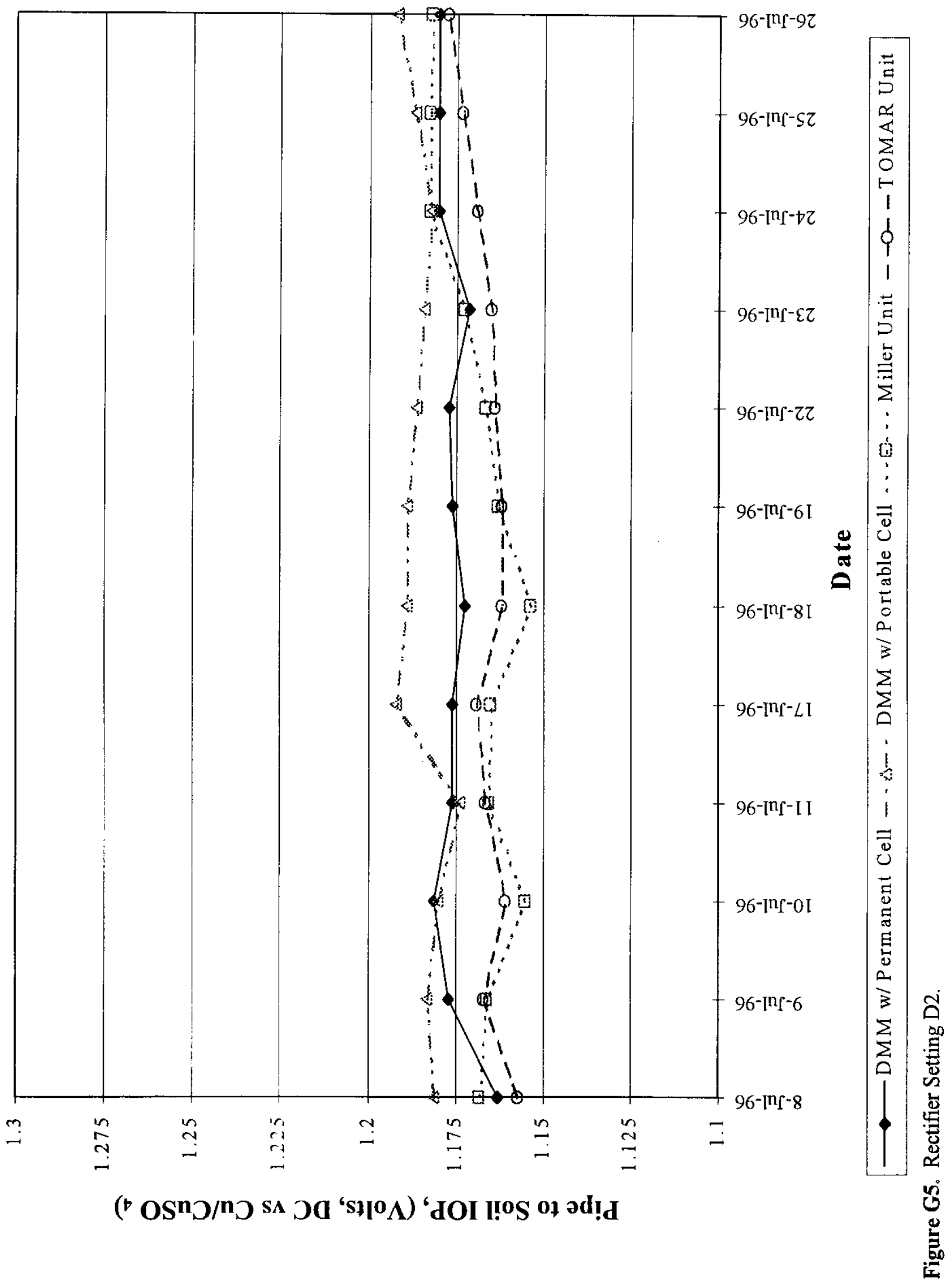




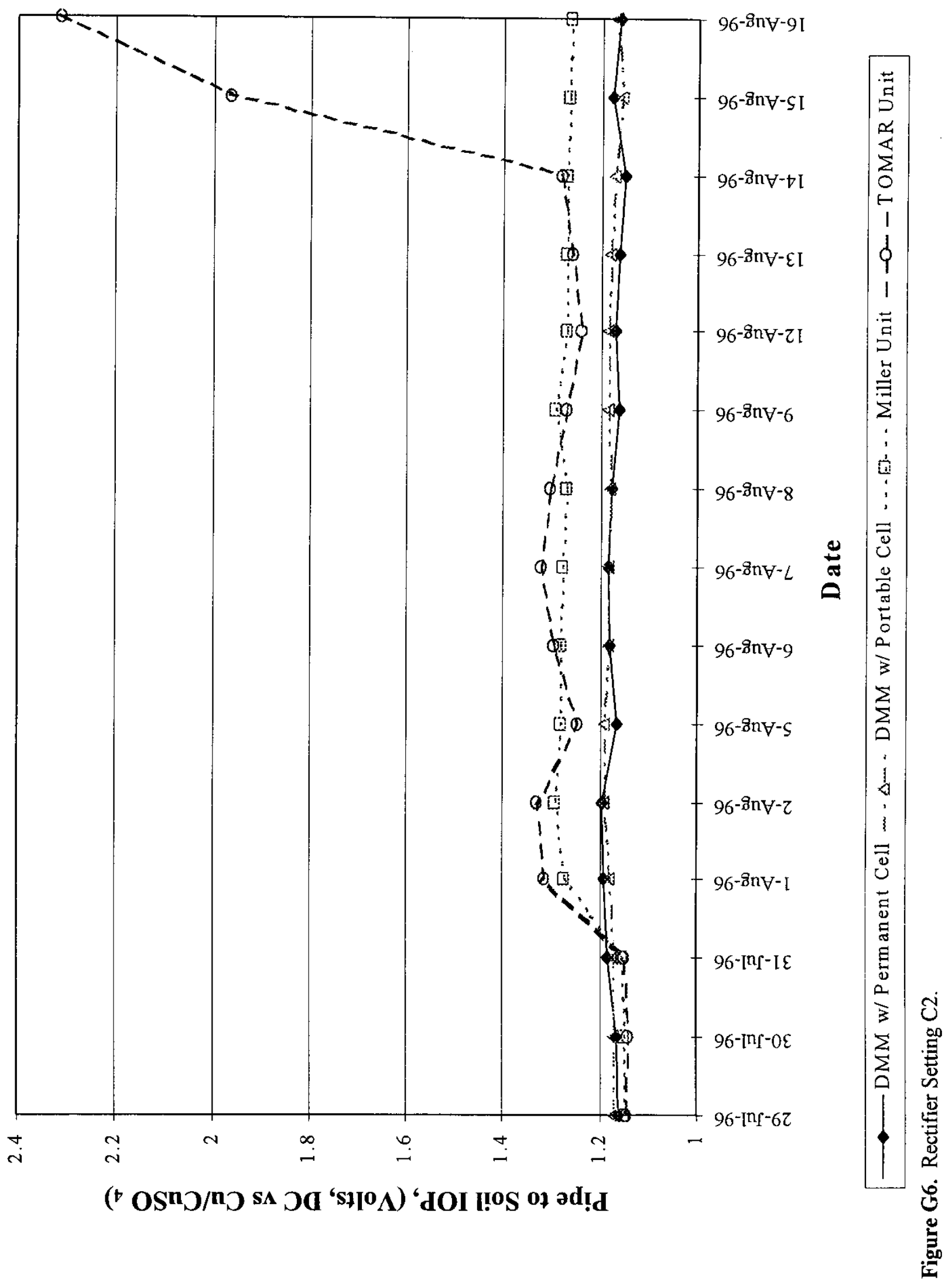




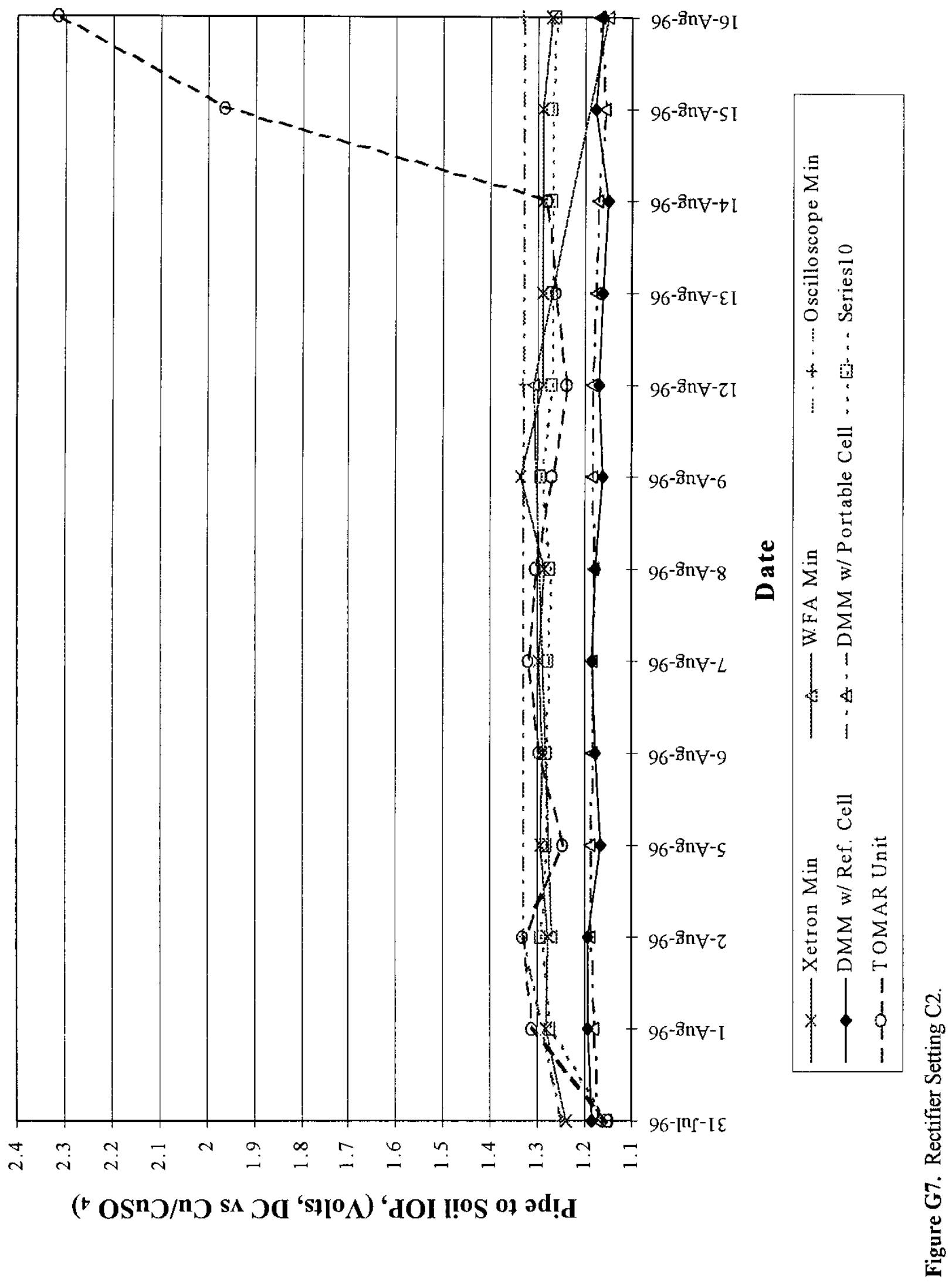




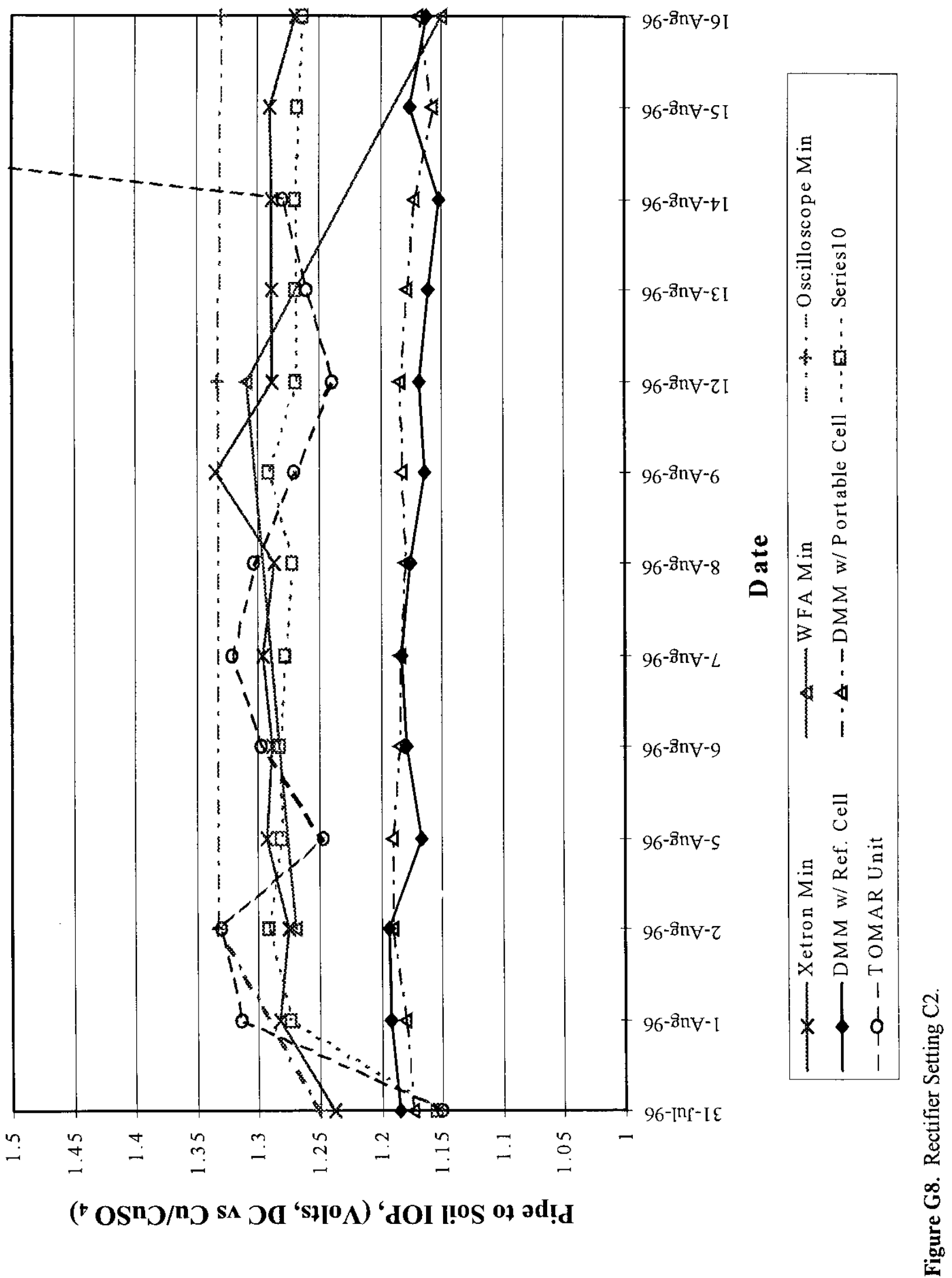




\section{Appendix H: Readings From Fort Drum Test Site}




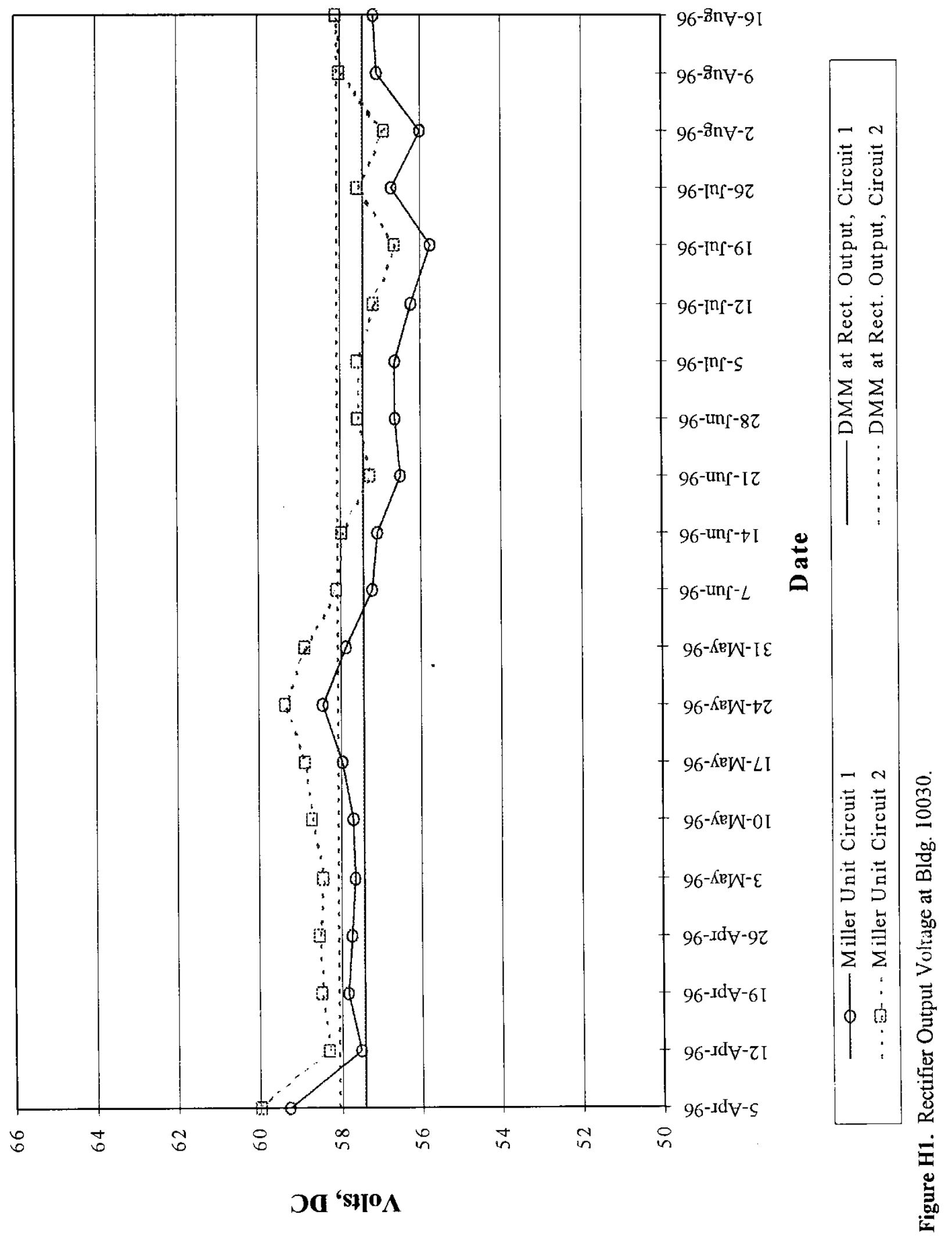




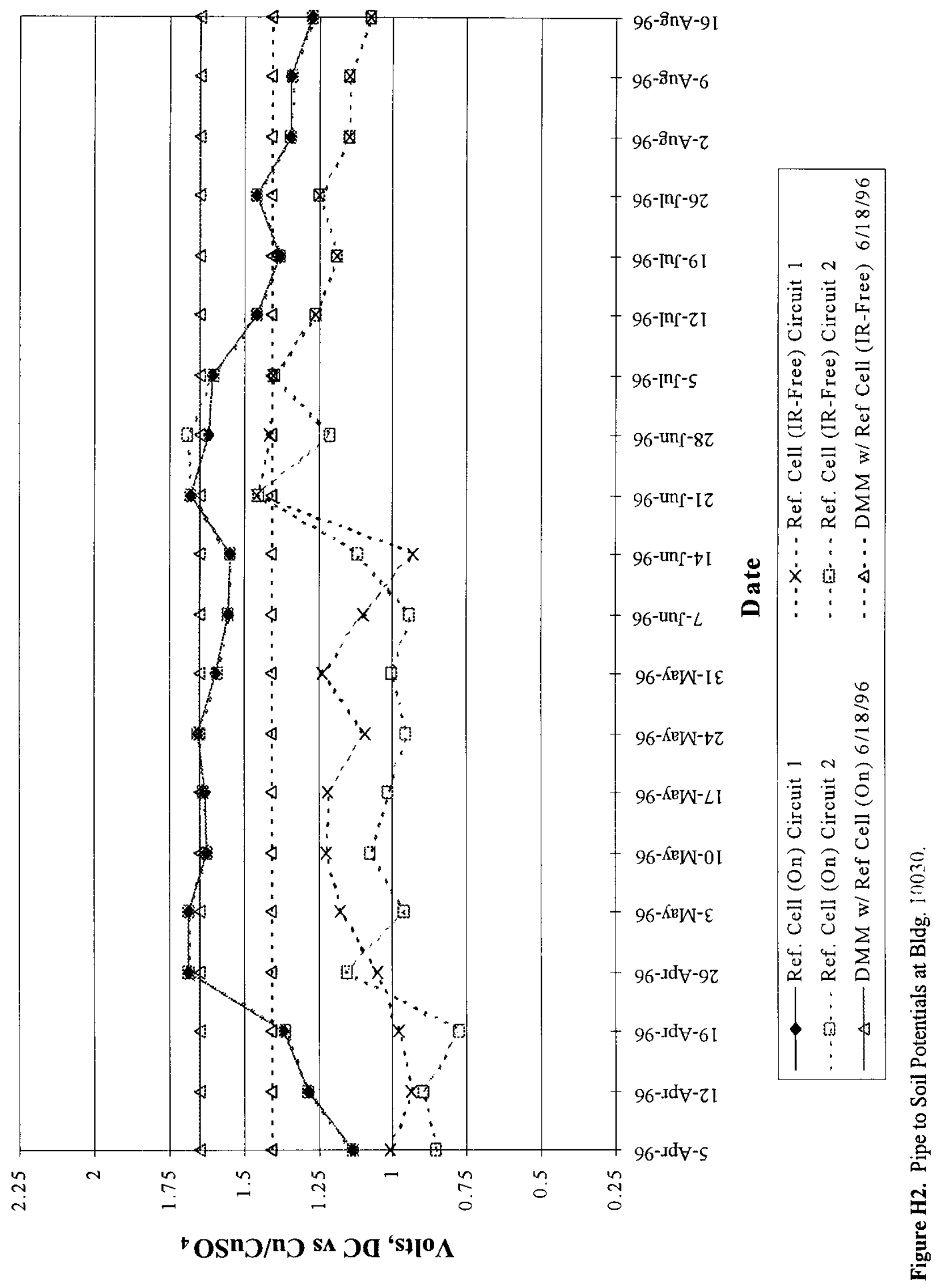




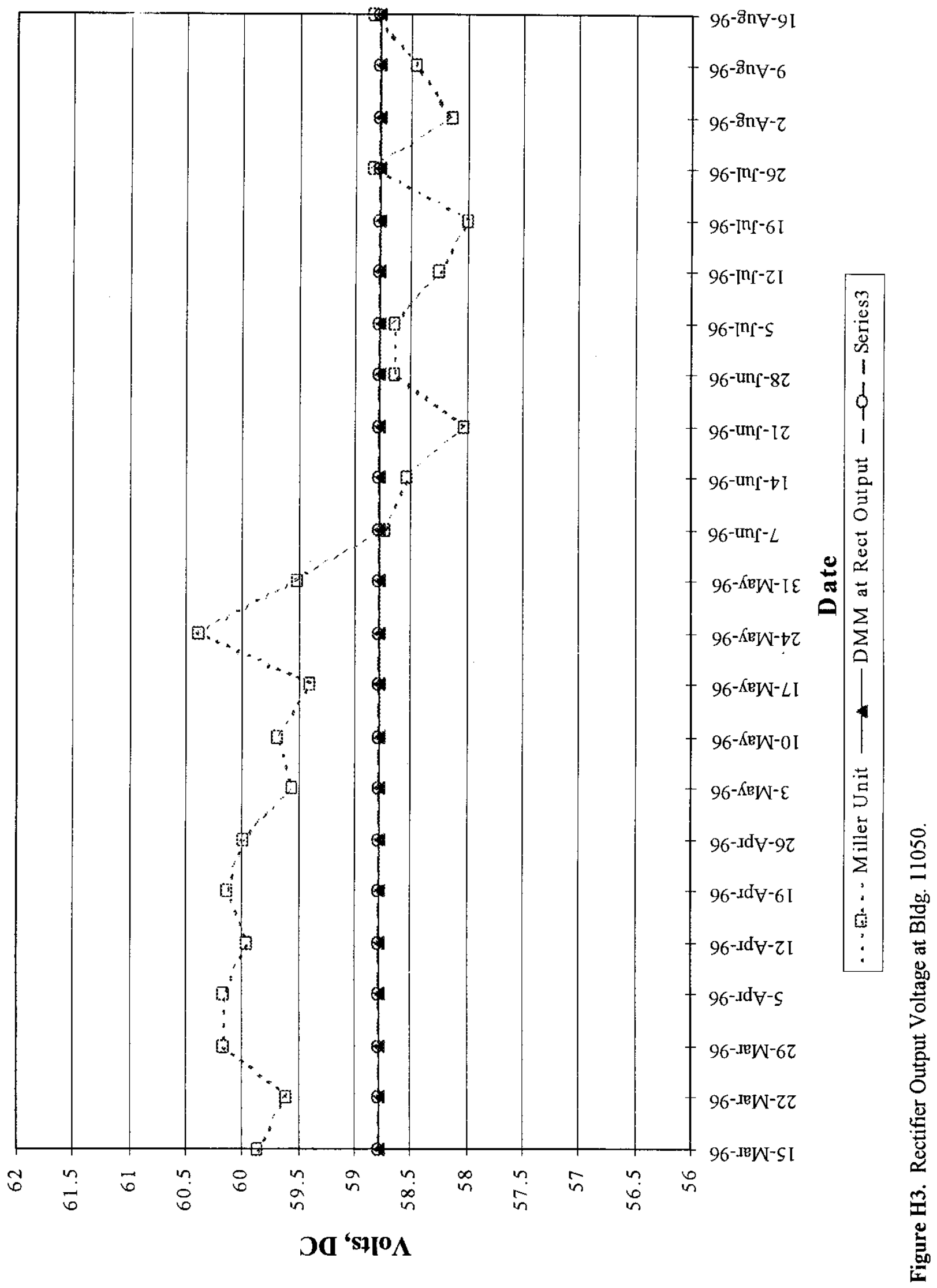




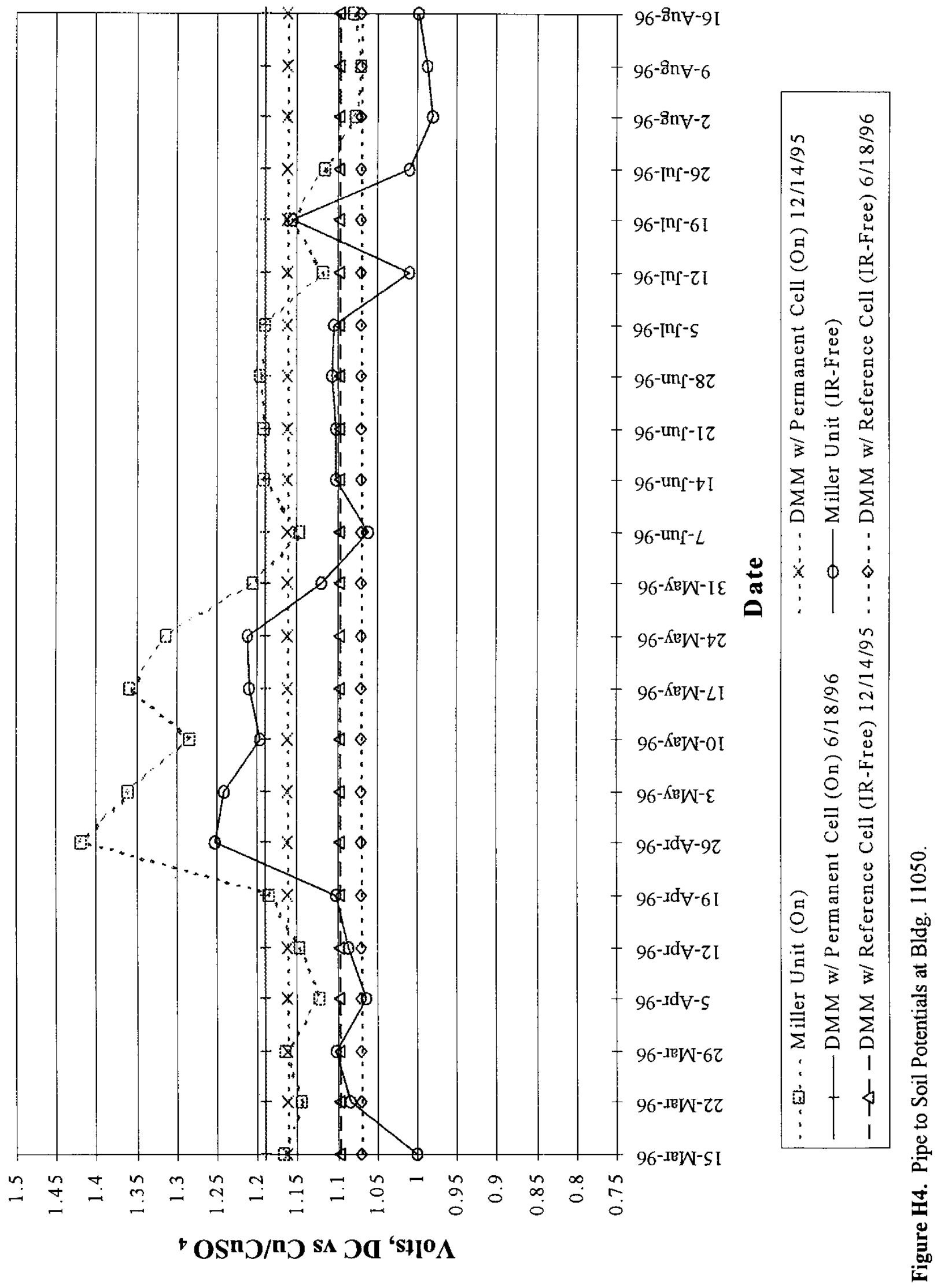




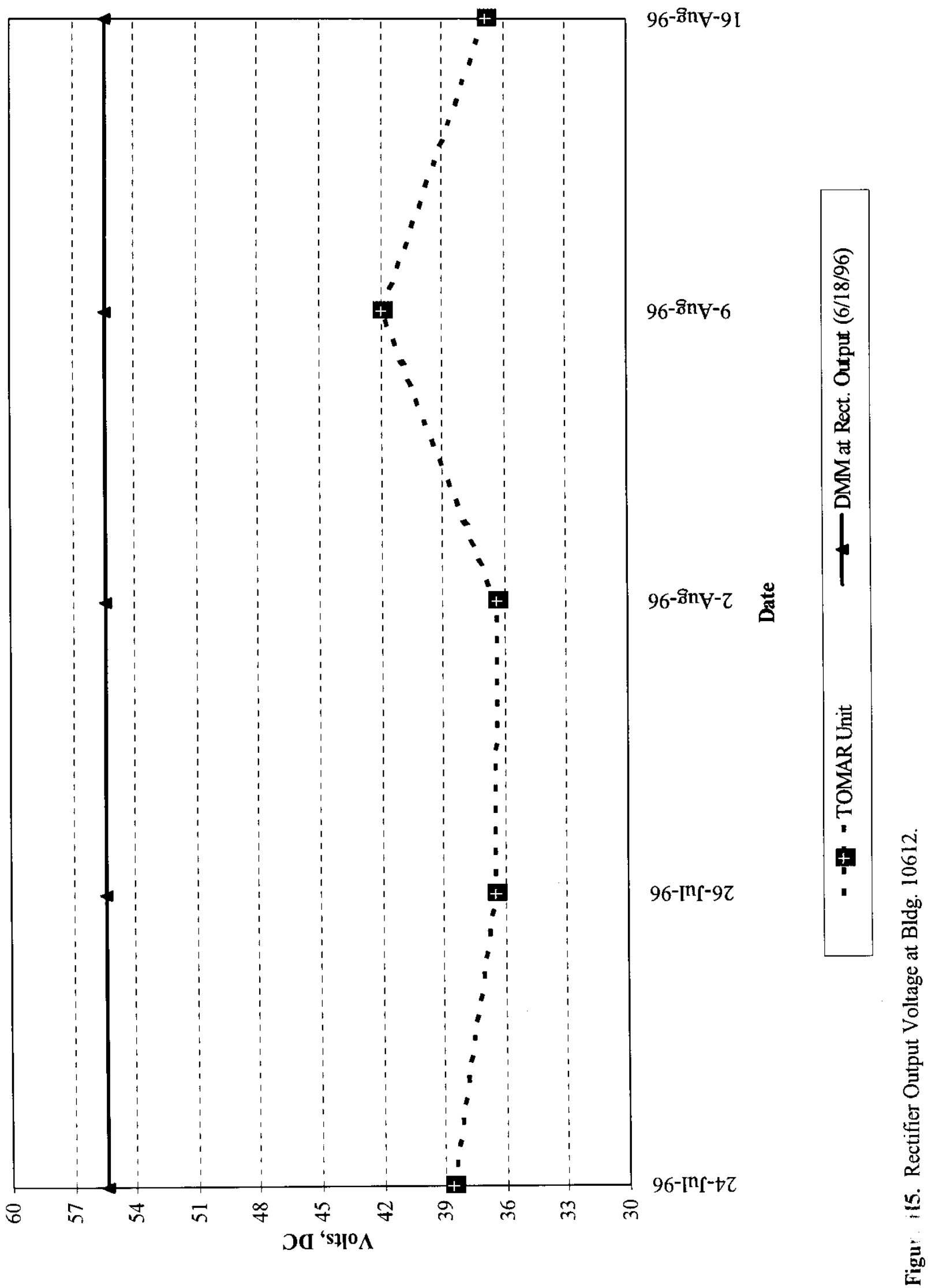




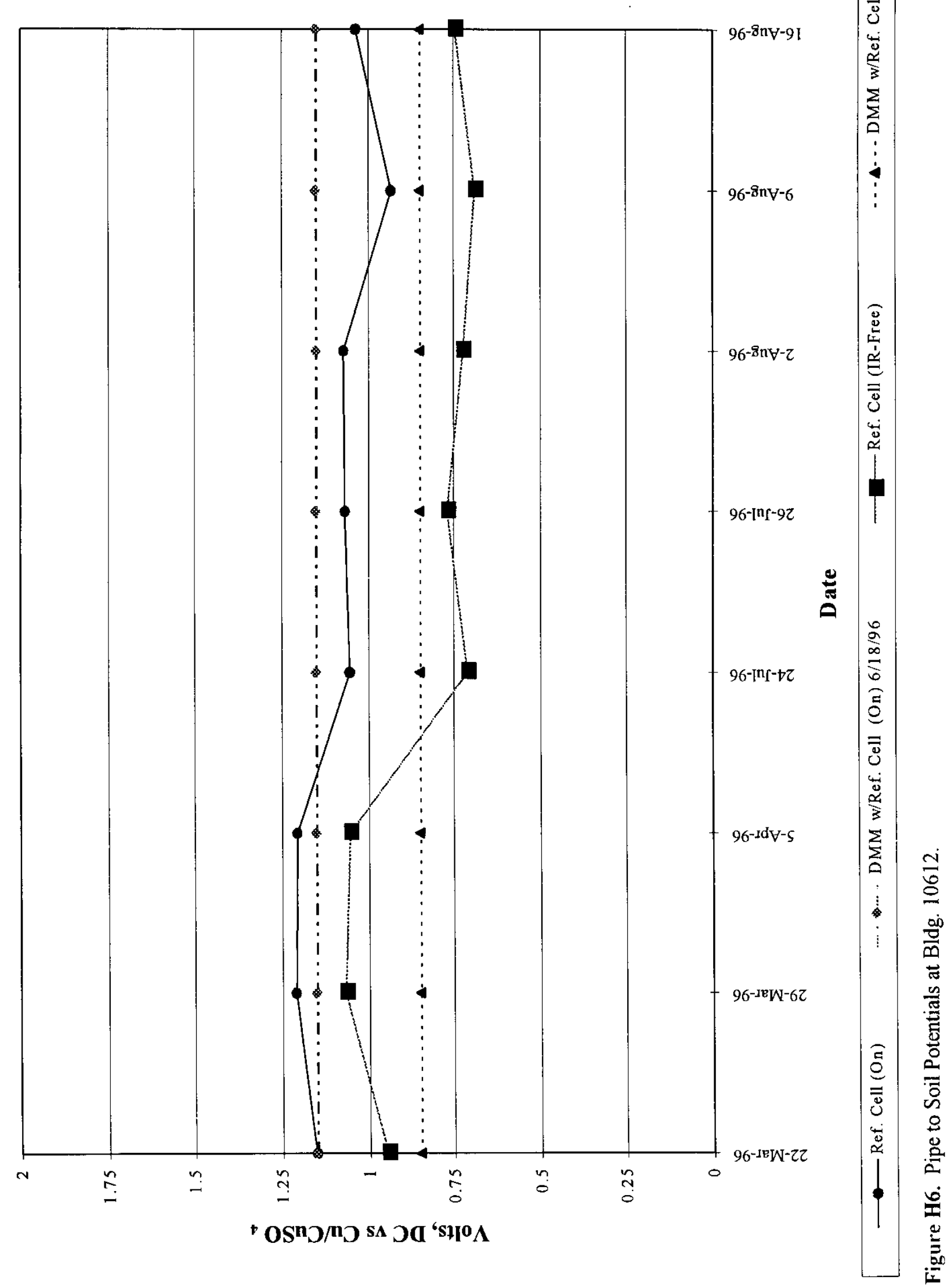




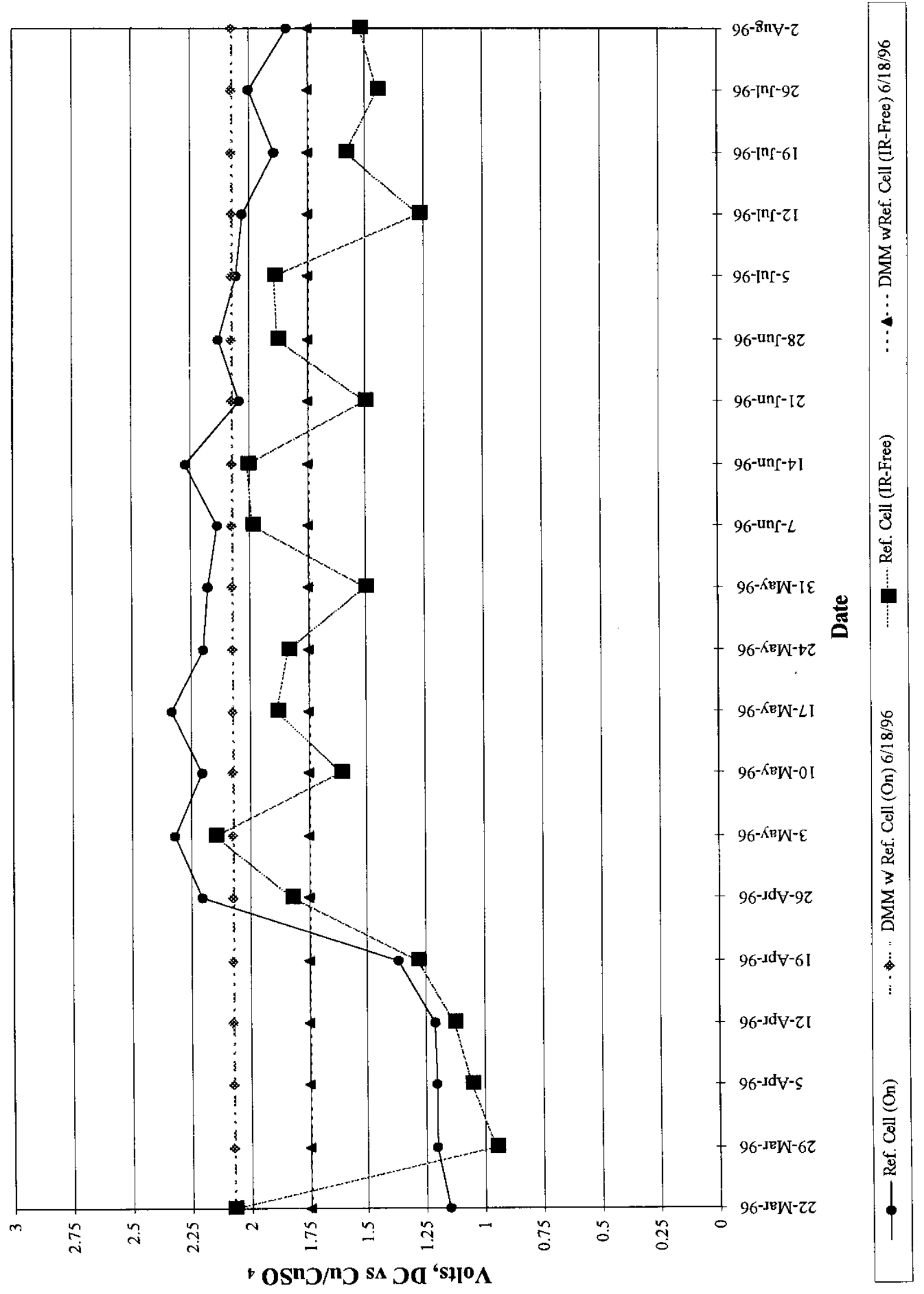

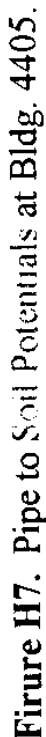


USACERL DISTRIBUTION

Chief of Engineers

ATTN: CEHEC-IM-LH (2)

ATTN: CEHEC-IM-LP (2)

ATTN: CECG

ATTN: CECC-P

ATTN: CECC-P

ATTN: CECW

ATTN: CECW-O

ATTN: CECW-P

ATTN: CECW-PR

ATTN: CEMP

ATTN: CEMP-E

ATTN: CEMP-C

ATTN: CEMP-M

ATTN: CEMP-R

ATTN: CERD-C

ATTN: CERD-ZA

ATTN: CERD-L

ATTN: CERD-M (2)

ACS(IM) 22060

ATTN: DAIM-FDP

CECPW 22310-3862

ATTN: CECPW-ES

ATTN: CECPW-FT

ATTN: CECPW.ZC

US Army Engr District

ATTN: Library (42)

US Army Engr Division

ATTN: Library (8)

US Army Transatlantic Program Center

ATTN: TAC 22604

ATTN: TAE 09096

US Army Engineering and Support Center ATTN: CEHND 35807-4301

US Army Europe

ATTN: AEAEN-EH 09014

ATTN: AEAEN-ODCS 09014

29th Area Support Group

ATTN: AEUSG.K.E 09054

222d BSB Unit \#23746

ATTN: AETV-BHR-E 09034

235th BSB Unit \#28614

ATTN: AETV-WG-AM 09177

293d BSB Unit \#29901

ATTN: AEUSG-MA-E 09086

409th Support Battalion (Base)

ATTN: AETTG-DPW 09114

412th Base Support Battalion 09630

ATTN: Unit 31401

221st Base Support Battalion

ATTN: Unit 2962309096

CMTC Hohenfels 09173

ATTN: AETTH-SB-DPW

Mainz Germany 09185

ATTN: AETV-MNZ-E

2†st Support Command

ATTN: DPW (8)

SETAF

ATTN: AESE-EN-D 09613

ATTN: AESE-EN 09630

Supreme Allied Command

ATTN: ACSGEB 09703

ATTN: SHIHB/ENGR 09705

INSCOM

ATTN: |ALOG-I 22060

ATTN: IAV-DPW 22186

USA TACOM 48397-5000

ATTN: AMSTA-XE

Defense Distribution Region East

ATTN: ASCE-WI 17070-5001
Defense Distribution Region West

ATTN: ASCW-WG 95296-0100

HQXVHI Airborne Corps 28307

ATTN: AFZA-DPW-EE

US Army Materiel Command (AMC)

Alexandria, VA 22333-0001

ATTN: AMCEN-F

ATTN: AMXEN-C $61299-7190$

installations: (20)

FORSCOM

Forts Gillem \& McPherson 30330

ATTN: FCEN

Installations: (20)

TRADOC

Fort Monroe 23651

ATTN: ATBO-G

installations: (20)

Fort Belvoir 22060

ATTN: CETEC-IM-T

ATTN: CETEC-ES 22315-3803

ATTN: Water Resources Support Ct

USA Natick RD\&E Center 01760

ATTN: STRNC-DT

ATTN: AMSSC-S-IM

US Army Materials Tech Lab

ATTN: SLCMT-DPW 02172

USARPAC 96858

ATTN: DPW

ATTN: APEN-A

SHAPE 09705

ATTN: Inirastructure Branch LANDA

Area Engineer, AEDC-Area Office

Amold Air Force Station, TN 37389

HQUSEUCOM 09128

ATTN: ECJ4-EN

CEWES 39180

ATTN: Library

CECRL 03755

ATTN: Library

USA AMCOM

ATTN: Facilities Engr 21719

ATTN: AMSMC-EH 61299

ATTN: Facilities Engr (3) 85613

USAARMC 40121

ATTN: ATZIC-EHA

Military Traffic Mgmt Command

ATTN: MT-LOF 22041-5000

ATTN: MTE-SU-FE 28461

Fort Leonard Wood 65473

ATTN: ATSE-DAC-LB (3)

ATTN: ATZT

ATTN: ATSE-CFLO

ATTN: ATSE-DAC-FL

ATTN: Australian Liaison Office

Military Dist of WASH

Fort McNair

ATTN: ANEN-IS 20319

USA Engr Activity, Capital Area

ATTN: Library 22211

US Army ARDEC 07806-5000 ATTN: AMSTA-AR-IMC
Engr Societies Library

ATTN: Acquisitions 10017

US EPA, Region V

ATTN: AFRC-ENIL-FE 60561

US Army Environmental Center ATTN: SFIM-AEC-NR 21010 ATTN: SFIM-AEC-CR 64152 ATTN: SFIM-AEC-SR 30335-6801

ATTN: AFIM-AEC.WR 80022-2108

Defense Nuclear Agency

ATTN: NADS 20305

Defense Logistics Agency

ATTN: MMDIS 22060-6221

National Guard Bureau 20310

ATTN: NGB-ARI

US Military Academy 10996

ATTN: MAEN-A

ATTN: Facilities Enginee

ATTN: Geography \& Envr Engrg

Naval Facilities Engr Command

ATTN: Facilities Engr Command (8)

ATTN: Engrg Field Divisions (11)

ATTN: Public Works Center (8)

ATTN: Naval Constr Battalion Ctr 93043

ATTN: Naval Facil. Engr. Service Ctr 93043-4328

8th US Army Korea

ATTN: DPW (11)

USA Japan (USARJ)

ATTN: APAJ-EN-ES 96343

ATTN: HONSHU 96343

ATTN: DPW-Okinawa 96376

416th Engineer Command 60623

ATTN: Gibson USAR Ctr

US Army MEDCOM

ATTN: MCFA 78234-6000

Fort Detrick 21702.5000

ATTN: MCHS-IS

Fort Sam Houston 78234-5000 ATTN: MCFA-PW

Walter Peed Army Medical Center 20007-5001 ATTN: MCHL.PW

Tyndall AFB 32403

ATTN: HOAFCESACES

ATTN: Engrg \& Srve Lab

USA TSARCOM 63120

ATTN: STSAS.F

American Public Works Assoc. 64104-1806

US Army CHPPM

ATTN: MCHB-DE 21010

US Govt Printing Office 20401 ATTN: Rec Sec/Deposit Sec (2)

Nat'I Institute of Standards \& Tech ATTN: Library 20899

Defense General Supply Center ATTN: DGSC.WI 23297-5000

Defense Construction Supply Center ATTN: DCSC-WI 43216-5000

Defense Tech Info Center 22060-6218 ATTN: DTIC-O (2) 
